\title{
UNICEF Nepal Adolescent Development and Participation (ADAP) baseline study: Final report
}

\author{
Sajeda Amin \\ Population Council \\ Ashish Bajracharya \\ Population Council \\ Michelle Chau \\ Mahesh Puri
}

Follow this and additional works at: https://knowledgecommons.popcouncil.org/departments_sbsr-pgy

Part of the Demography, Population, and Ecology Commons, Family, Life Course, and Society Commons, and the International Public Health Commons How does access to this work benefit you? Let us know!

\section{Recommended Citation}

Amin, Sajeda, Ashish Bajracharya, Michelle Chau, and Mahesh Puri. 2014. "UNICEF Nepal Adolescent Development and Participation (ADAP) baseline study: Final report." New York: Population Council. 


\section{UNICEF NEPAL}

\section{ADOLESCENT DEVELOPMENT AND PARTICIPATION (ADAP) BASELINE STUDY}

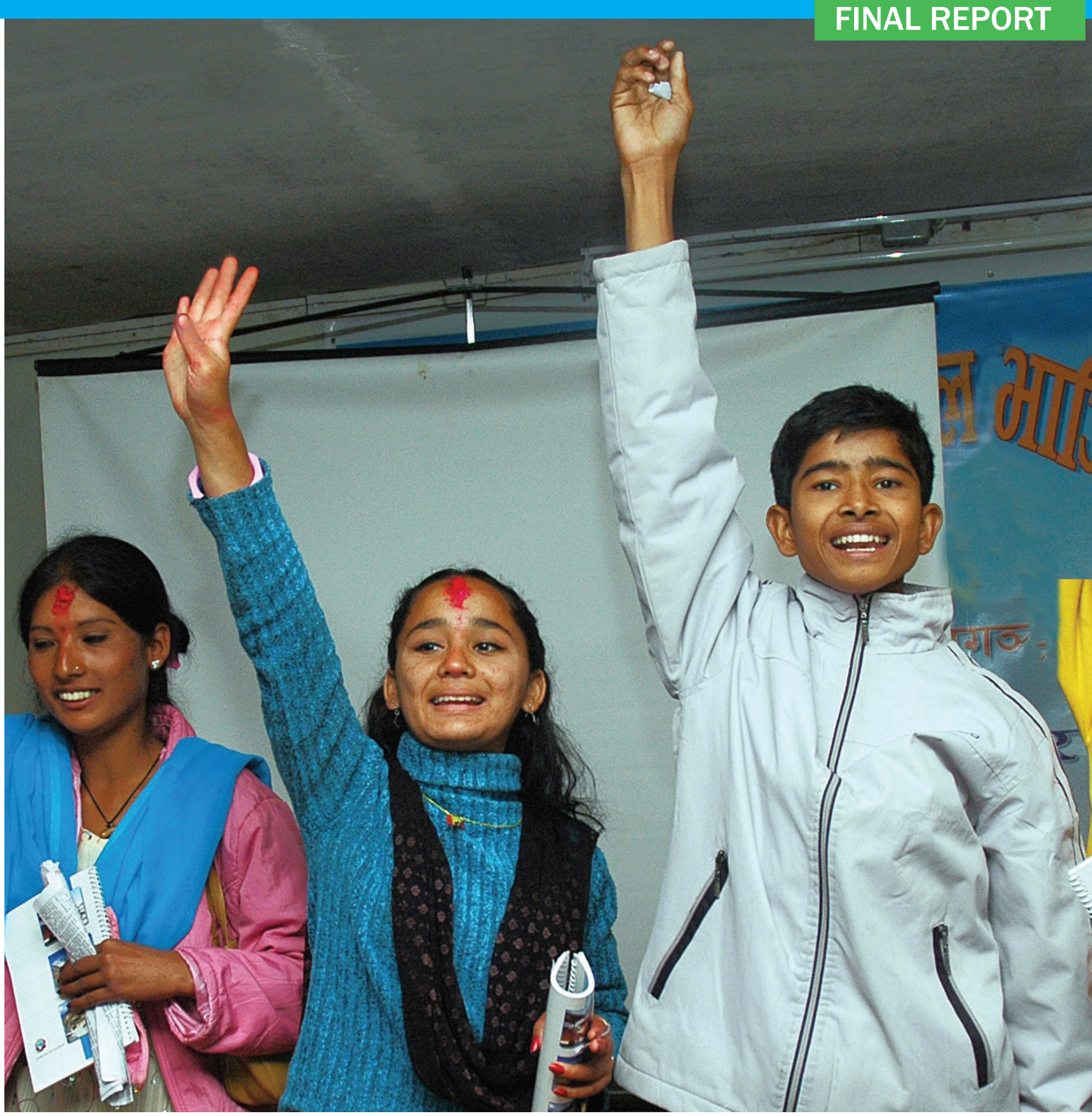

unicef 



\section{UNICEF NEPAL \\ ADOLESCENT DEVELOPMENT AND PARTICIPATION (ADAP) BASELINE STUDY}

FINAL REPORT

SAJEDA AMIN

ASHISH BAJRACHARYA

MICHELLE CHAU

MAHESH PURI

NOVEMBER 2014

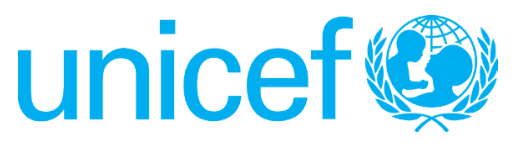




\section{unicef}

UNICEF is mandated by the United Nations General Assembly to advocate for the protection of children's rights, to help meet their basic needs and to expand their opportunities to reach their full potential. We are guided by the Convention on the Rights of the Child and strive to establish children's rights as enduring ethical principles and international standards of behaviour towards children. Through our country programmes, we work to promote the equal rights of women and girls and to support their full participation in the political, social, and economic development of their communities.

\section{Population counciL Ideas. Evidence. Impact.}

The Population Council confronts critical health and development issues-from stopping the spread of HIV to improving reproductive health and ensuring that young people lead full and productive lives. Through biomedical, social science, and public health research in 50 countries, we work with our partners to deliver solutions that lead to more effective policies, programs, and technologies that improve lives around the world. Established in 1952 and headquartered in New York, the Council is a nongovernmental, nonprofit organization governed by an international board of trustees.

Sajeda Amin is Senior Associate and Ashish Bajracharya is Associate at the Population Council. At time this report was written, Michelle Chau was Data Analyst at the Population Council. Mahesh Puri is Associate Director at CREHPA.

Suggested citation: Amin, S., Bajracharya, A., Chau, M., Puri, M. 2014. “UNICEF Nepal Adolescent Development and Participation (ADAP) Baseline Study: Final report." New York: Population Council.

Population Council

One Dag Hammarskjold Plaza

New York, NY 10017 USA

popcouncil.org

Cover photo: UNICEF Nepal.

(c) 2014 The Population Council, Inc.

Any part of this publication may be copied or adapted to meet local needs without permission, provided that the parts copied are distributed free or at cost (not for profit) and that the source is identified. We would appreciate receiving a copy of any materials in which the text is used. 


\section{Table of Contents}

Acknowledgments ........................................................ iv

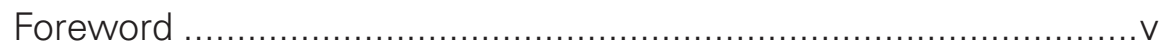

List of Abbreviations .......................................................

Executive Summary........................................................... vii

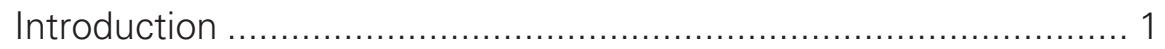

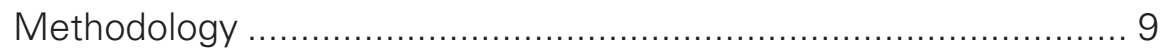

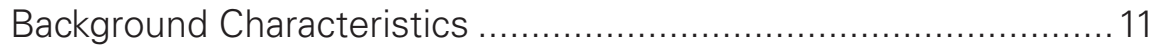

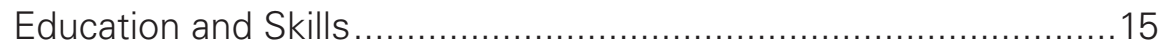

Livelihoods and Financial Literacy ........................................... 21

Enabling and Protective Environment .................................. 27

Gender Norms and Gender Equity ..................................... 35

Health and Healthy Behavior .................................................. 41

Civic Engagement and Participation of Adolescents ................... 51

Future Directions for ADAP ........................................... 55

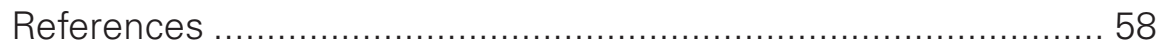

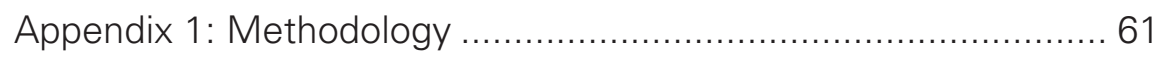

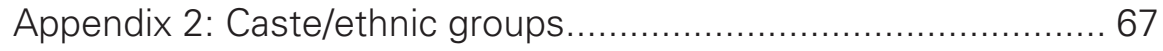

Appendix 3: Study team members of CREHPA and Yuwalaya ....... 68 


\section{Acknowledgments}

This report is the result of collaboration among the Population Council, the Center for Research on Environment Health and Population Activities (CREHPA), and Yuwalaya. UNICEF Nepal's

Adolescent Development and Participation (ADAP) program commissioned this research under the leadership of Nafisa Binte Shafique, Chief of the ADAP Section in Nepal. Key members of the UNICEF team included Jaya Burathoki and Pragya Shah Karki. The research team at CREHPA was led by Dr. Mahesh Puri, Associate Director, who led the adolescent household survey team as study coordinator. Yuwalaya, which conducted participatory research with adolescents, was led by Subash Neupane, President, and Chetana Tulachan.

The report benefited from the contributions of many individuals and institutions who made this research possible. The research team would like to extend their sincere thanks to all those who provided their expertise, hard work, and energy.

We wish to thank the field and data management teams of CREHPA for their work on the adolescent household survey and semi-structured key informant interviews. In particular, Shophika Regmi and Deepak Joshi for their work as research officers and field supervisors Badri Dulal, Lochan Bhattarai, Achala Shrestha, Zinita Dhakal, Kamala Karki, Umesh Giri, Sushma Sharma, and Dhurba Dhital. Special thanks go to the 36-member data collection team at CREHPA that spent over a month in the field in some of the most remote regions of Nepal.

Special thanks are also due to the Yuwalaya team for organizing and leading the adolescent participatory exercise. We are grateful to the group facilitators and rapporteurs.
Data collection efforts of both CREHPA and Yuwalaya would not have been possible without the district-level contacts who aided our research teams in coordinating data collection activities. These include UNICEF regional officers, child rights officers, officers at the District Child Welfare Board, and district coordinators for youth networks.

We are also indebted to anonymous reviewers at the Nepal Health Research Council and the Population Council Institutional Review Boards who reviewed and approved this project and provided ethical clearance. Thanks are also due to the Social Welfare Council for their approval of this research.

A warm thanks also goes to Population Council colleagues who made important contributions to this study and report. The Poverty, Gender, and Youth finance team managed the study funding, sub-awards, and vendor payments. We would like to extend our thanks especially to Barry Ravitch, Mary Elmoor, Jessica McBride, and Elizabeth Cottrell. The Publishing and Creative Services team (Michael Vosika, Christina Tse, and Sura Rosenthal, in particular) designed the report and coordinated layout and proofreading.

Finally, a special thank you goes to the adolescent girls and boys in 15 districts who shared their experiences and perspectives with us through participation in the household surveys and group exercises, without whom this study would not have been possible. 


\section{Foreword}

Nepal is home to 6.4 million adolescents aged 10-19, and one in four residents of Nepal is an adolescent. Adolescence is a time of transition and exploration. Adolescents experience the most dramatic growth in their body and mind and also the development of their identity. Today's adolescents in Nepal face complex challenges posed by rapid urbanization, the lack of protective environments, and harmful social norms deep-rooted in society. Experiences and opportunities during adolescence determine whether they will develop into responsible, independent, and active members of society.

UNICEF recognizes adolescence as an age of opportunity for children and is committed to work for the empowerment and protection of adolescents, especially girls, from excluded and disadvantaged communities. Investing in adolescents is the most effective way to fight against poverty and inequality, address harmful social norms and practices, and achieve social and economic development in society. We need a stronger focus on the second decade of life to build on to the achievements attained for young children since 1990. A probability of a child dying before his or her fifth birthday has been reduced by more than $66 \%$ since 1990 . Gender gaps in primary school enrollment have been nearly eliminated with the rapid increase in the overall enrollment rate. Tremendous progress has been achieved in access to safe water, health services, immunization, and child protection platforms. However, despite these great gains in improving the lives of children, if focused attention and resources are not directed toward adolescents, they will potentially reduce and confine the momentum of the achievements of the last two decades.
The Adolescent Development and Participation (ADAP) Baseline Survey is our endeavor to inform the design and implementation of an evidencebased program for adolescents. The survey is the first comprehensive study on the lives of adolescents in 15 districts with high levels of child deprivation where UNICEF is focusing its intervention. The ADAP Baseline Survey is aligned with the National Plan of Action for Holistic Development of Adolescents launched in 2013, and highlights the socio-cultural and behavioral aspects of adolescents in the six domains: 1) Education and Skills; 2) Livelihood, Employment and Financial Literacy; 3) Enabling and Protective Environment; 4) Gender Equity and Social Inclusion; 5) Health and Healthy Behavior; and 6) Participation and Civic Engagement. The findings of the ADAP Baseline Survey are invaluable and instrumental in planning well-targeted interventions for adolescents in the most marginalized districts.

I would like to extend appreciation to the Population Council New York and their partners for designing and carrying out such a participatory study with, for, and by adolescents. Voices of 3,000 adolescents engaged in the survey will provide the Government of Nepal, development partners, civil society organizations, and young leaders with in-depth understanding and insights into attitudes and behaviors of adolescents in Nepal.

TOMOO HOZUMI Country Representative, UNICEF Nepal 


\section{List of Abbreviations}

$\begin{array}{ll}\text { ADAP } & \text { Adolescent Development and Participation } \\ \text { ANC } & \text { Antenatal care } \\ \text { AIDS } & \text { Acquired immunodeficiency syndrome } \\ \text { CREHPA } & \text { Center for Research on Environment Health and Population Activities } \\ \text { HDI } & \text { Human Development Index } \\ \text { HIV } & \text { Human immunodeficiency virus } \\ \text { MCH } & \text { Maternal and child health } \\ \text { NDHS } & \text { Nepal Demographic and Health Survey } \\ \text { NPR } & \text { Nepali rupees } \\ \text { STI } & \text { Sexually transmitted infection } \\ \text { PGD } & \text { Participatory group discussion } \\ \text { PSU } & \text { Primary sampling unit } \\ \text { UNICEF } & \text { United Nations Children's Fund } \\ \text { USD } & \text { United States dollars } \\ \text { VDC } & \text { Village Development Committee }\end{array}$




\section{Executive Summary}

Nepal's Adolescent Development and Participation (ADAP) program aims to ensure the systematic, ethical, meaningful, and regular participation of adolescents in the program and to focus on vulnerable and disadvantaged groups using a holistic approach. The program aims to empower adolescents, especially girls, to initiate and sustain activities and interventions that create positive transformation in their families, communities, and society and realization of their rights. Three key strategies include: (1) ensuring active and meaningful participation of adolescents, especially girls and the younger age group (10-14 years); (2) ensuring that core interventions address age, sex, and situational diversity among adolescents, specifically those who are most at risk and especially vulnerable to HIV and different forms of violence; and (3) generating and sharing evidence, including participatory behavioral monitoring and district-level bottleneck analysis.

The Population Council, in collaboration with UNICEF Nepal, the Center for Research on Environment Health and Population Activities (CREHPA), and Yuwalaya, a Kathmandu-based research organization specializing in participatory and qualitative research, led a study to develop a research design and implement a baseline survey to inform UNICEF's Adolescent Development and Participation program. The primary aim was to inform the program with adequate and scientifically valid data on adolescents aged 10-19. To accomplish this, the study measured the sociocultural and behavioral aspects of the lives of Nepali adolescents in 15 districts $^{1}$ of the Terai plains and Mid and Far Western Hilly and Mountainous regions in UNICEF's six domains of holistic adolescent development: 1) Education and Skills; 2) Livelihood, Employment and Financial Literacy; 3) Enabling and Protective Environment; 4) Gender Equity and Social Inclusion; 5) Health and Healthy Behavior; and 6) Participation and Civic Engagement.

The baseline survey was designed as a household sample survey of adolescents, both boys and girls aged 10-19. Data were collected by a team of researchers, supervisors, and interviewers assembled by CREHPA. The team covered 150 clusters from the 15 districts in two phases beginning in December 2013. Data collection was completed in April 2014. The final sample consists of a total of 3,000 adolescents-1,366 boys and 1,634 girls_living in the Terai plains and Mid and Far Western Hilly and Mountainous region. In addition to the baseline survey, qualitative research on adolescents was conducted by Yuwalaya through 12 participatory group exercises and discussions in three districts and 96 key stakeholder semistructured interviews were conducted by CREHPA in all 15 districts to inform programs and policy.

Adolescents reported belonging to over 50 different ethnic groups. The dominant ethnicity in the Mid and Far Western Hilly and Mountainous regions (referred to as Mid and Far Western region throughout this report) is Chhetri. The Terai plains region (referred to as the Terai region throughout) is more diverse with a larger number of ethnicities and no one particularly dominant group. The largest groups are the Yadav and Muslims. The primary language spoken at home differs by region. In the

1 The districts chosen (Achham, Baitadi, Bajhang, Bajura, Dhanusa, Doti, Dolpa, Humla, Jumla, Kalikot, Mahotari, Mugu, Parsa, Rautahat, and Saptari) were selected based on the Nepal UNDAF/UNICEF Child Deprivation Index. The index consists of 10 indicators measurable at district and municipality level drawn from Government and UN data sources: food security phase; net enrollment rate (primary); working children 10-14 years; sanitation coverage; per capita development budget expenditure; DPT 3 immunization under 1 year of age; expected frequencies of outbreaks; ratio of girls to boys in secondary education; the MOFALD's Minimum Condition Performance Measures; and NDHS 2011 stunting prevalence rates. 
Mid and Far Western region, the main language is Nepali. In the Terai region, it is Maithali. The vast majority of adolescents in program regions are Hindu. In the Terai region, $85 \%$ are Hindu but there is a significant Muslim minority. In the Mid and Far Western region, 95\% of adolescents are Hindu. Educational attainment is increasing among younger generations in the study districts. $85 \%$ of mothers and $46 \%$ of fathers have no education. Among adolescents, only 10\% have never attended school. Most households in the Terai region have electricity. By contrast, fewer than one in five households in the Mid and Far Western region have electricity. Mobile phone access is high: $91 \%$ of households in the Terai region and $73 \%$ in the Mid and Far Western regions have a mobile phone. Few households have computers: $5 \%$ of adolescent households in the Terai region and only $1 \%$ in the Mid and Far Western region have a computer.

Over $90 \%$ of boys and $89 \%$ of girls ever attended school. This is particularly striking given the higher proportion of parents with no education suggesting that opportunities for schooling are relatively recent in the study districts. Another indication that schooling is recent is the higher proportion of younger adolescents aged 10-14 who attend school compared to adolescents aged 15-19. Girls drop out of school at a faster rate than boys despite the fact that they are much more likely than boys to receive stipend support. Efforts to promote schooling must take into account that most adolescents are the first generation attending school in their families. The Mid and Far Western districts have more favorable education indicators than the Terai region. The majority of girls and boys attend school supported by the government in both regions. About one in five children attend a religious or a private institution.

Families invest substantial resources in education in the form of private tutoring, and there are important gender differentials in this regard. Overall, $42 \%$ of boys and $37 \%$ of girls who attend school receive private tutoring, while $25 \%$ of boys and $69 \%$ of girls received stipend support in primary school. Financial assistance in secondary school is much lower-only $10 \%$ of boys and $33 \%$ of girls receive assistance. Boys are more likely to say they stopped attending school because of lack of interest, while girls report that the competing resource demands of time and money force them to stop going to school. Adolescents are more likely to have received training in disaster preparedness than vocational skills.

Adolescents actively seek livelihood opportunities but girls have fewer prospects. Although only $7 \%$ of adolescents currently work, they are active savers and borrowers. More than one in 10 (13\%) have ever worked in the past. Girls work an average of 25 hours per week compared to 36 hours for boys. Average weekly earnings total NPR 1313 (USD 13); boys earn twice as much as girls. $25 \%$ of adolescents have their own savings and average savings were NPR 3505 (USD 35). More girls than boys save and girls, on average, have about $50 \%$ more savings than boys. However, access to formal savings is practically nonexistent for these adolescents. Although one in four are savers, less than $2 \%$ have a bank account. All the savers save at home, with parents or siblings, or in a piggy bank. A small number (8\%) of adolescents have borrowed money, and only one-third of those report that the loan is interest-bearing. Borrowing is more common among girls and in the Mid and Far Western region. The majority (43\%) borrowed for educational purposes. The remainder of loans were for household purposes such as home building and health emergencies. Financial literacy as assessed by knowledge of financial planning and budgeting, and functioning of banks is generally poor.

Norms of child marriage and the cultural practice of dowry payments to the groom by the bride's family are important aspects of the normative structure affecting gender differences in the lives of adolescents. Girls marry earlier than boys and have more limited social networks of support and fewer friends. In general, young people have poor knowledge of laws regarding marriage and dowry. Most striking is the lack of knowledge about legal minimum ages at marriage. Poor knowledge about punishments for child marriage and dowry is under- 
standable because such laws are not clear. Sexual violence is more common than physical violencean unusual difference for South Asia in reports of violence. One in six married girls report experiencing physical violence and nearly one in three report being forced to have sex by their husbands.

Although young people hold values that men and women deserve to be treated equally, compared to boys, girls are more likely to perceive and experience discrimination. It is more common to perceive discrimination in the home and family than in school. Both boys and girls perceive that men more than women are allowed to say no in an arranged marriage. Boys and girls are equally likely to feel that a woman's most important role is to take care of the home; about two out of three respondents feel this way. There is little difference between boys and girls in beliefs that may promote men's violence as well as beliefs that women need to tolerate violence and be subject to violence as sanctions or disciplinary behavior.

Challenges for adolescents, particularly girls, remain as they go through puberty. Particularly in the Mid and Far Western districts, harmful practices about purity and pollution (such as Chaupadi) continue to dominate the experiences of girls as they go through this important physiological transition.
Although sexual debut occurs within marriage for most girls, child marriage results in early sexual debut. The mean age of first sex is as low as 15.7 years and first pregnancy 16.2 years, exposing girls to multiple risks. Fewer than half of the sexually active adolescents in study districts had ever used a contraceptive method. Only one in five reported currently using a modern method. Adolescents are aware of HIV, but only one in four adolescents had correct knowledge of HIV transmission.

There are multiple institutions that facilitate participation of adolescents in important aspects of their lives to advocate for their rights. Adolescents want to be involved with institutions such as clubs or informal groups. When they have access to them, they participate actively. Access to institutions such as youth and sports clubs, microfinance institutions, and vocational or livelihood institutions is limited in the study districts and particularly so in the Terai region. The most common forms of participation for adolescents of both sexes are outdoor games and cultural events at school. Participation in higher decision-making bodies such as school management committees, Village Development Committees, and health management committees for adolescents is nonexistent in the study districts. 



\section{Introduction}

In many developing countries, recent demographic changes in fertility and mortality have led to unprecedented growth in the population of adolescents. The largest cohorts are now entering adulthood. The forces of globalization and democratization, and the advent of technologies and newer social norms pose novel challenges to transitions to adulthood. Even as these changes offer important economic benefits, there is a high risk that they will be unequally distributed leading to inequitable and socially polarized societies. Relative to the past, the choices that adolescents make thus have even more significant implications for their health, productivity, and success as adults (Lloyd 2005).

While it has always been widely recognized that adolescence is a period of significant psychological, social, and biological changes, only recently has it been appropriately recognized as an important time to invest in an individual's health and development. Adolescents and the decisions they make are also tied to some of the most prominent challenges of our time including climate change, migration, urbanization, and HIV and AIDS. UNICEF has affirmed its commitment to adolescents by making their health and wellbeing an integral part of its programming agenda in the last decade, culminating in the formation of the Adolescent Development and Participation (ADAP) program.

Evidence on the importance of a range of factors as determinants of well-being has led to the development of multidimensional frameworks for understanding transitions to adulthood. In 2005, an

\section{Adolescents and the decisions they make are tied to some of the most prominent challenges of our time, including climate change, migration, urbanization, and HIV and AIDS.}

expert group report published by the United Statesbased National Academy of Sciences on Transitions to Adulthood was instrumental in drawing attention to the importance of investing in adolescents. We draw on this important framework of "growing up global" as a common characterization of adolescent lives across the developing world.

A successful transition to becoming healthy and productive adults in the developed and developing world entails the accumulation of an appropriate stock of human and social capital and adoption of pro-social values in order for adolescents to contribute to their communities and the societies they live in. Adolescents must develop selfefficacy, autonomy, and agency in making choices that result in their health and development. They must also negotiate risks and opportunities during this time to make well-timed transitions from school into productive work and citizenship and then, as they become ready, into marriage and subsequently parenthood. 
Healthy transitions also include avoiding and navigating risk. The data from developing countries show that young people are becoming sexually active at increasingly younger ages and engaging in risky sexual behavior, thus facing increased risks of HIV and STIs (Lloyd 2005). Poverty remains a significant barrier for young people, particularly for girls, which affects a range of issues, including low levels of secondary school enrollment, difficulties in continuing schooling for those who are enrolled, and decreased opportunities for work and livelihoods. Child marriage continues to be tied intrinsically to poverty; it hinders young women from leading productive lives and increases their risk of becoming victims of various forms of genderbased violence.

As in most of the developing world, adolescents in Nepal aged 10-19 are coming of age and transitioning into adulthood in a rapidly changing world. Nepali adolescents are faced with the task of navigating complex transitions to adulthood amid adverse social, political, and economic circumstances and with limited resources. They are also, as in many countries, one of the fastest growing and largest segments of the population of the country, accounting for $24 \%$ of the total population (6.4 million), up from 23\% (5.4 million) in the previous census (2001) (Government of Nepal, Central Bureau of Statistics, 2012).

Nepali adolescents, particularly girls, face significant barriers across a number of key adolescent transition-to-adulthood outcome domains including their equitable and unhindered access to schooling, smooth transitions from school to productive employment, free and full consent to marriage, and access to general and reproductive health services, among others. Adolescents, both girls and boys, are also faced with newer risks as a result of increasing globalization, including increased risky sexual behaviors; higher risk of STIs and HIV infection; and increased exposure to violence, exploitation, and trafficking.

\section{ADOLESCENT GIRLS' TRANSITIONS TO ADULTHOOD IN NEPAL}

Among adolescents, there are certain segments that are more vulnerable than others and thus should receive priority in policy and programmatic interventions. Adolescent girls are such a group and they face disproportionately tougher barriers in making proficient, sequential, and timely transitions to adulthood in Nepal. Gender inequality is deeply rooted in society, and prescribes vastly different and unequal roles to women and men.

Previous research and data for adolescent girls in Nepal suggest that an unusual dynamic exists in the interrelationship among three of the most important outcomes during adolescence and young adulthood: marriage timing, schooling, and workforce participation (Bajracharya and Amin 2012). These data suggest that even while education and workforce participation increased, child marriage remained common in Nepal. The Demographic and Health Survey of Nepal (DHS) of 2011 showed that girls married at a median age of 17.4 years and more than $28 \%$ of women aged 15-19 were in unions. Similarly, approximately $40 \%$ of young women aged $20-24$ were married by the age of 18 (MOHP et al. 2012). These high rates are surprising because they coexist with relatively high rates of schooling and workforce participation.

According to the 2011 NDHS, only 7\% of girls aged 10-14 in Nepal had never been enrolled in school, a significant improvement from 2006 when this figure was $11 \%$, indicating that Nepal is on its way to achieving universal primary education. Among girls aged $15-19$, this figure was only $13 \%$, an even more striking decline from the 2006 figure of $22 \%$. These statistics for schooling are significantly anomalous in the sense that they are better than those for neighboring regions. The percentage of girls aged 10-14 who have never attended school in three regions of India is 38\% (Bihar), 37\% (Jharkhand), 28\% (Rajasthan); in Pakistan, 29\% of girls aged 10-14 have never attended school (Girls Discovered 2005-08). In Pakistan, marriage occurs much later, while marriage and poverty levels in Bihar, Jharkhand, and Rajasthan are similar to Nepal. When women's labor-force participation is considered, this anomaly becomes even more striking. 
Women's economic participation in Nepal is uncharacteristically high: in 2011, close to half (48\%) of adolescent girls aged 15-19 reported that they had been employed in the last 12 months in forms of work other than housework (MOHP et al., 2012). These figures are significantly higher than those for women in Bangladesh and Bihar where rates of economic activity among girls aged 15-19 are as low as 10 and $15 \%$ in their most recent DHS, respectively.

This dynamic is indicative of the fact that poverty and other interrelated sociocultural factors might play a significant role in hindering smooth adolescent transitions in Nepal. In a study in Nepal, Bajracharya and Amin (2012) examined these relationships, finding that poverty status during childhood significantly affects a girl's likelihood of being married early as opposed to staying in school. The study also hypothesized that harmful traditional practices such as dowry might be driving poor families to marry their daughters off early to avoid having to pay large sums in dowry.

Adolescent girls (and boys) in Nepal face additional vulnerabilities as well. In terms of sexual and reproductive health and behavior, the 2011 DHS shows that over $29 \%$ of adolescents aged 15-19 had ever had sexual intercourse and $5 \%$ had had sex by the age of 15 , indicating that sexual debut in Nepal is occurring at young ages. This is exposing young boys and girls to high risks of diseases like HIV. Among 15-19-year-olds, however, awareness about HIV and AIDS was relatively high, with over $88 \%$ indicating that they had heard about AIDS. We also see in the data that girls are exposed to gender-based violence at early ages. Nearly $10 \%$ of all girls aged 15-19 had experienced some form of violence in their lifetime. These risks were seen to escalate with age and marriage, with significantly higher rates of prevalence among those who are married (25\%) and among 20-24-year-olds (18\%). While reliable estimates for migration are not available for present-day adolescents, DHS data show that among women who migrated in the 10 years prior to the survey, $36 \%$ migrated between the ages of $15-19$ and $20 \%$ migrated before age 15 (MOHP, New Era and ICF International 2012).
While reliable estimates for migration are not available for present-day adolescents, DHS data show that among women who migrated in the 10 years prior to the survey, 36\% migrated between the ages of $15-19$ and $20 \%$ had migrated before they were 15 years old. These striking figures indicate significant economic vulnerabilities being experienced by adolescents, which compel them to migrate at young ages, often to domestic servitude in urban areas, and also expose them to the risk of sexual abuse and of being trafficked into prostitution. These figures are illustrative of the current risks that adolescents are exposed to in Nepal.

\section{GEOGRAPHIC, ECONOMIC, AND SOCIAL ISOLATION}

Adolescents who have grown up in geographically and economically isolated areas that lack infrastructure such as roads and bridges have poor access to schools and health facilities. Social isolation also plays a significant role in exacerbating vulnerabilities for adolescents. Socially marginalized groups that face institutionalized discrimination based on gender, caste, ethnic, and linguistic differences have to navigate greater barriers to achieving healthy and productive outcomes.

In Nepal, two geographic regions have always fared worse than the rest of the country in terms of all human development indicators and, as expected, in adolescent outcomes as well. The burden of disadvantage in these two regions is largely a function of a combination of geographic, economic, and social isolation. These regions are:

- the northern region of the Far Western and Mid Western zone that lies in the hilly and mountainous ecological zones (referred to as Mid and Far Western region throughout this report); and

- the southern Terai plains belt in Mid to Eastern Nepal between Kapilbastu and Saptari districts (excluding Chitwan) (referred to as the Terai region throughout this report). 
All study districts incidentally fall within these two regions, indicating that independent assessments of disadvantage in these regions are consistent and that targeting these areas is extremely important and appropriate. Population Council researchers recently mapped key adolescent outcomes in schooling, employment, and child marriage for adolescent girls at the district level in Nepal utilizing DHS 2006 data (Bajracharya and Amin unpublished). The analysis revealed a clear geographic concentration of disadvantage in these two areas, showing significantly lower proportions of school attendance and workforce participation and higher incidence of child marriage.

In Bajhang and Mugu-two districts in the remote Far Western region-enrollment levels were lowest at $40 \%$ or less among 10-14-year-olds while 52 districts had enrollment levels of over $80 \%$. In terms of primary school completion for girls aged 15-19, figures were particularly low for the Mid and Far Western districts, with a number of districts within this region at completion rates under $20 \%$. In both cases, the belt of districts in the Terai region showed notably low rates of enrollment and completion, respectively.

In terms of workforce participation of girls aged 15-19, the eastern Terai belt showed significantly lower rates of work among girls of this age, and participation in two districts, Dhanusha and Rautahat, were the lowest with figures under 20\%, while 34 districts in the rest of the country had workforce participation rates of over $80 \%$.

Finally, in terms of child marriage, patterns of disadvantage are again observed in these two regions. All seven districts where the median age at marriage is between 14-16 are within these two geographic areas. A similar pattern is observed in four districts where between $60 \%$ to $80 \%$ of girls aged 15-19 were married (Bajhang, Kalikot, Jajarkot, and Mugu) in the Mid and Far Western regions.

Within these regions, several districts, namely Mugu and Bajhang (in the northwest) and Rautahat and Dhanusha (in the Terai) placed at the bottom of most indicators for adolescent girls.
Not surprisingly, the Mugu and Bajhang districts in the northwest are consistently listed among the most remote districts in Nepal and have the lowest Human Development Index (HDI) ${ }^{1}$ scores (under 0.400), and Rautahat and Dhanusha fall in the bottom third among all districts in Nepal (UNDP 2004). All four of these districts are included in the study. The two regions in general also consistently score in the lowest ranges on poverty, empowerment, and gender-based indices as reported in the 2004 Nepal Human Development Report (UNDP 2004). The pattern of disadvantage therefore is clearly concentrated in these two regions, not only for adolescent girls transitioning into adulthood, but in general for most development outcomes for the general population.

Despite the similarity of both regions in their poverty and low human development status, they are starkly distinct in terms of population size; topography; land resources: caste/ethnic, linguistic, and religious composition; and in their access to modern amenities such as roads, schools, health posts, communication, electricity, etc. The key difference between the regions is that disadvantage in the Mid and Far Western region is likely a result of geographic and economic isolation, with its extremely difficult mountainous terrain, sparse populations, low arability of land, high levels of poverty, and low levels of human development indicators. In the Terai region, although districts are characterized by high population densities, high agricultural productivity, and arable land, the cause of disadvantage is likely due to social isolation. In particular, its population is dominated by the low caste groups such as the Yadavs and ethnic groups such as the Muslims and the Tharus, among others, who have traditionally been marginalized, both socially and institutionally. Gender discrimination and harmful practices such as gender-based violence, exploitive dowry demand, and trafficking are concentrated in this region as well.

\footnotetext{
1 The Human Development Index (HDI) is a summary measure of average achievement in key dimensions of human development: a long and healthy life, being knowledgeable, and having a decent standard of living. <http://hdr.undp.org/en/content/ human-development-index-hdi> Accessed 15 September 2014.
} 
Under these circumstances, adolescents in these two regions face much more significant barriers than anywhere else in the country. Thus a focus on these areas through the UNICEF ADAP program is not only important and strategic, but essential to ensure that adolescents in these regions get a fair chance at a healthy transition to adulthood. The collection of multidimensional data in this study will provide unprecedented access to knowledge about the lives of adolescents in these regions. The study will provide better insight to UNICEF's ADAP program as well as government and other stakeholders in assessing the needs of adolescents in these areas and effectively targeting programs for them.

\section{UNICEF ADAP PROGRAM DESCRIPTION}

Nepal's ADAP program focuses on vulnerable and disadvantaged adolescents. This holistic program aims to empower adolescents, especially girls, to initiate and sustain activities and interventions that create positive transformations in their families, communities, and society and bring about realization of their rights. Three key strategies include: (1) ensuring active and meaningful participation of adolescents, especially girls and those in the younger age group (10-14 years); (2) ensuring that core interventions address the age, sex, and situational diversity among adolescents, specifically those who are most at risk and especially vulnerable to HIV and different forms of violence; and (3) generating and sharing evidence including participatory behavioral monitoring and district-level bottleneck analysis.

The ADAP program plans to engage adolescents in two regions of $\mathrm{Nepal}$ - the Terai (indicated in blue and red on the map) and the Mid and Far Western region (indicated in green) (see Figure 1). The program will offer a comprehensive financial and social skills training package to adolescents that will include topics such as self-awareness, rights and responsibilities, gender and social inclusion, puberty, nutrition, civic engagement, disaster risk management and climate change adaptation, savings, spending, livelihood options, sexual and reproductive health, and gender-based violence. ADAP also offers micro-enterprise development and entrepreneurial training for adolescents. The program uses

\section{FIGURE 1 Map of UNICEF program districts}

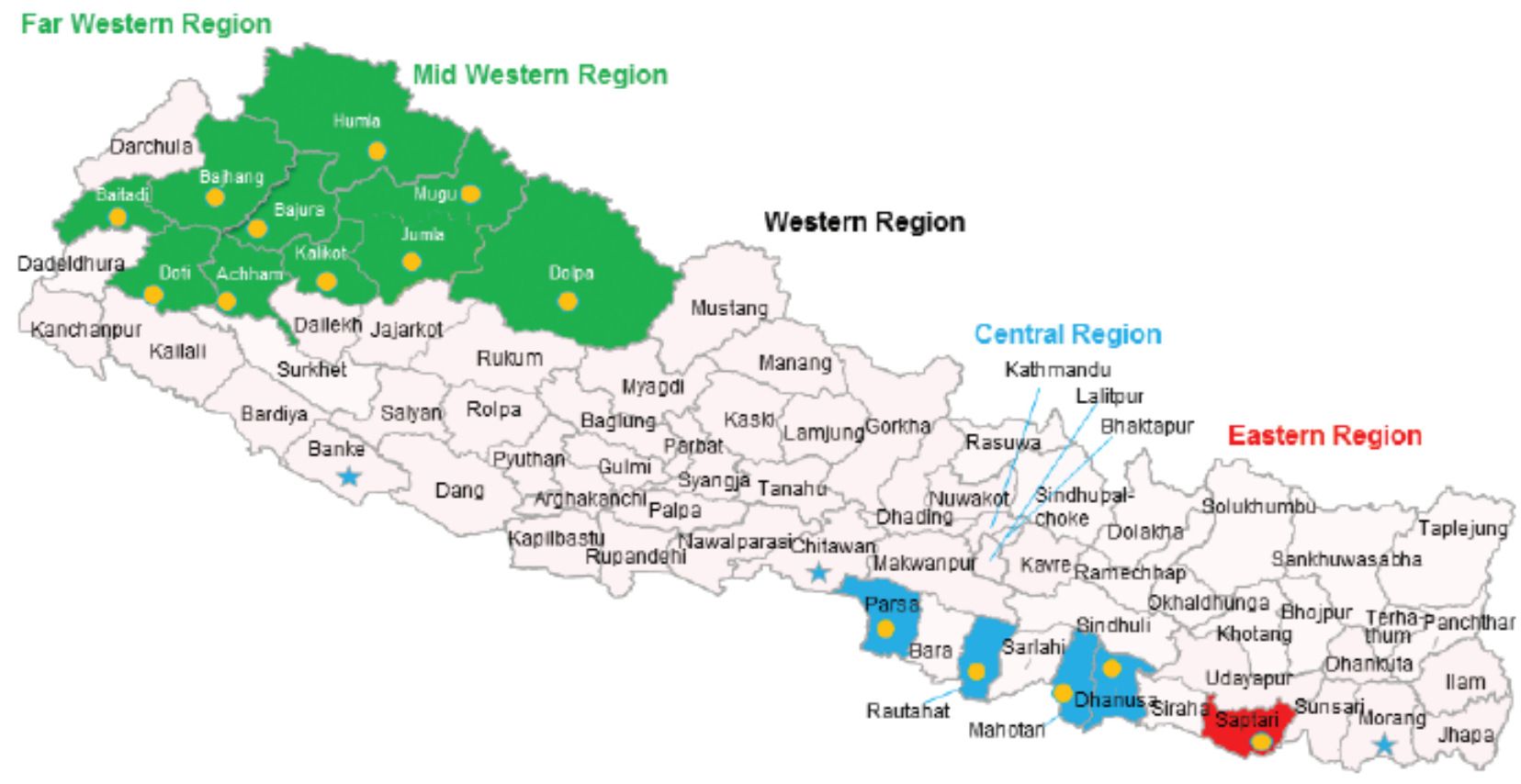


a two-generational approach engaging the parents of adolescents as well. Programming for parents includes sessions on child rights, puberty, sex and gender, sexual and reproductive health, child marriage, abuse, HIV, drug abuse, and livelihoods and financial literacy.

Although adolescent outcomes and the factors that influence them are measured almost invariably at the individual level, researchers and policymakers are increasingly examining adolescence utilizing ecological models. The determinants of adolescent well-being are complex, and exist and interact on multiple levels. Family members and household environments have the most direct interactions with adolescents. But as members of communities, the distal and larger social, political, and economic environments affect adolescents as well. As a result, comprehensive frameworks that reach beyond the individual are needed to fully understand the scope and dynamics of influences shaping vulnerability. Accounting for such higher level influences in program and policy development for adolescents is critical for the success of programs.

In designing this survey in Nepal, we drew from a multilevel ecological framework of human development to guide our work. As conceptualized by Bronfenbrenner (1981) (Figure 2), the framework recognizes human development as a process occurring within individuals and their immediate and larger surroundings. At the core are individuals and their direct interactions with family, schools, social groups, and neighborhoods. More distal influences include institutions of society such as government and social networks. Laws and informal ideologies, norms, and customs that shape interactions in society are at the highest level (Bronfenbrenner 1977). This nested arrangement of influences is extremely valuable in conceptualizing and subsequently averting risks and vulnerabilities at various levels. More importantly, this framework enables development practitioners, policymakers, and program developers to harness the power of neighborhoods, social groups, and networks, institutions, and government to facilitate a smooth transition to adulthood.
Along with multiple levels of influence, the lifecourse perspective also suggests that adolescents have different needs and vulnerabilities across the age spectrum. The negative outcomes adolescents experience are more likely to occur in late adolescence. For this reason, early adolescence, defined as ages 10-14, can be a particularly ripe time for interventions. Puberty brings risks to fertility, sexuality, and threats of violence. This is particularly true for girls where the onset of adolescence alters the ways in which families, communities, and social institutions treat girls. Intervening before the onset of puberty can lead to safer behaviors and better health outcomes in later life. Additionally, younger adolescents are more likely to be in school compared to those in older age groups. Once children leave school, few succeed at returning and getting back on track. Delaying interventions to later years may miss these sensitive periods for avoiding disadvantage. This aligns well with UNICEF's focus on younger adolescents aged 10-14 and on girls. In designing the study, particular focus was paid to this group to address their vulnerability, as the rewards of intervening at this age are likely to be significant.

Another overarching impediment to adolescent well-being is social isolation. Adolescents who have left school, who do not live with parents, who live in remote regions, or who are members of marginalized groups that are institutionally discriminated against based on caste, ethnic, and linguistic differences are among the most vulnerable. Girls are often more socially isolated than boys with smaller networks and fewer opportunities to meet friends. Social isolation is particularly important in the context of the study districts. In these districts, added layers of both geographic and cultural isolation compound adolescents' vulnerabilities. Evidence from a Population Council study examining ethnic minority youth in similarly remote mountainous areas of Vietnam suggests that they experience disproportionately negative outcomes and have great difficulty accessing resources (Teerawichitchainan, Hac, and Nguyen 2007). Sensitivities to the needs of the marginalized were included in our approach to examining the well-being of young people in Nepal. 


\section{FIGURE 2 Social ecological model}

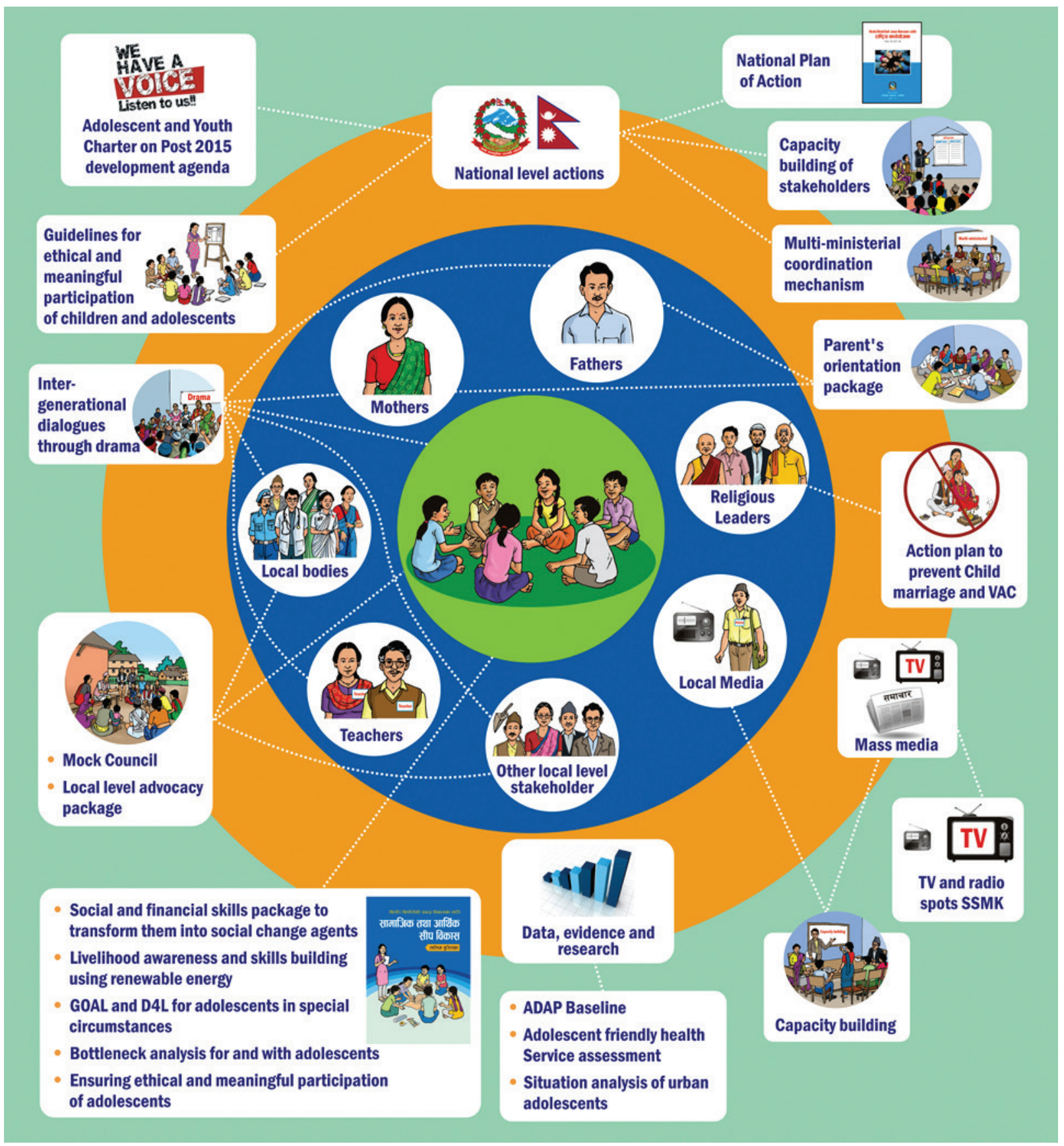

Source: UNICEF Nepal 
Programmatic efforts need to not only reduce deprivations but also promote the essential elements adolescents need to grow and thrive. The safe spaces approach has been a key strategy used by the Population Council for providing social support, improving girls' self-conceptions, and imparting new skills. We will draw from this framework to inform questions about building social, human, and financial assets among adolescents in Nepal to expand opportunities and improve their livelihoods. In Nepal, and particularly in the aforementioned study districts, little is known about adolescents' access to safe spaces and programs and initiatives that help develop financial and social assets.

\section{RATIONALE FOR SURVEY}

This study was designed to be a comprehensive cross-sectional study that aims to fill significant knowledge gaps on adolescents in Nepal. It will generate data and evidence to inform UNICEF as well as other partners on key priority areas for adolescents. While a number of efforts to address adolescent issues have been initiated, there is a significant dearth in data on adolescents in Nepal that are essential in order for programs to be properly targeted, based on robust needs assessments, and to reach their intended beneficiaries and achieve desired outcomes. Only a very few data sources in Nepal exist that focus on adolescents exclusively and very few delve into the nuanced aspects of adolescent lives that can address the complex vulnerabilities faced.
Several surveys include information on adolescents such as the Demographic Health Survey (2006 and 2011), the Nepal Adolescent and Youth Survey (2011), and UNICEF's Multiple Indicator Cluster Survey (MICS). As national surveys that report on the entire population, these are often constrained by costs and other factors in collecting more nuanced data on adolescents that would greatly aid the process of program and policy development targeted toward them. This baseline survey was designed and implemented in collaboration with the UNICEF ADAP team to address specific topic areas of interest in the 15 study districts. 


\section{Methodology}

\section{STUDY DESIGN AND SAMPLE}

The Population Council conducted a baseline survey of a sample of adolescents aged 10-19 living in 15 districts of Nepal with support from UNICEF Nepal, in collaboration with the Center for Research on Environment Health and Population Activities (CREHPA). A qualitative research study was also conducted to supplement the quantitative data. The study used a mixed method approach of qualitative and quantitative research tools to collect data from the 15 study districts: Achham, Baitadi, Bajhang, Bajura, Dhanusha, Dolpa, Doti, Humla, Jumla, Kalikot, Mahotari, Mugu, Parsa, Rautahat, and Saptari. Data were collected through household surveys, participatory group discussions with adolescent boys and girls aged 10-19, and semi-structured interviews with community-level key stakeholders in the sampled districts. Table 1 summarizes research and data-gathering activities for the study.

\section{The Adolescent Development and Participation program identified the need for adequate and scientifically valid data on adolescents aged 10-19 from the study districts in Nepal.}

\section{Adolescent Household Survey}

The Population Council led the baseline study and the overall research and instrument design. Fieldwork training, survey tool refinements, sample design, and data collection and management were led by a team of researchers, supervisors, and interviewers at CREHPA.

TABLE 1 Summary of research and data-gathering activities

\begin{tabular}{llll}
\hline & Adolescent survey & $\begin{array}{l}\text { Participatory group } \\
\text { discussion (PGD) }\end{array}$ & Key stakeholder interviews \\
\hline Study population & $\begin{array}{l}\text { Adolescents, both boys } \\
\text { and girls aged 10-19 }\end{array}$ & $\begin{array}{l}\text { Adolescents, both boys } \\
\text { and girls aged 10-14 } \\
\text { and 15-19 }\end{array}$ & $\begin{array}{l}\text { Community-level key stakeholders, gatekeepers, } \\
\text { and community members and other key } \\
\text { individuals in government and civil society }\end{array}$ \\
\hline Sample size & 3,000 in 15 districts & $\begin{array}{l}\text { 12 group discussions } \\
\text { segregated by age group } \\
\text { and sex in three districts }\end{array}$ & 96 in 15 districts (2 to 10 per district) \\
\hline Location of activity & Household & Community & Household, district headquarters \\
\hline Method & $\begin{array}{l}\text { Household Survey } \\
\text { Structured Questionnaire }\end{array}$ & $\begin{array}{l}\text { Participatory group } \\
\text { and structured exercises }\end{array}$ & Semi-structured interviews \\
\hline
\end{tabular}


Study design

The baseline survey was designed as a household sample survey of 3,000 adolescents, both boys and girls aged 10-19 years in the 15 study districts in the Mid and Far Western region and the Terai region (Figure 1 and Table 2). The individual sample survey figure is based on calculations used to obtain adequate representative estimates for adolescent related indicators by sex, two age groups (10-14 and 15-19), and two broad regional categories.

(See Appendix 1 for more details on Methodology).

TABLE 2 UNICEF baseline survey data collection districts

\begin{tabular}{|c|c|c|}
\hline Region & Development zone & District \\
\hline \multirow{2}{*}{$\begin{array}{l}\text { Far and } \\
\text { Mid Western } \\
\text { Region }\end{array}$} & Far Western & $\begin{array}{l}\text { Achham } \\
\text { Baitadi } \\
\text { Bajhang } \\
\text { Bajura } \\
\text { Doti }\end{array}$ \\
\hline & Mid Western & $\begin{array}{l}\text { Dolpa } \\
\text { Humla } \\
\text { Jumla } \\
\text { Kalikot } \\
\text { Mugu }\end{array}$ \\
\hline \multirow[t]{2}{*}{ Terai Region } & Central & $\begin{array}{l}\text { Dhanusa } \\
\text { Mahotari } \\
\text { Parsa } \\
\text { Rautahat }\end{array}$ \\
\hline & Eastern & Saptari \\
\hline
\end{tabular}




\section{Background characteristics}

\section{ETHNICITY}

Nepal is a country of multiple ethnic, linguistic, and cultural groups. Although the survey is limited to 15 disadvantaged districts, there is a wide variety of ethnicities from 50 different groups represented in the survey. The ethnic composition of the Terai region is different from that of the Mid and Far Western region (Figure 3). The dominant ethnicity in the Mid and Far Western region is Chhetri. The Terai is more diverse with a larger number of ethnicities and no one particularly dominant group. The largest groups are the Yadavs and Muslims.

\section{Ethnic, caste, and religious groups}

Because of the large number of ethnic groups, it is common practice to analyze data from sample surveys after classifying them in a way that differentiates by caste, advantaged and disadvantaged indigenous groups, and religious

FIGURE 3 Four largest ethnic groups among adolescents aged 10-19, by region in Nepal

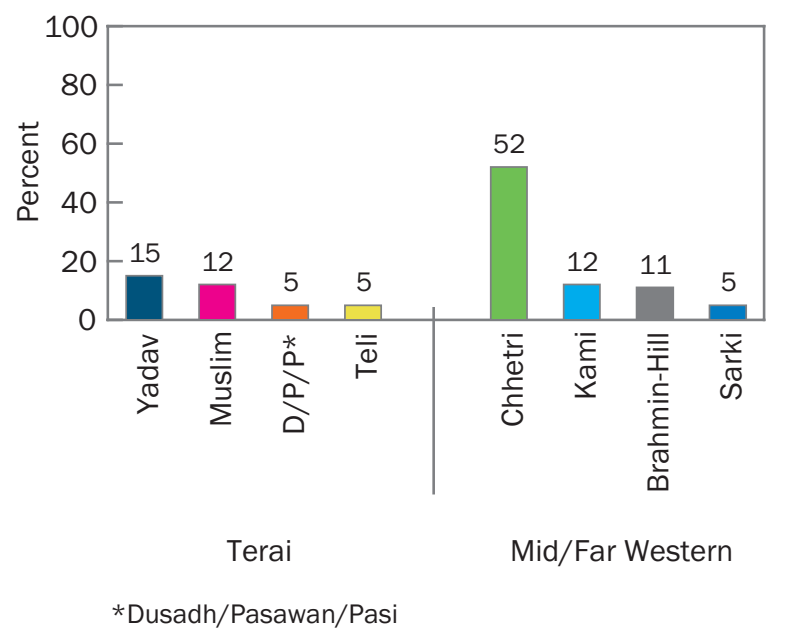

\section{Adolescents reported belonging to over 50 different ethnic groups, and the majority of them live in rural areas that rely on agriculture for their livelihood.}

minority status. ${ }^{2}$ In Nepal, the resulting categories were: Dalit, religious minorities, disadvantaged indigenous (Janajati), disadvantaged non-Dalit, advantaged indigenous (Janajati), and upper castes. Dalits include but are not limited to Kami, Damai, Dholi, Chamar, Harijan, Ran, Khatwe, and Pasi. Religious minorities include Musalman or Muslims. Disadvantaged indigenous groups include Tharu, Magar, Dhanuk, Tamang, and Sherpa among others. Disadvantaged non-Dalits include Yadav, Mallaha, Teli, Kurmi, and others. Advantaged indigenous groups include Newar and Gurung. Upper caste groups include Chhetri, Brahmin-Hill and -Terai,

2 Nepal's diverse population has a complex system of casteethnic-religious divisions. Nepal's caste system has its origins in the traditional Hindu caste system and codified into the National Legal Code of 1854, with revisions in National Civil Code of 1963 and in the post-1990 democratic constitution. While non-Hindu indigenous ethnic groups do not follow the Hindu caste system, they may be categorized into advantaged and disadvantaged groups based on distinctions rooted in geographical divisions and social class. Caste and ethnicity intersect with religion and class to dictate the patterns of power and discrimination, including norms of purity, pollution and untouchability in Nepal resulting in a complex range of caste-ethnic-religious groups that have been outlined in Appendix 2. See Pradhan and Shrestha (2005) for a detailed historical perspective on caste, ethnicity and religion based distinctions in Nepal. 
Thakuri, and several other small ethnic groups. For a complete list of caste/ethnic categorizations by group, see Appendix 2.

Due to small numbers of observations within these groups, we further combined ethnic subgroups into categories that are broadly homogeneous following a common reclassification system for Nepal grouping religious minorities with disadvantaged indigenous groups. Similarly, we grouped advantaged indigenous groups with the Upper Caste.

Table 3 shows the distribution of ethnic/religious affiliations among adolescents within age, and gender groups by region. In the Terai, the vast majority (92\% of adolescents interviewed) belonged to disadvantaged groups (Dalit, religious minorities, disadvantaged indigenous/non-Dalit). Only $8 \%$ of adolescents in the Terai reported being a member of an advantaged indigenous or upper caste group. In contrast, in the Mid and Far Western region, twothirds of adolescents were from advantaged groups.

\section{PRIMARY LANGUAGE}

An important correlate of ethnic groupings is differences in language. There is wide variation in the language spoken at home across groups (Figure 4). Maithili is the dominant language in the Terai whereas Nepali is dominant in the Mid and Far Western region. Other languages spoken are Bhojpuri, Baitadeli, and Bajhangi. Diversity in languages spoken at home poses important challenges for the school system.

\section{RELIGION}

The vast majority of adolescents in the study districts are Hindu. In the Terai, $85 \%$ are Hindu but there is a significant (12\%) Muslim minority (Figure 5). In the Mid and Far Western region, 95\% of adolescents are Hindu.

FIGURE 4 Primary language among adolescents aged 10-19, by region

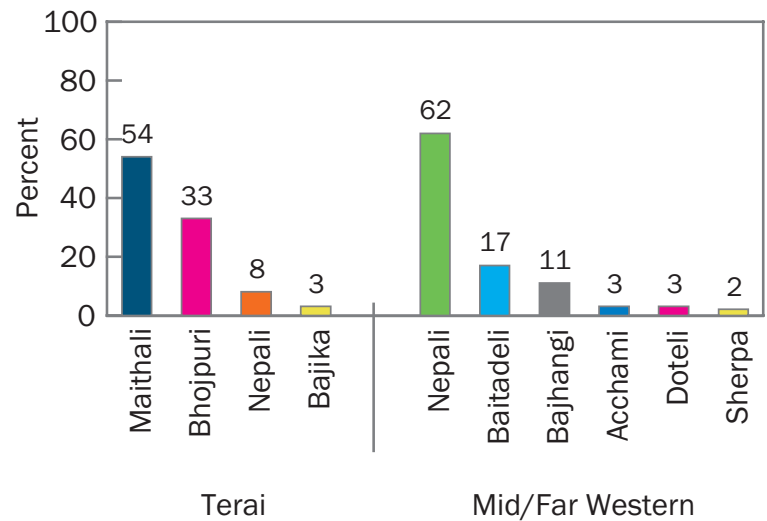

Note: All remaining individual-linguistic groups comprised fewer than $1 \%$ of the adolescent populations within their respective regions.

TABLE 3 Ethnic/religious groups among adolescents aged 10-19, by age, sex, and region (\%)

\begin{tabular}{lcrr}
\hline & Females aged 10-19 & Males aged 10-19 & Total (N) \\
\hline TERAI REGION & & & \\
Dalit & 20 & 23 & $(455)$ \\
Religious minorities and disadvantaged indigenous groups & 24 & 20 & $(473)$ \\
Disadvantaged non-Dalit & 46 & 50 & $(1,001)$ \\
Advantaged indigenous and upper castes & 9 & 7 & $(171)$ \\
TOTAL & 100 & 100 & $(2,100)$ \\
& & & $(239)$ \\
MID AND FAR WESTERN REGION & & & $(44)$ \\
Dalit & 26 & 5 & $(607)$ \\
Disadvantaged indigenous and non-Dalit groups & 7 & 68 & $(890)$ \\
Advantaged indigenous and upper castes & 67 & 100 & \\
TOTAL & 100 & & \\
\hline
\end{tabular}

Note: No adolescents in the Mid and Far Western region reported their ethnic group as a religious minority. 


\section{PARENTAL EDUCATION}

Parents of adolescents in the survey have low educational attainment: $85 \%$ of mothers and $46 \%$ of fathers have no education (Figure 6). Approximately one in three fathers had secondarylevel schooling and only $2 \%$ had a bachelor's degree or higher. Among adolescents, only 10\% have never attended school. Low educational achievement among adults limits the possibility of schooling expansion because of the lack of supply of teachers of appropriate age and educational qualifications. Low parental education can also influence intergenerational dynamics within households to the extent that education confers authority and status.

\section{HOUSEHOLD ASSETS}

Most adolescents' households in the Terai have electricity (Figure 7). In contrast, only $17 \%$ of households in the Mid and Far Western region have electricity. Mobile phone access, however, is high in both regions. $91 \%$ of households in the Terai and $73 \%$ in the Mid and Far Western regions have a mobile phone. Owning a television or radio can also be one indication of exposure to media. Television ownership is also relatively high in the Terai (49\%) but only $11 \%$ in the Mid and Far Western region where a relatively greater proportion own radios (40\%). Still newer technologies have yet to enter many adolescent households. Few households have computers: $5 \%$ of adolescent households in the Terai and only $1 \%$ in the Mid and Far Western region. Because these are households that rely wholly or partially on agriculture for their livelihoods, the majority own livestock-62\% in Terai and 94\% in the Mid and Far Western regions.

\section{HOUSEHOLD WEALTH QUINTILES}

We constructed an index of household wealth using an extensive list of asset ownership and housing quality indicators. The methodology followed is similar to one used in Demographic and Health Surveys to assign households into wealth quintiles. The resulting ranking of households within the survey shows that
FIGURE 5 Religion among adolescents aged 10-19, by region

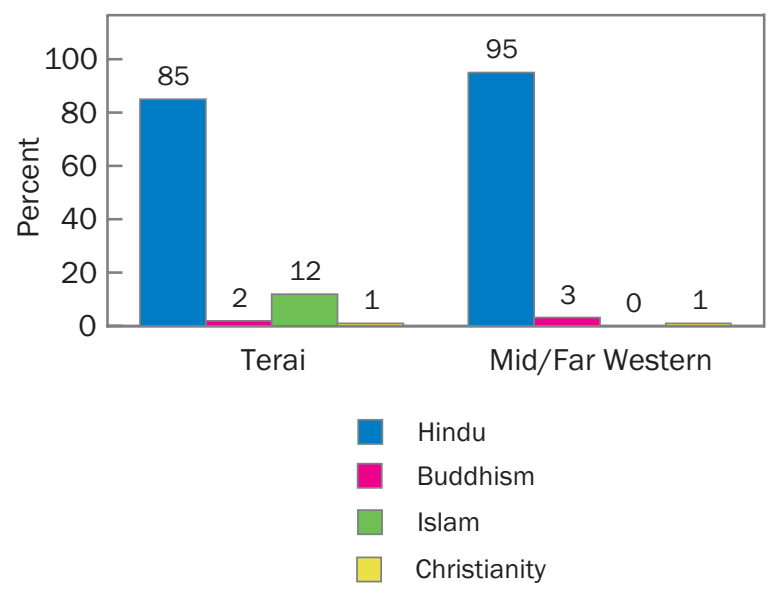

FIGURE 6 Educational attainment among parents and adolescents

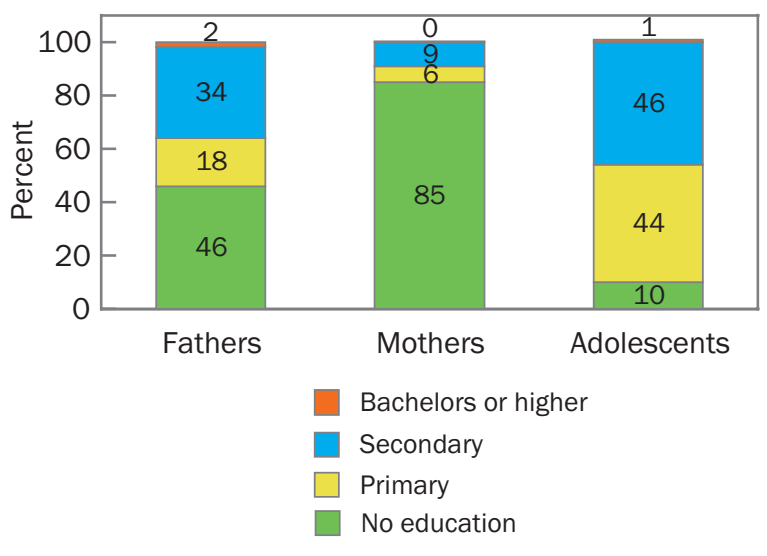

FIGURE 7 Asset ownership within adolescents' households, by region

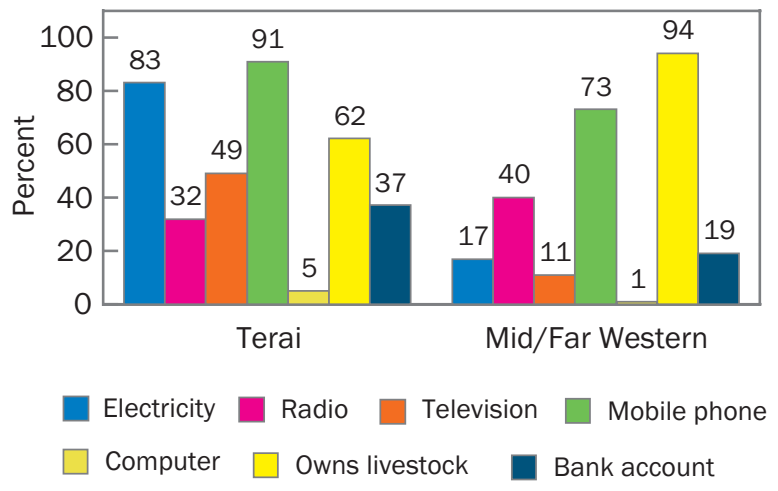


household distribution is considerably more skewed in the Mid and Far Western region compared to the Terai (Figure 8). In the former areas there are many more people in the poorest quintile and hardly any households in the richest quintile. According to this wealth index, nearly half of all households in the Mid and Far Western region are in the poorest quintile compared to only $8 \%$ of the households in the Terai.

\section{FIGURE 8 Household wealth quintiles, by region}

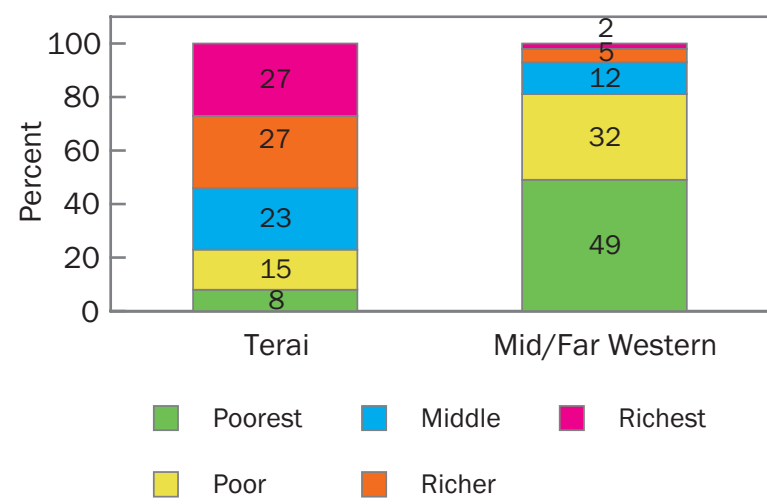

FIGURE 9 Wealth among adolescents, by caste/ethnicity

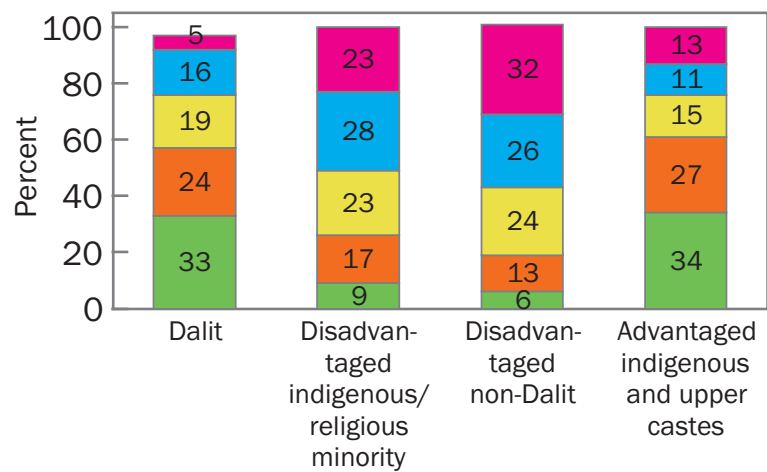

Poorest $\square$ Middle $\square$ Richest
Wealth ranking of households by ethnic and religious categories offers important insights into what these identities represent (Figure 9). In terms of wealth, Dalits and advantaged indigenous and upper caste groups are similarly distributed with one in three being in the poorest category. Relative to them, the disadvantaged indigenous and nonDalit groups are wealthier with over one in four households in the wealthiest category and less than $10 \%$ in the poorest category. 


\section{Education and Skills}

Recent Demographic and Health Surveys show that school attendance has increased rapidly in recent decades and is nearly universal in Nepal. Education among adults suggests that the expansion of schooling is a relatively new phenomenon and the educational opportunities available to the current generation of adolescents did not exist for their parents' generation when few people had any schooling, particularly women. The opportunity to attend and complete school and to acquire new skills can have important implications for healthy and timely transitions to adulthood. Receiving credentials in schooling as well as age-appropriate skills are an important part of that healthy transition. Schooling experiences, however, are not consistent across groups, particularly between boys and girls. Sex differentials in the experience of and access to schooling can have important consequences for later in life such as getting married and having children, the ability to earn a livelihood, and raising healthy children.

\section{EVER ATTENDED SCHOOL AND LITERACY}

As shown in Figure 10, schooling rates are higher in the Mid and Far Western region than in the Terai. The literacy gap is even greater. The survey measured literacy as the ability to read four simple sentences in Nepali. Not all respondents who attended school at some time in their lives were literate. The gap in literacy is at least 10 percentage points between boys and girls within both the Terai and Mid and Far Western regions.

\section{The educational opportunities available to the current generation of adolescents in Nepal did not exist for their parents' generation. Ensuring access to these new opportunities is essential for improving young people's lives.}

\section{FIGURE 10 School attendance and literacy among adolescents, by sex and region}

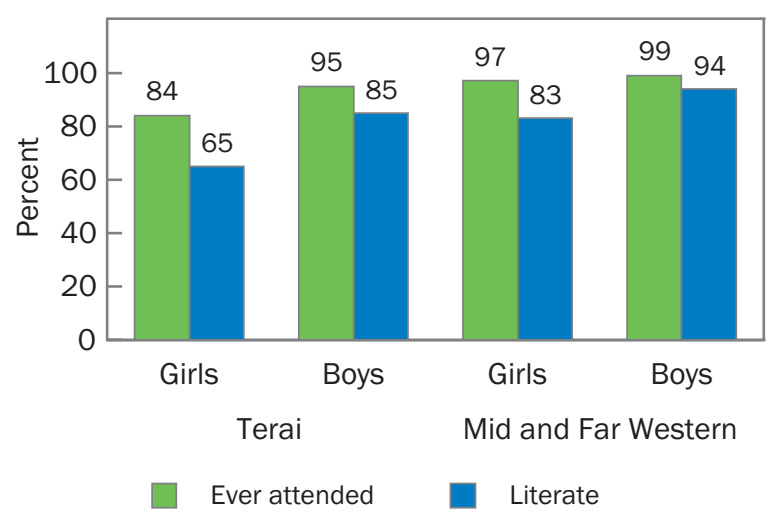

Note: Literate is defined as being able to read four simple sentences in Nepali. 
As with current school attendance disadvantaged caste/ethnic and wealth groups show significantly lower rates of ever attending school (Figure 11). However, rates of ever going to school are high, at nearly or above 90\%, among all groups. By caste/ ethnicity, Dalits and disadvantaged indigenous and minority religious groups are least likely to ever have gone to school. Similarly, by wealth, the poorest groups have slightly lower rates of attending school.

The majority of students attend schools run by the government (Table 4). Four out of five respon-

\section{FIGURE 11 Ever attended school among adolescents aged 10-19, by wealth and caste/ethnicity}

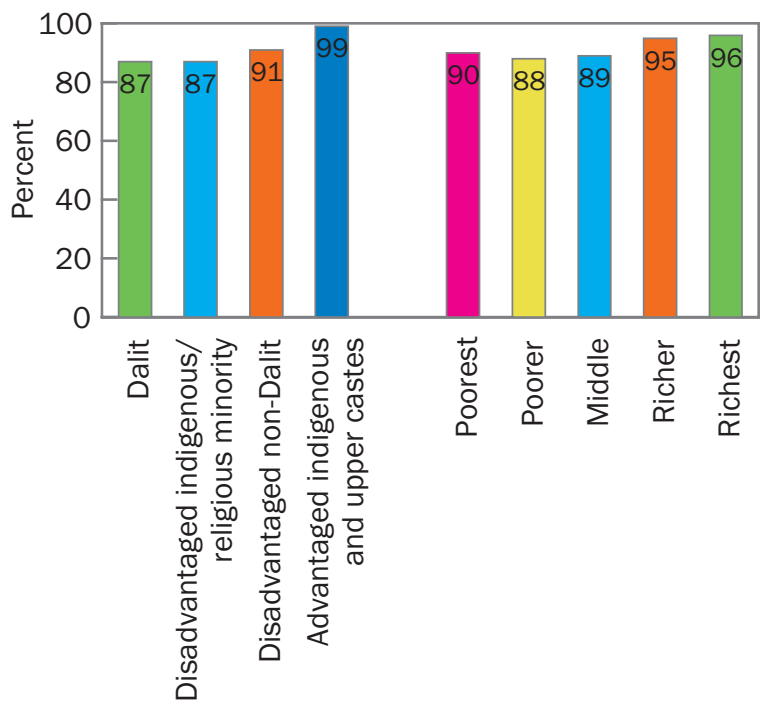

dents attend government schools. Comparing across gender and age groups we find that younger adolescents are more likely to be in private schools than older adolescents, and boys are more likely to be in a private school than girls. Private schooling is more common in the Terai than in the Mid and Far Western region. Overall religious schools do not account for a large portion of those who are in school; $2 \%$ of children in the Terai attend religious schools. There are no reports of religious schools in the Mid and Far Western region. Adolescent reports suggest that on average children first start attending school at relatively young ages. The age range at first enrollment is wide: from age 2-15. Among those who ever attended school and can recall age at first attendance, only 14\% reported first attending school when they were age six or younger.

\section{CURRENT SCHOOL ATTENDANCE}

Data on school attendance shown in Figure 12 show that while it is uniformly high at young ages, a large proportion of students drop out starting at around age 15, and the rate of dropout is far greater for girls than for boys. Girls in the Terai have the lowest levels of school attendance at all ages and they also drop out at a relatively greater rate compared to girls in the Mid and Far Western region and relative to boys.

TABLE 4 Schooling characteristics among adolescents aged 10-19, by age, sex, and region

\begin{tabular}{|c|c|c|c|c|c|}
\hline & \multirow[b]{2}{*}{ Ever attended $(\%)$} & \multirow{2}{*}{$\begin{array}{l}\text { Mean age at first } \\
\text { enrollment [range] }\end{array}$} & \multicolumn{3}{|c|}{ Type of school attended (\%) } \\
\hline & & & Government & Private & Religious \\
\hline \multicolumn{6}{|l|}{ Age } \\
\hline $10-14$ & 93 & $5.4[2-12]$ & 80 & 18 & 2 \\
\hline $15-19$ & 89 & $5.7[2-15]$ & 87 & 12 & 1 \\
\hline \multicolumn{6}{|l|}{ Sex } \\
\hline Boys & 96 & $5.4[2-12]$ & 78 & 21 & $<1$ \\
\hline Girls & 88 & $5.7[2-15]$ & 86 & 11 & 2 \\
\hline \multicolumn{6}{|l|}{ Region } \\
\hline Terai & 89 & $5.3[2-12]$ & 76 & 21 & 2 \\
\hline Mid/Far Western & 98 & 6 [2-15] & 96 & 4 & 0 \\
\hline Total & 92 & $5.5[2-15]$ & 82 & 16 & 1 \\
\hline$(\mathrm{N})$ & $(3,000)$ & $(2,747)$ & $(2,264)$ & $(434)$ & (39) \\
\hline
\end{tabular}


FIGURE 12 School attendance, by age, sex, and region

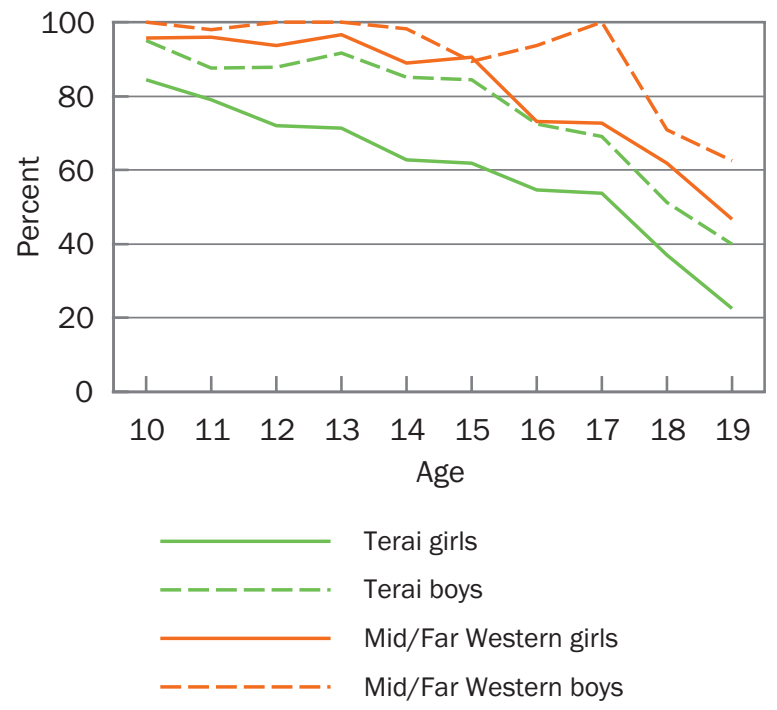

Over $90 \%$ of boys and $89 \%$ of girls ever attended school. This is particularly striking given that $85 \%$ of respondents' mothers and $46 \%$ of respondents' fathers have no education, suggesting that opportunities for schooling are relatively recent in the study area. Another indication that schooling is recent is the higher proportion of younger adolescents aged 10-14 who ever attended school compared to adolescents aged 15-19.

School attendance is not only associated with age and sex but there are also differences by region, wealth, and caste/ethnic group (Table 5). In the Terai, school attendance is significantly lower than in the Mid and Far Western regions. Low socioeconomic status and social disadvantage can often be linked to fewer educational opportunities. The poorest and more disadvantaged caste/ethnic groups are less likely to currently be in school.

Overall, 22\% of adolescents are not attending school. Girls are more likely to not be attending school compared to boys ( $29 \%$ versus $15 \%$ ). Adolescent respondents were asked to report the top three reasons why they were not attending school (Table 6). The most common reason adolescents are not attending school is because of household chores. Lack of interest, financial constraints, parental disapproval, and marriage also play roles in nonattendance. Reasons differed by gender. Over
TABLE 5 Currently attending school among adolescents aged 10-19, by age, sex, region, wealth quintile, and caste/ethnicity

\begin{tabular}{lc}
\hline Characteristic & $\%$ \\
\hline Age and sex & \\
Females aged 10-14 & 80 \\
Males aged 10-14 & 92 \\
Females aged 15-19 & 57 \\
Males aged 15-19 & 73 \\
Region & \\
Terai & 72 \\
Far and Mid Western & 91 \\
Wealth quintile & \\
Poorest & 75 \\
Poorer & 76 \\
Middle & 75 \\
Richer & 80 \\
Richest & 82 \\
Caste/ethnic group & \\
Dalit & 71 \\
Disadvantaged indigenous/religious minority & 70 \\
Disadvantaged non-Dalit & 74 \\
Advantaged indigenous and upper castes & 92 \\
\hline
\end{tabular}

TABLE 6 Most common reasons for not currently attending school among adolescents aged $10-19$, by sex (\%)

\begin{tabular}{lrrr}
\hline & All & Boys & Girls \\
\hline Household chores & 43 & 27 & 49 \\
Lack of interest & 36 & 56 & 27 \\
Financial constraints & 25 & 39 & 20 \\
Parents disapprove & 24 & 7 & 31 \\
Got married & 12 & 2 & 17 \\
Distance & 3 & 5 & 3 \\
\hline
\end{tabular}

\section{MOST ADOLESCENT GIRLS ARE THE FIRST GENERATION IN SCHOOL}

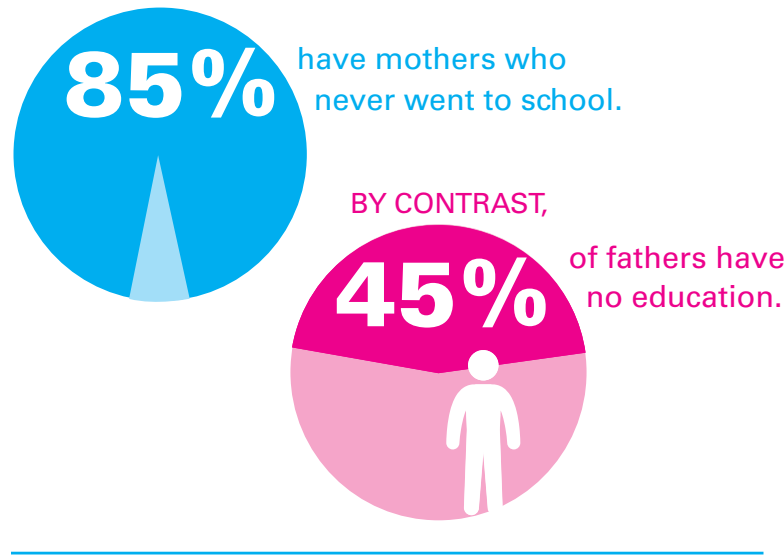


half of boys who were not in school expressed a lack of interest; $39 \%$ cited financial constraints. For girls, household obligations and parental disapproval were the main impediments to attending school.

Qualitative data from key informants suggest that household responsibilities are recognized locally as a major impediment to school attendance and success:

"Parents are not able to afford books or uniforms for their daughters. Moreover, girls have to do the household chores and cannot balance them with schoolwork.... There is also the possibility of touching others (polluting) during menstruation - this is why they need to stop attending school." -TEACHER, KALIKOT

"Although we are sent to school, daughters have the burden of household work." -GIRL, GROUP DISCUSSION, AGED 10-14, ACHHAM

\section{TUTORING AND STIPENDS}

Children receive financial and other support for schooling (Figure 13). In the study districts overall, boys are more likely than girls to receive private tutoring but girls are more likely than boys to receive stipend support. $42 \%$ of boys and $37 \%$ of girls who attend school receive private tutoring while $25 \%$ of boys and $69 \%$ of girls received stipend support in primary school. Financial assistance in secondary school is much lower- $10 \%$ of boys and $33 \%$ of girls.

FIGURE 13 Receipt of tutoring and stipends for primary and secondary schooling among adolescents aged 10-19

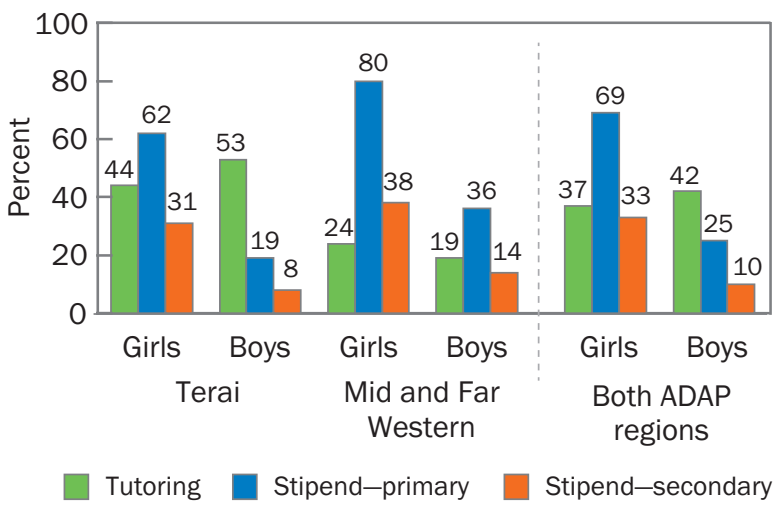

\section{EDUCATIONAL ATTAINMENT}

Although the majority of adolescents have ever attended school, educational attainment among older adolescents is still lagging (Figure 14). The average age of secondary school entrance age is 13 in Nepal. However, among adolescents aged 15-19, a significant proportion have either never attended school or have only attended primary school. This is particularly true in the Terai where $21 \%$ of adolescent girls aged $15-19$ have never attended school.

Caste and ethnicity also play a role in educational attainment (Figure 15). Within all castes and

FIGURE 14 Educational attainment among adolescents aged $15-19$, by sex and region

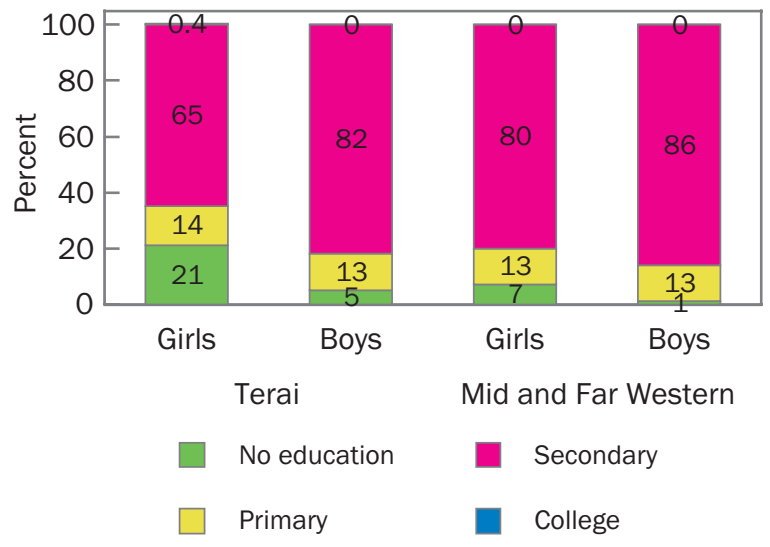

FIGURE 15 Educational attainment among adolescents aged 15-19, by caste/ethnicity and sex

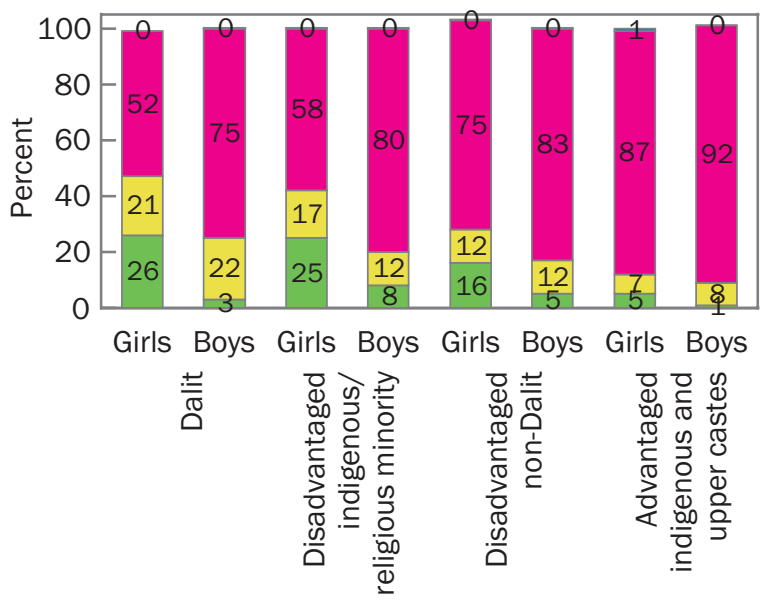


ethnic groups girls are less likely to have reached secondary school compared to their male counterparts. In the advantaged and upper castes where overall education levels are higher, however, girls are nearly at par with boys. They attend secondary school at similar rates and $1 \%$ are in tertiary schools.

\section{SCHOOL CHARACTERISTICS}

The physical characteristics and resources within schools can be an indication of school quality (Table 7). Among those attending school, younger adolescents are less likely to attend schools with electricity. These age differences may be due to the fact that a greater proportion of younger adolescents attend primary school that are more numerous and likely under-resourced relative to the secondary schools in the area. Those living in the Mid and Far Western region in the study districts are more likely to go to schools without electricity because more of them are in communities where the entire community does not have electricity.

Having physical spaces to interact with peers can have positive effects on the social development of adolescents. Nearly all adolescents reported having playgrounds in their schools and using them. Social interactions, however, are often limited to their own gender. With the exception of the Mid and Far Western region, fewer than half of adolescents report playing with the opposite sex. Enrichment resources such as school libraries are not common in schools in the study districts. In general, less than half of adolescents attend a school with a library and only a small proportion use the libraries when available. Adolescent-friendly school environments that are sensitive to their needs can encourage adolescents to stay in school. Lack of toilet facilities in schools can be an impediment to attending school, particularly for girls. Most adolescents report schools have toilets that are separated by gender.

Disaster preparedness and vocational training among those currently attending school is not common in Nepal (Table 8). Like many mountainous countries, Nepal is prone to natural disasters such as floods, landslides, and earthquakes. Overall, only $10 \%$ of adolescents in the study districts have received disaster preparedness training. Older adolescents and those living in the Terai region are

TABLE 7 School characteristics, by adolescents' age and region (\%)

\begin{tabular}{|c|c|c|c|c|c|}
\hline & \multicolumn{2}{|c|}{ Age } & \multicolumn{2}{|r|}{ Region } & \multirow[b]{2}{*}{ Total } \\
\hline & $10-14$ & $15-19$ & Terai & Mid and Far Western & \\
\hline Has electricity & 57 & 70 & 66 & 51 & 61 \\
\hline Has a toilet & 91 & 97 & 91 & 97 & 93 \\
\hline Has separate toilets & 81 & 89 & 83 & 86 & 84 \\
\hline Has school library & 39 & 58 & 45 & 45 & 45 \\
\hline School library is used & 15 & 35 & 21 & 22 & 21 \\
\hline Has playground & 97 & 98 & 97 & 98 & 97 \\
\hline Playground is used & 86 & 79 & 80 & 92 & 84 \\
\hline Plays with opposite sex & 40 & 41 & 31 & 58 & 40 \\
\hline
\end{tabular}

TABLE 8 Disaster preparedness and vocational training among adolescents aged 10-19 currently attending school, by sex and region (\%)

\begin{tabular}{|c|c|c|c|c|c|}
\hline & \multirow[b]{2}{*}{ Age } & \multicolumn{2}{|c|}{ Terai } & \multicolumn{2}{|c|}{ Mid and Far Westerr } \\
\hline & & Girls & Boys & Girls & Boys \\
\hline \multirow[t]{2}{*}{ Ever received disaster preparedness training } & $10-14$ & 9 & 4 & 9 & 18 \\
\hline & $15-19$ & 12 & 13 & 6 & 20 \\
\hline \multirow[t]{2}{*}{ Ever received vocational training } & $10-14$ & 5 & 1 & 0 & 1 \\
\hline & $15-19$ & 14 & 8 & 1 & 2 \\
\hline
\end{tabular}


more likely to have received disaster preparedness training. Vocational training is even less common. Only $5 \%$ of those in school have received any vocational training. Girls in the Terai region are most likely to have received this type of training. In the Mid and Far Western region it is rare.

\section{DISCUSSION}

Girls drop out of school at a faster rate than boys despite the fact that they are much more likely than boys to receive stipend support from the school or the government. While most adolescents have some opportunities for schooling, the majority of mothers have never been to school and a little less than half of the fathers have no education. Thus, any schooling-related policy must take into account that most adolescents are the first generation attending school in their families. To the extent that success in school is in part attributable to the educational environment at home, such factors as availability of books and homework help are largely absent.

The Mid and Far Western region has more favorable education indicators than the Terai region, a result that contradicts the conventional wisdom about educational access in remote regions covered by these districts. The majority of respondents described their schools as public or government institutions. Only about one in five children attend a religious or a private institution. Over $60 \%$ of children say they have electricity in school, over $90 \%$ have toilets, and $84 \%$ have separate toilets for girls. About half of the respondents said they had a library in their school but only $20 \%$ said they have used the library. Almost all respondents said they had a playing field in the school that they use and there is no notable gender or age difference in this regard.
Families invest substantial resources in education in the form of private tutoring, and there are important gender differentials in private tutoring. While boys are more likely to say they quit school because of lack of interest, for girls the dominant reasons are competing resource demands of time and money.

While schooling levels are high and have improved considerably, there is great variability in schooling by economic and social status. Girls in the Terai region are particularly disadvantaged. Poor girls and those in the disadvantaged communities are most at risk of never attending school and dropping out early when they do attend. The most important reason for dropping out is competing demands to do household chores for girls whereas for boys it is lack of interest in studies. Our qualitative evidence confirms and elucidates how chores demand time in ways that compete with schooling.

As we will see in later chapters, schooling confers many advantages. Programming for adolescent girls needs to recognize these demands on girls' time. Efforts to improve adolescents' lives should include specific measures to ensure that they have time for education and skill acquisition. The potential benefits of these measures to girls and households should be emphasized so that households recognize and value the necessary accommodations required for girls to participate effectively. Programs need to target girls in disadvantaged ethnic groups. The data show that few adolescents received any livelihood skills training. Programs for skills development may have the necessary valued attributes to convince households to free girls from their domestic responsibilities. 


\section{Livelihoods, Employment and Financial Literacy}

Young people can acquire important skills during adolescence through engagement in ageappropriate work and financial transactions. A successful transition to adulthood and a safe and productive entry into the world of work are a function of acquiring necessary education and skills as well as a timely transition into these roles at developmentally appropriate ages.

A recent global study has documented high rates of mobility among young people and calling attention to the important role that migration can play in the life of adolescents with regard to livelihoods (Temin et al. 2013). Increasingly, migration is linked to accessing livelihood opportunities and safe mobility is a strong correlate of appropriate timing of workforce entry. Key informants in our study confirmed migration is high in both study regions. The majority of community leaders identified the absence of opportunities for work and appropriate skills as a motivation for migration.

\author{
In Nepal, as in most \\ contexts, finding age- \\ appropriate employment \\ and having the right \\ financial skills can be critical \\ for making successful \\ transitions to adulthood.
}

According to key informant interviews, agriculture remains the main source of livelihood in the study areas and migration to India for employment is an important livelihood trajectory for people in these regions of Nepal. The following statements exemplify the current situation:
"The main reason [for migrating] is poverty. Adolescents have to work

to earn money due to the poor economic conditions of the family. Another thing, working to earn money after reaching 15-16 years of age has become a social culture here. The household environment of the families in this area has become like that."

-TECHNICAL ASSISTANT OF VILLAGE DEVELOPMENT COMMITTEE, BAITADI
"Poverty.... the guardian (father) does not work and engages in card playing and drinking alcohol, and does not care for family and children.

So as an elder son, adolescent boys of 15-16 years have to go to India to earn money and look after the family."

-FEMALE COMMUNITY HEALTH VOLUNTEER, BAJURA
"Poverty is the main reason why adolescent youths are attracted to our paying jobs. They also have aspirations of earning money. Besides, adolescent boys have the responsibility of saving for their sister's dowry."

-VILLAGE DEVELOPMENT COMMITTEE SECRETARY, DHANUSHA 


\section{GENDER DIFFERENCES IN WORKFORCE PARTICIPATION}

Overall, $13 \%$ of adolescents reported having ever worked and $7 \%$ reported working at the time of survey (Table 9). Older adolescent boys are more likely to work than girls and also more likely to work than younger boys. There are substantial regional differences with higher proportions reporting work in the Mid and Far Western region. Among younger adolescents, girls have the highest rates of ever working (15\%). Very few young adolescents report currently working (4\%). $13 \%$ of older adolescents work, with boys in the Terai region having the highest proportion currently employed (26\%). In order to explore to what extent work competes with schooling, an enduring concern about child labor, we computed variables from reports of school attendance and work to explore the extent to which they overlap. Table 9 shows the distribution of the sample that report being in school only, working only, working and in school, and neither, by region and gender. The majority of boys and girls are in school and few combine work with schooling. Those who are neither in school nor working are most at risk for becoming disconnected to pathways leading to successful transitions to adulthood. In the study districts, more girls than boys are likely to

TABLE 9 School and work activities, by sex and region (\%)

\begin{tabular}{|c|c|c|c|c|c|}
\hline & \multirow[b]{2}{*}{ All } & \multicolumn{2}{|c|}{ Terai } & \multicolumn{2}{|c|}{$\begin{array}{l}\text { Mid/Far } \\
\text { Western }\end{array}$} \\
\hline & & Girls & Boys & Girls & Boys \\
\hline \multicolumn{6}{|l|}{ Aged 10-14 } \\
\hline Ever worked & 7 & 4 & 6 & 15 & 9 \\
\hline Currently working & 4 & 3 & 4 & 5 & 3 \\
\hline Working and in school & 2 & 1 & 2 & 3 & 3 \\
\hline Working only & 2 & 2 & 3 & 1 & 0 \\
\hline In school only & 84 & 73 & 88 & 91 & 97 \\
\hline $\begin{array}{l}\text { Neither working nor } \\
\text { in school }\end{array}$ & 13 & 25 & 8 & 5 & 1 \\
\hline \multicolumn{6}{|l|}{ Aged 15-19 } \\
\hline Ever worked & 24 & 12 & 33 & 21 & 43 \\
\hline Currently working & 13 & 5 & 26 & 5 & 17 \\
\hline Working and in school & 6 & 2 & 8 & 4 & 14 \\
\hline Working only & 7 & 3 & 18 & 1 & 3 \\
\hline In school only & 59 & 48 & 60 & 70 & 74 \\
\hline $\begin{array}{l}\text { Neither working nor } \\
\text { in school }\end{array}$ & 29 & 47 & 14 & 24 & 9 \\
\hline
\end{tabular}

be neither working nor in school. Girls in the Terai are considerably more likely to not be in school nor working compared to girls in the Mid and Far Western region. Among adolescent girls aged 10-14 in the Terai region, $25 \%$ are not in school or working. In the older age group, $24 \%$ of girls in the Mid and Far Western region and $47 \%$ in the Terai region are in this disconnected group.

Figure 16 shows work status by broad ethnic categories. There appears to be some variation in workforce participation. The Dalits and advantaged indigenous and upper castes have significantly greater rates of ever working compared to the other caste/ethnic groups. The disadvantaged Dalits and non-Dalits have higher proportions of currently working adolescents.

Table 10 shows occupational distribution in three broad occupation categories: temporary daily wage labor, own business/trade/entrepreneur and all other forms of skilled or semi-skilled employment and economic activities. More than $50 \%$ of the respondents worked as daily laborers. Boys are more likely to be employed in temporary wage labor $(54 \%)$ than girls $(42 \%)$ in our study districts. Girls are slightly more likely to work in their own enterprise-22\% compared to $16 \%$ among boys. Girls are also more likely than boys to report a semiskilled employment and $16 \%$ of them reported working in tailoring or sewing included in the table in the other skilled work category.

FIGURE 16 Adolescents who have ever worked and those who are currently working, by caste/ethnicity

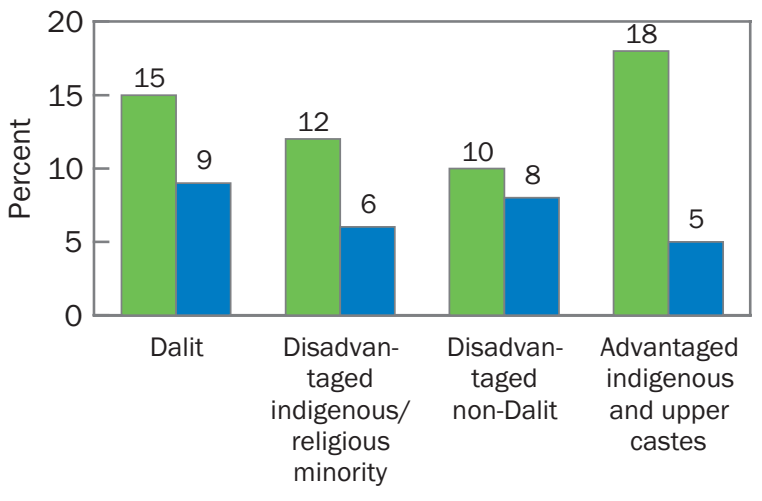

Ever worked Currently working 
TABLE 10 Major occupations among adolescents aged 10-19 who are employed (\%)

\begin{tabular}{|c|c|c|c|c|c|c|}
\hline & All & Ages 10-14 & Ages 15-19 & Male & Female & $(\mathrm{N})$ \\
\hline Daily wage/labor work & 51 & 58 & 47 & 54 & 42 & $(106)$ \\
\hline Business/trade/entrepreneur & 18 & 22 & 16 & 16 & 22 & (38) \\
\hline $\begin{array}{l}\text { Service jobs, tailoring, agriculture, livestock, horticulture, } \\
\text { collecting firewood, or other skilled labor }\end{array}$ & 32 & 21 & 37 & 30 & 35 & (66) \\
\hline
\end{tabular}

Boys work longer hours than girls-36 hours per week on average compared to 25 hours for girls. There is regional difference, with boys and girls in the Terai having higher levels of workforce participation compared to boys and girls in the Mid and Far Western region (Figure 17 and Table 11). While having work experience can benefit adolescents, working long hours among the younger age cohort is considered exploitative. Earnings follow similar patterns. Boys earn more than girls, perhaps due to longer work hours. Older adolescent boys in the Mid and Far Western region have the highest average weekly income.

FIGURE 17 Average hours worked in last week among adolescents who are working, by sex and region

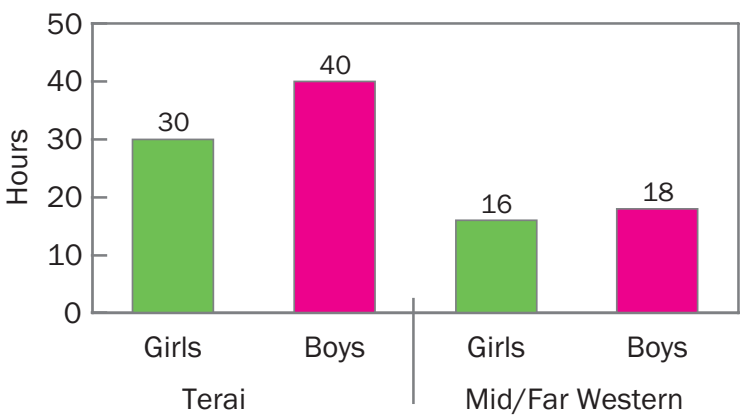

TABLE 11 Average weekly income and hours worked among adolescents, by age, gender, and region

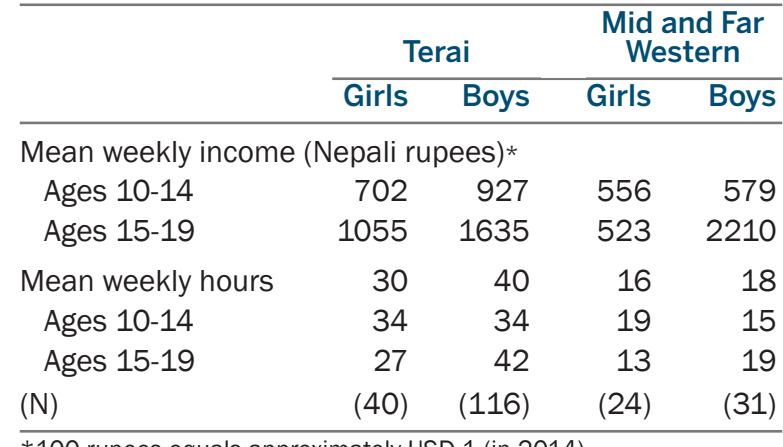

\section{SAVING AND BORROWING}

Adolescents engage in saving and borrowing from an early age. Overall $25 \%$ of the respondents said they saved-28\% among girls and 20\% among boys (Figure 18). Less than $1 \%$ saved with a bank. Although $55 \%$ of adolescents have heard of a bank, less than $1 \%$ reported using one. Adolescents most often saved in their own houses, with their families, or in their piggy banks. Girls are more likely to save than boys. They also have more savings than boys. Older adolescents are more likely to save than younger ones. There were no differences in overall savings rates by region. Borrowing is also unexpectedly common as a financial activity among adolescents. $8 \%$ of adolescents have borrowed money and one-third report the loan is interest-bearing.

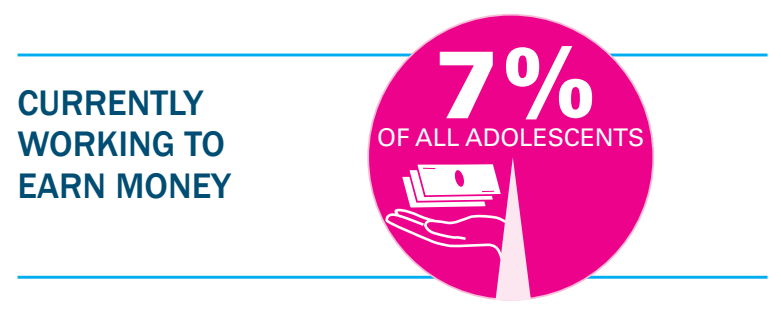

FIGURE 18 Adolescents aged 10-19 who have savings and have ever borrowed money, by sex and region

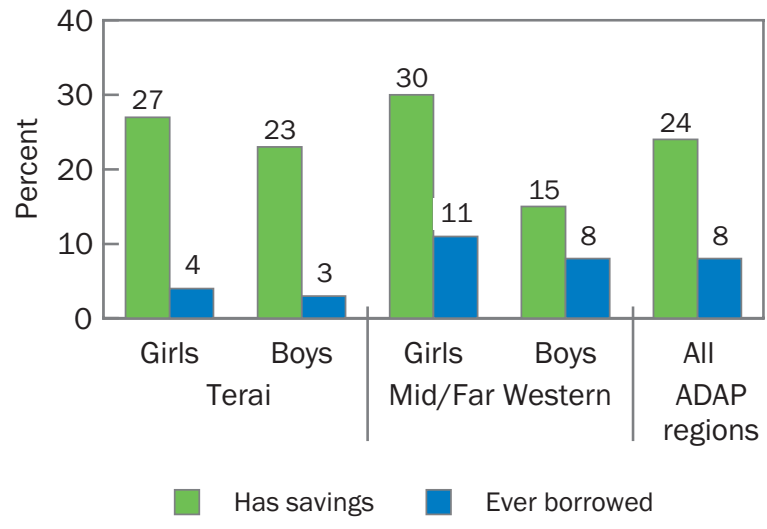


Overall, respondents who had savings reported holding NPR 3505 equivalent to USD 35 at the time of the survey. Figure 19 shows average savings in NPR by gender and region. Both boys and girls save and borrow more in the Mid and Far Western region than in the Terai region.

\section{FINANCIAL LITERACY}

The survey tried to assess adolescents' financial literacy through a series of questions on financial planning and specific questions about banking (Table 12). Overall, older adolescents had greater awareness about budgets and banking (Figure 20). Girls had better knowledge relative to boys, although boys were more able to mention specific banking services such as money transfer and

FIGURE 19 Average savings (in Nepali rupees) among adolescents, by sex and region

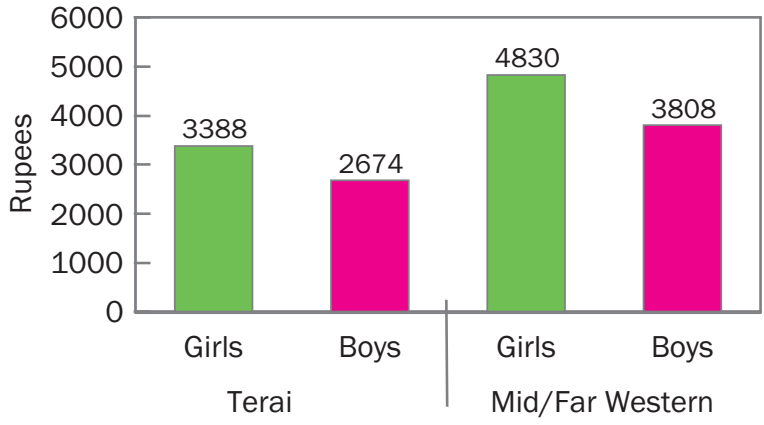

TABLE 12 Knowledge about components of a budget among adolescents aged 10-19 (\%)

\begin{tabular}{lccrc}
\hline & \multicolumn{4}{c}{ Type of budget } \\
\cline { 2 - 5 } & Income & $\begin{array}{c}\text { Expen- } \\
\text { ditures }\end{array}$ & Savings & $\begin{array}{r}\text { Don't } \\
\text { know any }\end{array}$ \\
\hline Age & & & 8 & 71 \\
$10-14$ & 22 & 13 & 20 & 37 \\
$15-19$ & 53 & 34 & & \\
Sex & & & 12 & 63 \\
$\quad$ Male & 30 & 22 & 12 & 54 \\
$\quad$ Female & 37 & 21 & & \\
Region & & & 10 & 58 \\
$\quad$ Terai & 35 & 21 & 18 & 58 \\
$\quad$ Mid/Far West. & 32 & 22 & 12 & 58 \\
Total & 34 & 21 &
\end{tabular}

FIGURE 20 Gender differences in knowledge of banking

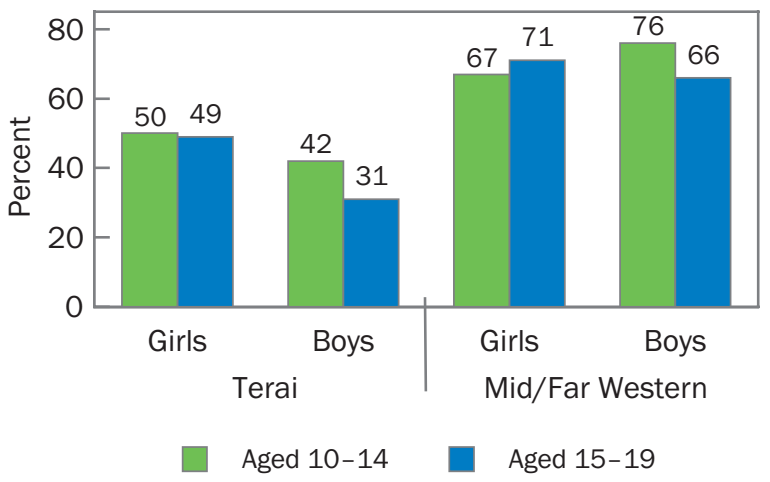

automated transfer machine (ATM) withdrawal (Table 13). There were small differences in responses regarding awareness about banking services with the Terai reporting higher awareness.

\section{MIGRATION}

The survey asked questions about migration and responses show that migration is an important aspect of life in these areas (Table 14 and Table 15). Among 10-14-year-olds, $5 \%$ have moved to their current community while among 15-19-yearolds, $17 \%$ have moved to the current area, most from another town. Girls are more likely to have moved presumably because of marriage-most of these populations are patriarchal. Questions about migration of family members are an indication of the importance of migration as a livelihood strategyoverall $47 \%$ of adolescents have at least one household member who has moved for work (Table 15). Nearly $16 \%$ of the respondents reported a family member had migrated to another destination within Nepal, 19\% reported someone from the household migrated to India, and 20\% reported migration by a family member to the Gulf states or Malaysia. Questions on whether adolescents would like to move if given the choice showed that girls were more likely than boys to say they would like to move, older adolescents were more likely to respond in the affirmative, and adolescents in the Mid and Far Western region were more likely to say they would like to move. Most adolescents however said that they would consult with others before making a decision to migrate (Table 16). 
TABLE 13 Banking knowledge and use among adolescents aged 10-19, by age, sex, and region (\%)

\begin{tabular}{|c|c|c|c|c|c|c|c|c|c|c|}
\hline & \multirow[b]{2}{*}{$\begin{array}{r}\text { Knowledge } \\
\text { of banks }\end{array}$} & \multirow[b]{2}{*}{$\begin{array}{r}\text { Uses a } \\
\text { bank }\end{array}$} & \multicolumn{8}{|c|}{ Heard of specific services } \\
\hline & & & $\begin{array}{l}\text { Depo- } \\
\text { sits }\end{array}$ & $\begin{array}{r}\text { Money } \\
\text { transfers }\end{array}$ & $\begin{array}{r}\text { Checking } \\
\text { account }\end{array}$ & $\begin{array}{l}\text { ATM with- } \\
\text { drawal }\end{array}$ & Loan & $\begin{array}{l}\text { Insur- } \\
\text { ance }\end{array}$ & $\begin{array}{r}\text { Inter- } \\
\text { est }\end{array}$ & $\begin{array}{r}\text { Money } \\
\text { exchange }\end{array}$ \\
\hline \multicolumn{11}{|l|}{ Age } \\
\hline $10-14$ & 45 & $<1$ & 42 & 8 & 1 & 18 & 12 & $<1$ & 3 & $<1$ \\
\hline $15-19$ & 71 & 4 & 67 & 19 & 2 & 33 & 30 & 1 & 7 & $<1$ \\
\hline \multicolumn{11}{|l|}{ Sex } \\
\hline Boys & 51 & 2 & 49 & 14 & 2 & 27 & 18 & 1 & 5 & $<1$ \\
\hline Girls & 57 & 1 & 54 & 10 & 1 & 21 & 20 & 1 & 4 & $<1$ \\
\hline \multicolumn{11}{|l|}{ Region } \\
\hline Terai & 56 & 2 & 53 & 10 & 1 & 28 & 20 & $<1$ & 5 & 0 \\
\hline Mid/Far Western & 51 & 2 & 48 & 15 & 2 & 14 & 16 & 1 & 4 & $<1$ \\
\hline Total & 55 & 2 & 52 & 12 & 2 & 24 & 19 & 1 & 5 & $<1$ \\
\hline
\end{tabular}

TABLE 14 Characteristics of adolescents aged 10-19 who have migrated (\%)

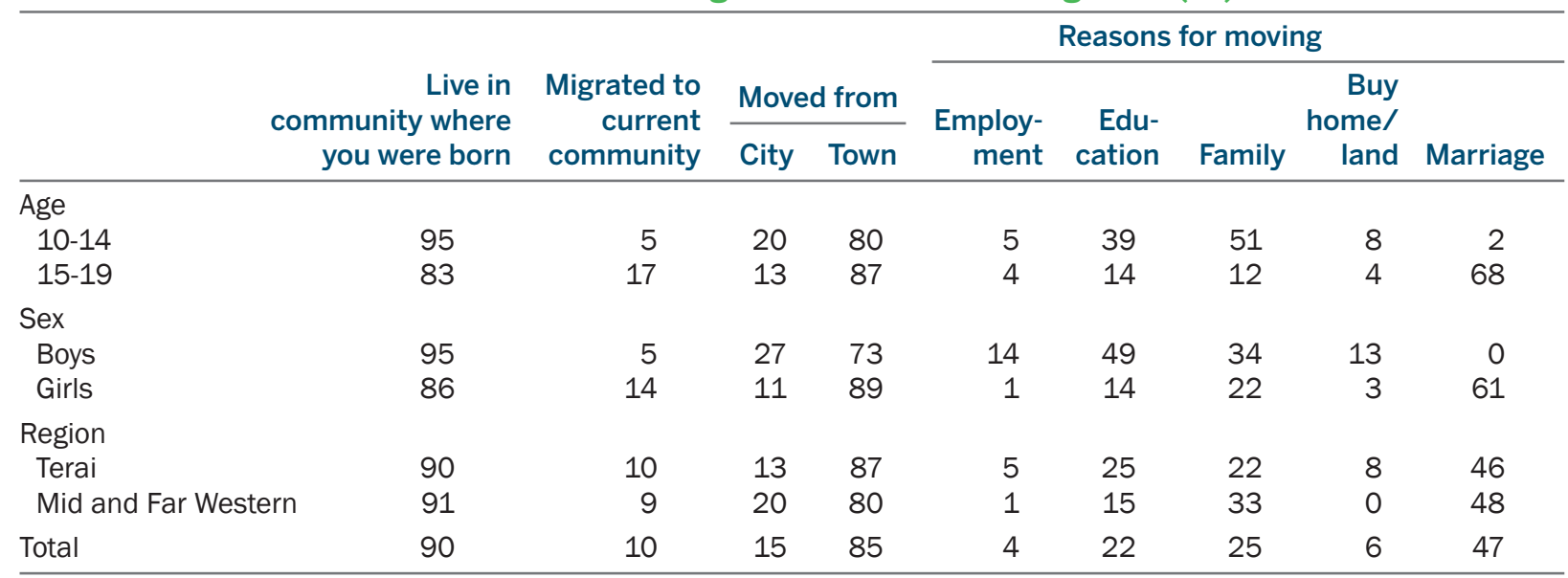

TABLE 15 Has a household member who has moved for work among adolescents, by age, sex, and region (\%)

\begin{tabular}{lrrrr}
\hline & \multicolumn{3}{c}{ Household member moved to } \\
\cline { 2 - 5 } & $\begin{array}{r}\text { Any } \\
\text { other } \\
\text { community }\end{array}$ & Nepal & $\begin{array}{r}\text { Malaysia, } \\
\text { Gulf, or } \\
\text { other }\end{array}$ \\
\hline Age & 48 & 14 & 19 & 19 \\
$10-14$ & 46 & 18 & 18 & 21 \\
$15-19$ & & & & \\
Sex & 46 & 14 & 19 & 20 \\
Male & 48 & 17 & 19 & 20 \\
Female & & & & \\
Region & 44 & 14 & 9 & 27 \\
$\quad$ Terai & 53 & 19 & 42 & 4 \\
$\quad$ Mid and Far Western & 47 & 16 & 19 & 20 \\
Total & $(1,411)$ & $(471)$ & $(558)$ & $(592)$ \\
(N) & & & & \\
\hline
\end{tabular}

TABLE 16 Migration among adolescents, by age, sex, and region (\%)

\begin{tabular}{|c|c|c|c|c|}
\hline & \multicolumn{2}{|c|}{ Terai } & \multicolumn{2}{|c|}{$\begin{array}{c}\text { Mid and Far } \\
\text { Western }\end{array}$} \\
\hline & Girls & Boys & Girls & Boys \\
\hline \multicolumn{5}{|l|}{ Has migrated } \\
\hline Ages 10-14 & 6 & 4 & 5 & 6 \\
\hline Ages 15-19 & 25 & 7 & 26 & 4 \\
\hline \multicolumn{5}{|c|}{ Has interest in moving } \\
\hline Ages 10-14 & 20 & 6 & 18 & 10 \\
\hline Ages 15-19 & 23 & 13 & 31 & 30 \\
\hline \multicolumn{5}{|c|}{$\begin{array}{l}\text { If approached, would } \\
\text { discuss migration with } \\
\text { someone }\end{array}$} \\
\hline Ages 10-14 & 90 & 92 & 87 & 73 \\
\hline Ages 15-19 & 93 & 96 & 94 & 89 \\
\hline
\end{tabular}




\section{DISCUSSION}

The data on work, saving, and borrowing were surprising in the low proportions that are engaged in work, particularly among older adolescent girls who are not in school. Overall, $7 \%$ of adolescents in the sample currently work and about double that number (13\%) have worked in the past. More adolescents have worked in the past than are currently working, and more than half of them work as temporary wage laborers, suggesting that opportunities for work are sporadic. These numbers, as well as the articulated perceptions of key informants suggest that there are limited opportunities for work in the study area. On the other hand, data on savings suggest that adolescents, particularly girls, are active financial actors. Although few adolescents save with or borrow from banks, over one in four report saving and hold substantial savings.

Among girls who are currently working, the average number of hours worked is 25 per week compared to 36 hours for boys. Average weekly earnings for those who work is NPR 1300 (USD 13). Boys earn twice as much as girls, partly due to longer working hours.

One-fourth of respondents say they have their own savings. Average savings were around NPR 3505 or about USD 35. More girls than boys save and girls on average have about $50 \%$ more savings than boys. Access to formal savings is practically nonexistent for these adolescents. Although one in four are savers, and a higher proportion among girls, less than $2 \%$ have a bank account. All of the savers save at home, either with parents or siblings or in a piggy bank.
A small proportion (8\%) of adolescents say they have borrowed money and one-third reported that the loan is interest-bearing. Borrowing is more commonly reported by boys than by girls, and more common in the Mid and Far Western region than in the Terai. Given the practices of saving and borrowing, the level of financial knowledge and comprehension of budgeting among both boys and girls seem to be low according to questions asked to test these abilities. There is some gender difference in financial awareness and girls are more likely than boys to know about functions of banking and personal budgets.

Out-migration is an important aspect of household strategy with nearly half of respondents reporting that a household member moved for work. In response to questions about intention to migrate adolescent girls were more likely than boys to say they would like to move if given the opportunity.

Providing specific skills training to increase productive employment opportunities may be an important way of expanding opportunities for adolescents, particularly in the Mid and Far Western Region. Even though adolescents are financially active, it is clear that financial literacy is low and adolescent boys and girls would benefit from programs for financial literacy. 


\section{Enabling and Protective Environment}

Nepal ranks high among the countries with the earliest pattern of child marriage among girls and boys (UNICEF 2014). Customs of child marriage and the practice of dowry exchange are aspects of the normative environment that can have important implications for young people's transitions to adulthood. The legal minimum age at marriage is 20 but boys and girls can get married at 18 with parental consent. Early assumption of productive and reproductive roles is closely related to child marriage norms.

Expectations regarding women's and girls' roles in the family are important determinants of their social networks that can in turn influence their support structures and access to information and services.

Similarly, the role of violence in gender relations is important in terms of perpetuating gender norms that privilege one group over another. The prevalence of violence in interpersonal relationships can exert varied influences on women's ability to access services and exercise rights. In this regard, knowledge and awareness of laws can play a role in women's ability to respond to and cope with violence.

Other factors that can play a protective role are birth registration and identity cards to establish age and awareness about various legal provisions such as minimum legal ages at marriage and laws regarding dowry and divorce. These factors were explored in the survey and are discussed in this chapter.

\section{MARRIAGE AND DOWRY NORMS}

The survey results show that marriage occurs at an early age for girls in both regions and to a lesser extent among boys in the Mid and Far Western
Expectations regarding women's and girl's roles in the family are important determinants of their social networks that, in turn, can influence their support structures and access to information and services.

region (Figure 21). Child marriage is far more common among girls than among boys. Overall, in our sample survey girls are over four times more likely to be married than boys before reaching the legal age. A higher proportion among adolescents is married in the Mid and Far Western districts than in the Terai.

FIGURE 21 Proportion of adolescents aged 15-19 who are married, by sex and region

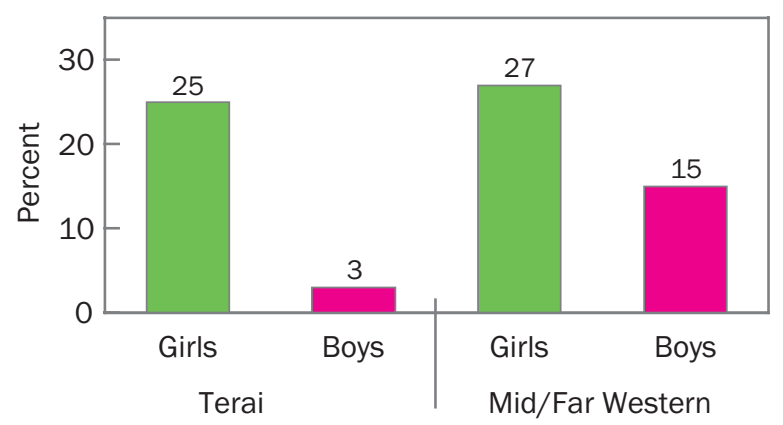


Examining marriage rates by religion, ethnicity, and wealth categories reveals that each is significantly related to marital status among older adolescents (Table 17). Hindus have the lowest rates of marriage $(16 \%)$ followed by Buddhists $(21 \%)$ and Muslims (28\%). There are also significant differences by ethnicity and caste, with Dalits having higher rates of child marriage (22\%) compared to non-Dalit disadvantaged groups (19\%) including Muslims. The

\section{TABLE 17 Proportion of adolescents aged} 15-19 who were married, by religion, caste/ ethnicity, and wealth quintile

\begin{tabular}{lc}
\hline Characteristic & $\%$ \\
\hline Religion & 16 \\
Hinduism & 21 \\
Buddhism & 28 \\
Islam & $*$ \\
Christianity & \\
Caste/ethnicity & 22 \\
Dalit & 19 \\
Disadvantaged indigenous/religious minority & 14 \\
Disadvantaged non-Dalit & 17 \\
Advantaged indigenous and upper castes & \\
Wealth quintile & 23 \\
Poorest & 20 \\
Poor & 18 \\
Middle & 10 \\
Richer & 17 \\
Richest & 17 \\
Total & \\
\hline Note: Asteriskindicates that sample size is too small to be reliable
\end{tabular}

poor are also more likely to marry early, and child marriage rates decline monotonically with increasing wealth except for the two richest categories.

Table 18 characterizes marriage by the manner in which the spouses were selected to explore the extent of own choice or couple's involvement in marriage. Although the majority of marriages are family-arranged, for boys almost half of all marriages are reported to be chosen by the boys themselves. Nearly $25 \%$ of girls who are married were involved in choosing their own marriage. Adolescents in the Terai are considerably less likely to choose their own marriage relative to adolescents in the Mid and Far Western region. When asked whether they had wanted to marry their chosen partner, the majority of adolescents responded in the affirmative and boys were more likely than girls to say they wanted to get married. Among adolescents aged $15-19,61 \%$ of boys but only $34 \%$ of girls were able to meet and talk with their future partners before marriage; thus, boys were almost twice as likely as girls to have met their future partner.

\section{DOWRY}

The study population varies substantially with regard to dowry payment (Table 19 and Figure 22). Overall $42 \%$ of marriages involved a dowry payment. Dowry is more often reported by girls than by boys. This is likely because dowry is illegal and received by boys so they are less likely to report

TABLE 18 Marriage selection process among married adolescents aged 15-19 (\%)

\begin{tabular}{lccccc}
\hline & \multicolumn{5}{c}{ Marriage selection } \\
\cline { 2 - 6 } & $\begin{array}{c}\text { Adolescent or } \\
\text { both chose }\end{array}$ & $\begin{array}{c}\text { Arranged } \\
\text { by family }\end{array}$ & $\begin{array}{r}\text { Partner } \\
\text { chose }\end{array}$ & $\begin{array}{r}\text { Wanted to } \\
\text { marry partner }\end{array}$ & $\begin{array}{r}\text { Able to meet, } \\
\text { talk, etc }\end{array}$ \\
\hline $\begin{array}{l}\text { Age } \\
\text { 15-19 }\end{array}$ & 27 & 65 & 8 & 64 & 38 \\
Sex & & & & & \\
$\quad$ Boys & 45 & 55 & 0 & 84 & 61 \\
Girls & 24 & 66 & 10 & 60 & 34 \\
Region & & & & & \\
$\quad$ Terai & 13 & 82 & 5 & 56 & 21 \\
Mid and Far Western & 53 & 34 & 14 & 77 & 68 \\
Total & 28 & 64 & 8 & 64 & 38 \\
\hline
\end{tabular}


it. Dowry is more commonly reported in the Terai region with $60 \%$ of girls who are married reporting dowry as opposed to $12 \%$ in the Mid and Far Western region.

Study respondents were astute in their observations regarding the factors associated with dowry. Qualitative data from one group in the Terai highlighted a link between dowry demands and age at marriage, suggesting that saving on dowry is a motivation for early marriage. This finding shows that adolescents recognize and know less is paid when girls are married at an early age:

"In our community, daughters are married off at an early age. And if daughters are married off early, parents feel they have to give less dowry."

$$
\text { -GIRLS' GROUP, AGES 15-19, PARSA }
$$

Another group attributed the practice of dowry to more generalized preference for boys and to the practice of patrilocal residence common in the area:

"The main reason behind the dowry system in Saptari is to give preference and priority to the sons. Parents (of boys) think 'we are going to keep someone else's daughter for life, so we need something out of that'."

-GIRLS' GROUP, AGES 15-19, SAPTARI

There are significant differences in dowry practices by religion, caste, and wealth (Table 20). A surprisingly high number of Muslim marriages were reported to involve dowry (73\%) compared to $39 \%$ among Hindus and 20\% among Buddhists. Dowry was more likely to be paid by the disadvantaged non-Dalit communities (70\%), compared to the Dalit $(28 \%)$ and the upper castes (15\%). The probability that a marriage will involve dowry increases with wealth: the wealthiest $66 \%$ of households paid dowry compared to only $20 \%$ of the poorest households.

While a part of the explanation for wealth differentials is ability to pay, a key informant described how dowry expectations can also influence decisions about schooling. He argues that educating girls may signal wealth and thus indirectly signal an ability to pay dowry. Parents who are poor are therefore
TABLE 19 Dowry practices among married adolescents aged 15-19

\begin{tabular}{lcc}
\hline & $\begin{array}{r}\text { Marriage } \\
\text { involved dowry } \\
\text { or other demands }\end{array}$ & $\begin{array}{r}\text { Family } \\
\text { consulted } \\
\text { about dowry }\end{array}$ \\
\hline $\begin{array}{l}\text { Age } \\
15-19\end{array}$ & 42 & 64 \\
Sex & & \\
Male & 16 & 40 \\
Female & 47 & 66 \\
Region & & \\
Terai & 60 & 64 \\
Mid and Far Western & 12 & 67 \\
Total & 42 & 64 \\
\hline
\end{tabular}

FIGURE 22 Dowry receipt among married adolescents aged $15-19$, by sex and region

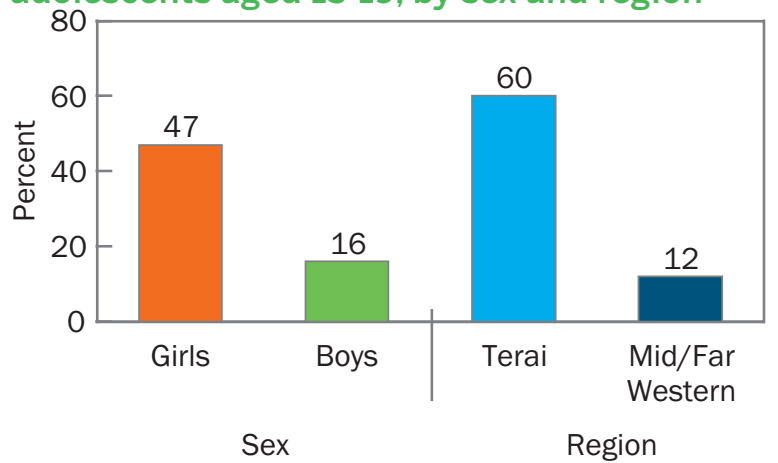

TABLE 20 Proportion of married adolescents aged 15-19 whose marriages involved dowry, by religion, caste/ethnicity, and wealth quintile

\begin{tabular}{ll}
\hline Characteristic & $\%$ \\
\hline Religion & \\
Hinduism & 39 \\
Buddhism & 20 \\
Islam & 73 \\
Caste/ethnicity & \\
Dalit & 28 \\
Disadvantaged indigenous/religious minority & 61 \\
Disadvantaged non-Dalit & 70 \\
Advantaged indigenous and upper castes & 15 \\
Wealth quintile & \\
Poorest & 20 \\
Poor & 28 \\
Middle & 45 \\
Richer & 56 \\
Richest & 66 \\
\hline
\end{tabular}


reluctant to send girls to school for fear that they would be perceived to be wealthy and face high dowry demands from potential grooms:

"There is the belief that if a girl is educated, an even more educated groom is needed for her marriage and more dowry is demanded by educated boys. This is the reason why parents (who are poor) don't send their daughters to school and don't educate them to higher level."

-LOCAL COMMITTEE MEMBER, DHANUSHA

The survey also explored adolescents' knowledge about marriage and dowry laws (Table 21). The responses suggest that knowledge is low in general but varies by the type of law. In general they have better knowledge about issues related to divorce and dowry than about the age at marriage. Overall about $26 \%$ of the respondents knew the legal age at marriage for girls and $20 \%$ knew the legal age at marriage for boys. A higher overall percentage knew about a woman's right to divorce $(41 \%)$ and girls and older adolescents were more aware. Only $13 \%$ knew what the punishments were for marriage before the legal age of 20 , but nearly $40 \%$ knew that it is illegal to demand dowry in Nepal. However, only $10 \%$ were able to state the punishments for dowry.

\section{SOCIAL NETWORKS}

To explore how norms and practices influence adolescent social networks the survey asked respondents about their friends. It is clear that while social networks for boys expand as they get older they shrink for girls (Figure 23). The two regions were similar in this regard. Whereas older girls have fewer friends on average relative to younger girls, older boys have more friends than younger boys. At every age, boys reported having more friends than girls. Table 22 explores social networks as

FIGURE 23 Mean number of same-sex friends among adolescents, by age, sex, and region

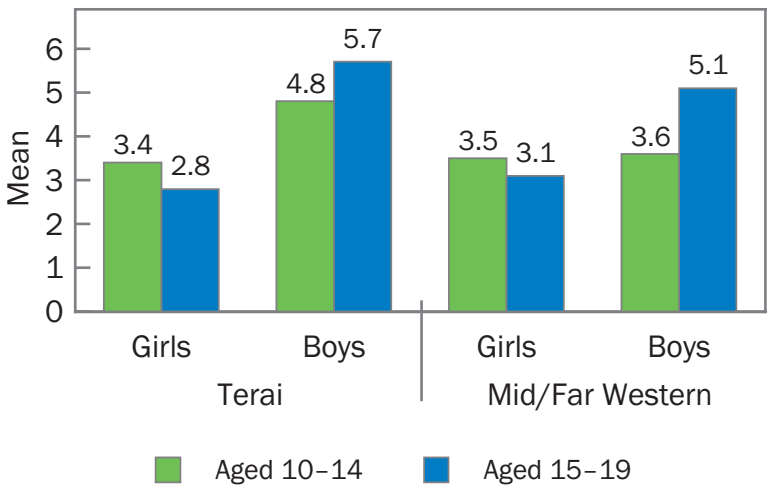

TABLE 21 Knowledge of marriage and dowry laws in Nepal among adolescents aged 10-19, by age, sex, and region (\%)

\begin{tabular}{|c|c|c|c|c|c|c|}
\hline & \multicolumn{4}{|c|}{ Marriage } & \multicolumn{2}{|c|}{ Dowry } \\
\hline & $\begin{array}{r}\text { Knows } \\
\text { the legal age } \\
\text { at marriage } \\
\text { for girls }\end{array}$ & $\begin{array}{r}\text { Knows } \\
\text { the legal age } \\
\text { at marriage } \\
\text { or boys }\end{array}$ & $\begin{array}{r}\text { Knows } \\
\text { women have } \\
\text { the right } \\
\text { to divorce }\end{array}$ & $\begin{array}{r}\text { Knows the } \\
\text { punishment } \\
\text { for marriage } \\
\text { before age } 20\end{array}$ & $\begin{array}{l}\text { Knows it is } \\
\text { illegal to de- } \\
\text { mand dowry } \\
\text { in Nepal }\end{array}$ & $\begin{array}{r}\text { Knows } \\
\text { punishment } \\
\text { for dowry }\end{array}$ \\
\hline \multicolumn{7}{|l|}{ Age } \\
\hline $10-14$ & 20 & 18 & 32 & 10 & 33 & 7 \\
\hline $15-19$ & 36 & 23 & 56 & 18 & 51 & 17 \\
\hline \multicolumn{7}{|l|}{ Sex } \\
\hline Boys & 24 & 21 & 32 & 18 & 49 & 13 \\
\hline Girls & 28 & 20 & 49 & 9 & 32 & 9 \\
\hline \multicolumn{7}{|l|}{ Region } \\
\hline Terai & 23 & 19 & 38 & 11 & 40 & 13 \\
\hline Mid and Far Western & 32 & 22 & 48 & 16 & 39 & 5 \\
\hline Total & 26 & 20 & 41 & 13 & 40 & 10 \\
\hline
\end{tabular}


TABLE 22 Mean number of same-sex friends among adolescents aged $10-19$, by religion, caste/ethnicity, wealth quintile, and marital status

\begin{tabular}{lr}
\hline Religion & $\begin{array}{r}\text { Mean } \\
\text { number } \\
\text { of friends }\end{array}$ \\
\hline Hinduism & 3.9 \\
Buddhism & 3.9 \\
Islam & 3.9 \\
Christianity & $*$ \\
Caste/ethnicity & \\
Dalit & 4.0 \\
Disadvantaged indigenous/religious & \\
$\quad$ minority & 3.9 \\
Disadvantaged non-Dalit & 4.2 \\
Advantaged indigenous and & \\
$\quad$ upper castes & 3.8 \\
Wealth quintile & \\
Poorest & 3.6 \\
Poorer & 3.9 \\
Middle & 4.2 \\
Richer & 4.1 \\
Richest & 4.0 \\
Marital status & \\
Married & \\
Not married & 2.8 \\
\hline Note: Asterisk indicates that sample size is too small to be reliable.
\end{tabular}

Note: Asterisk indicates that sample size is too small to be reliable. measured by number of same-sex friends reported. There was no variation by religious group and the average numbers reported by ethnicity showed advantaged caste groups had fewer friends. The average number of friends varied significantly by wealth status with the poorest groups reporting fewer friends. Interestingly social networks also varied by marital status - married girls and boys were more likely to have fewer friends compared to single adolescents.

Boys are more likely than girls to have someone in their community to borrow money from (71\% versus $59 \%$ for girls), to stay with if they have a problem (70\% versus 58\%), to confide in about violence at home (52\% versus $44 \%$ ), and to have a place to meet a friend of the same sex outside the home or school (84\% versus 68\%) (Table 23 ). Regional differences are not large, but supportive social networks are generally poorer for adolescents in the Terai.

Gender- and age-wise contrasts do not follow the same consistent pattern on questions related to what topics they can discuss with their same sex friends (Table 24). Relative to older adolescents, younger adolescents are more likely to say they discuss matters related to school but less likely to

TABLE 23 Adolescents' social networks and characterizations of their communities, by age, sex, and region (\%)

\begin{tabular}{|c|c|c|c|c|c|c|}
\hline & \multicolumn{4}{|c|}{ Have someone in the community outside of family to: } & \multirow{2}{*}{$\begin{array}{r}\text { Have a } \\
\text { place to meet } \\
\text { same sex friends } \\
\text { outside of school } \\
\text { and home }\end{array}$} & \multirow{2}{*}{$\begin{array}{r}\text { Men or boys } \\
\text { sometimes } \\
\text { harass girls or } \\
\text { women in the } \\
\text { community }\end{array}$} \\
\hline & $\begin{array}{r}\text { borrow } \\
\text { money } \\
\text { from }\end{array}$ & $\begin{array}{l}\text { stay with } \\
\text { in case of } \\
\text { a problem }\end{array}$ & $\begin{array}{r}\text { confide in } \\
\text { about } \\
\text { violence }\end{array}$ & $\begin{array}{r}\text { assist you if } \\
\text { someone is } \\
\text { harassing you }\end{array}$ & & \\
\hline \multicolumn{7}{|l|}{ Age } \\
\hline $10-14$ & 58 & 58 & 42 & 55 & 76 & 30 \\
\hline $15-19$ & 74 & 72 & 57 & 69 & 75 & 45 \\
\hline \multicolumn{7}{|l|}{ Sex } \\
\hline Boys & 71 & 70 & 52 & 69 & 84 & 40 \\
\hline Girls & 59 & 58 & 44 & 53 & 68 & 32 \\
\hline \multicolumn{7}{|l|}{ Region } \\
\hline Terai & 63 & 62 & 46 & 60 & 74 & 40 \\
\hline Mid and Far Western & 68 & 68 & 51 & 62 & 79 & 26 \\
\hline Total & 65 & 64 & 48 & 60 & 75 & 36 \\
\hline
\end{tabular}


TABLE 24 Discussed the following topics with their closest same-sex friend among adolescents aged $10-19$, by age, sex, and region (\%)

\begin{tabular}{lcccccc}
\hline & $\begin{array}{r}\text { Going to school/ } \\
\text { education }\end{array}$ & $\begin{array}{r}\text { Hopes/goals } \\
\text { for future }\end{array}$ & $\begin{array}{r}\text { Problems in } \\
\text { your home or } \\
\text { community }\end{array}$ & $\begin{array}{r}\text { Same-sex person } \\
\text { you admire or } \\
\text { want to be like }\end{array}$ & $\begin{array}{r}\text { Family } \\
\text { planning } \\
\text { or sex }\end{array}$ & $\begin{array}{r}\text { Gender- } \\
\text { based } \\
\text { violence* }\end{array}$ \\
\hline Age & 81 & 57 & 54 & 38 & - & - \\
$10-14$ & 71 & 66 & 69 & 50 & 41 & 38 \\
$15-19$ & & & & & & \\
Sex & 83 & 65 & 56 & 50 & 62 & 34 \\
Boys & 72 & 56 & 63 & 37 & 25 & 42 \\
Girls & & & & & & \\
Region & 74 & 59 & 59 & 41 & 38 & 35 \\
Terai & 86 & 63 & 61 & 45 & 49 & 48 \\
Mid and Far Western & 77 & 60 & 60 & 43 & 41 & 39 \\
Total & & & & & &
\end{tabular}

*Only asked of adolescents aged 15-19.

say they discuss their hopes, goals, and problems in the home or community. Adolescents in the Terai region are less likely to report that they are able to discuss topics with a friend of the same sex.

\section{BIRTH REGISTRATION AND CITIZENSHIP}

Birth registration and citizenship cards provide legal recognition of an individual and are often central to the acknowledgment of a number of rights and the receipt of government services. Younger people are less likely to have their birth registered (Table 25). However, a significant percentage also did not know whether they had their birth registered. Overall $76 \%$ of the sample had birth registration cards with little difference by gender. The proportion whose births were registered was much higher in the Terai. In Nepal individuals aged 16 and over are also able to obtain a citizenship card; in our sample, $32 \%$ owned such a card. As with birth registration, there is little regional difference overall but a substantial gender difference within the Terai where boys are more than twice as likely as girls to hold citizenship cards.
TABLE 25 Birth registration and citizenship cards among adolescents aged 10-19, by age, sex, and region (\%)

\begin{tabular}{|c|c|c|c|c|}
\hline & \multicolumn{3}{|c|}{ Registered birth } & \multirow{2}{*}{$\begin{array}{l}\text { Citizenship } \\
\text { card (age } \\
16 \text { and older) }\end{array}$} \\
\hline & Yes & No & $\begin{array}{l}\text { Don't } \\
\text { know }\end{array}$ & \\
\hline \multicolumn{5}{|l|}{ Age } \\
\hline $10-14$ & 72 & 19 & 9 & $\mathrm{n} / \mathrm{a}$ \\
\hline $15-19$ & 82 & 15 & 3 & 32 \\
\hline \multicolumn{5}{|l|}{ Sex } \\
\hline Boys & 77 & 16 & 7 & 42 \\
\hline Girls & 75 & 18 & 7 & 24 \\
\hline \multicolumn{5}{|l|}{ Region } \\
\hline Terai & 87 & 7 & 6 & 32 \\
\hline Boys & 88 & 6 & 6 & 46 \\
\hline Girls & 87 & 8 & 5 & 20 \\
\hline Mid/Far Western & 49 & 41 & 10 & 32 \\
\hline Boys & 50 & 38 & 12 & 32 \\
\hline Girls & 48 & 44 & 8 & 33 \\
\hline Total & 76 & 17 & 7 & 32 \\
\hline $\mathrm{N}$ & & $(3,00$ & & (793) \\
\hline
\end{tabular}




\section{INTIMATE PARTNER VIOLENCE AMONG MARRIED ADOLESCENTS}

An alarmingly high proportion of married adolescents reported experiencing emotional, physical, and sexual violence (Figure 24). In general, reports of violence were higher in the Terai than in the Mid and Far Western region. More than one-third reported that they had experienced sexual violence, while about one in six reported experiencing physical violence.

\section{PHYSICAL AND SEXUAL VIOLENCE EXPERIENCED BY CURRENTLY MARRIED GIRLS AGED 15-19}

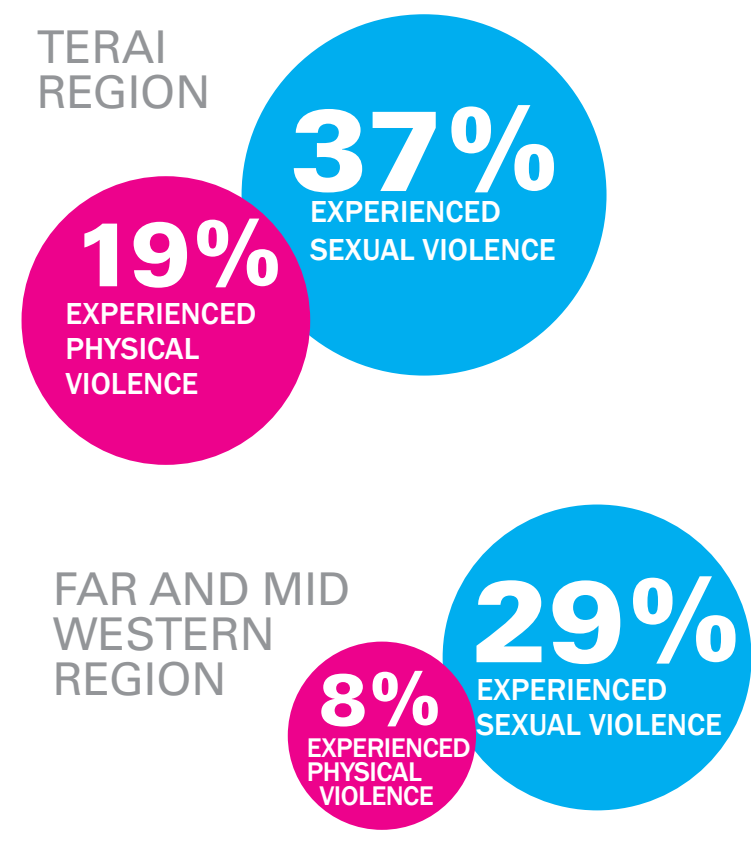

FIGURE 24 Emotional, sexual, and physical violence experienced among currently married adolescent females aged 15-19

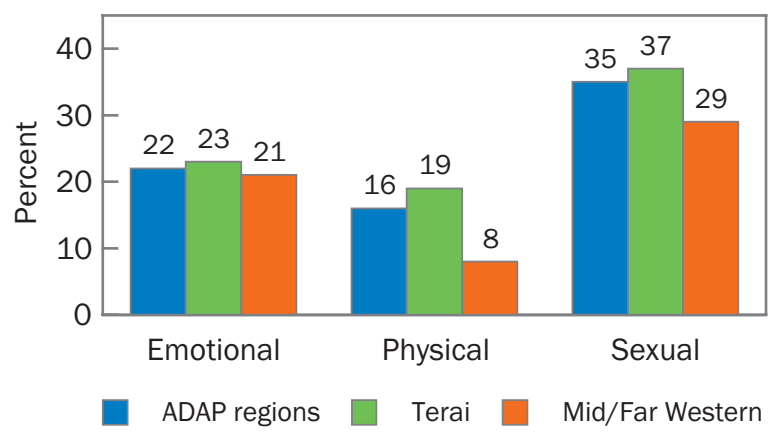

\section{DISCUSSION}

Norms of child marriage and the cultural practice of dowry payments by the bride's family to the groom are important aspects of the normative structure affecting gender differences in the lives of adolescents. More girls than boys marry early in the study area. Payments of dowry are common and surprisingly high among Muslims. The variation in marriage and dowry practices by religion, ethnicity/caste, and wealth is striking. These differences suggest that the ways in which social exclusion operates has a strong normative influence that works through the institution of marriage and dowry practices.

In general, young people have poor knowledge of laws regarding marriage and dowry. Most striking is the lack of knowledge about legal minimum ages at marriage. Poor knowledge about punishments for child marriage and dowry is understandable because such laws are not clear.

Girls have more limited social support networks and fewer friends. As girls get older, their social networks decline while boys' social networks grow. The qualitative evidence suggests growing domestic responsibilities and fear of harassment and violence may increase the isolation of women and girls as they get older and when they get married. These are 
also factors frequently cited as the reason for dropping out of school cited by qualitative respondents as the main reason for school dropout of girls.

Sexual violence is more common than physical violence-an unusual difference for South Asia in reports of violence. One in six married girls report experiencing physical violence and one in three report being forced to have sex.

Programs for adolescents need to address the harmful norms of child marriage and dowry and associated social isolation and violence. Reducing social isolation and increasing knowledge about laws to protect girls and women can be important components of a strategy to reduce the prevalence of harmful traditional practices. 


\section{Gender norms and gender equity}

Young people form their own attitudes about gender equity as well as their opinions about differences between men and women early in life. Perceptions of norms and values as well as social practices may circumscribe the choices made by young people with respect to careers, choice of partners, marriage, and childbearing and are important to take into account in designing programs and policies to empower young people.

To measure respondents' notions about gender norms and equity the survey asked a series of attitudinal questions corresponding to the following broad categories: rights and responsibilities, perceived discrimination, values about masculinity, and attitudes about violence tolerance.

\section{RIGHTS AND RESPONSIBILITIES}

The overwhelming majority of girls (92\%) believe that men and women should be treated the same compared to $81 \%$ among boys. In general, older adolescents are more likely to express such genderequitable values-93\% among 15-19-year-olds compared to $83 \%$ among $10-14$-year-olds. Both boys and girls feel that women should have the right to divorce- $77 \%$ of girls compared to $56 \%$ among boys.

Both boys and girls feel that more men have the right to refuse an arranged marriage compared to women (Figure 25 and Table 26). Older girls and boys are more likely to think that adolescents have the right to refuse an arranged marriage, i.e., to exert their preferences. There are substantial regional

\section{Gender norms and values are formed early and can influence behaviors and outcomes during adolescence as well as later in life.}

differences with adolescents in the Mid and Far Western region more likely to report that adolescent girls have the right to refuse. About $62 \%$ of respondents feel that a woman's most important role is to take care of the home. Younger adolescents and adolescents living in the Terai are slightly more likely to support the thesis that domestic responsibilities are primary for women but there are no

FIGURE 25 Percentage of adolescents aged 10-19 who agree that girls can refuse arranged marriage, by age, sex, and region

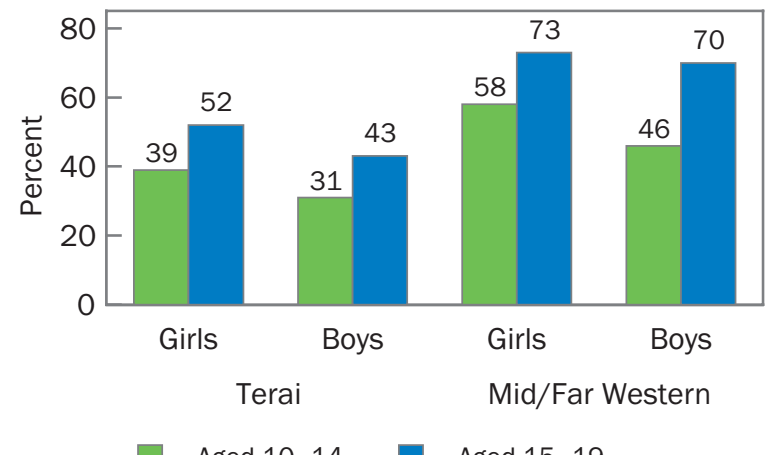

Aged 10-14 Aged 15-19 
TABLE 26 Percentage of adolescents aged 10-19 who strongly agree or agree with statements on gender norms, equality, and masculinity, by age, sex, region, wealth quintile, and caste/ ethnicity

\begin{tabular}{|c|c|c|c|c|c|c|}
\hline & $\begin{array}{c}\text { ople should } \\
\text { be treated } \\
\text { the same } \\
\text { regardless } \\
\text { of gender }\end{array}$ & $\begin{array}{r}\text { A woman's } \\
\text { most important } \\
\text { role is to } \\
\text { take care of } \\
\text { the home }\end{array}$ & $\begin{array}{r}\text { Boys are } \\
\text { allowed to } \\
\text { say no to } \\
\text { an arranged } \\
\text { marriage }\end{array}$ & $\begin{array}{r}\text { Girls are } \\
\text { allowed to } \\
\text { say no to } \\
\text { an arranged } \\
\text { marriage }\end{array}$ & $\begin{array}{r}\text { If someone } \\
\text { insults a man, } \\
\text { he should } \\
\text { defend his } \\
\text { reputation }\end{array}$ & $\begin{array}{r}\text { To be a } \\
\text { man, you } \\
\text { need to be } \\
\text { tough }\end{array}$ \\
\hline \multicolumn{7}{|l|}{ Age } \\
\hline $10-14$ & 83 & 64 & 54 & 41 & 60 & 45 \\
\hline $15-19$ & 93 & 58 & 68 & 55 & 72 & 45 \\
\hline \multicolumn{7}{|l|}{ Sex } \\
\hline Boys & 81 & 62 & 57 & 41 & 64 & 48 \\
\hline Girls & 92 & 62 & 61 & 50 & 64 & 44 \\
\hline \multicolumn{7}{|l|}{ Region } \\
\hline Terai & 86 & 63 & 55 & 40 & 65 & 42 \\
\hline Mid and Far Western & 88 & 58 & 69 & 59 & 63 & 53 \\
\hline \multicolumn{7}{|l|}{ Wealth quintile } \\
\hline Poorest & 83 & 61 & 61 & 46 & 62 & 52 \\
\hline Poorer & 86 & 64 & 59 & 45 & 64 & 52 \\
\hline Middle & 86 & 67 & 58 & 42 & 65 & 47 \\
\hline Richer & 88 & 60 & 57 & 46 & 62 & 39 \\
\hline Richest & 91 & 55 & 62 & 51 & 69 & 37 \\
\hline \multicolumn{7}{|l|}{ Caste/ethnicity } \\
\hline Dalit & 81 & 65 & 59 & 46 & 60 & 47 \\
\hline Disadvantaged indigenous/ & s/ & 63 & 53 & 39 & 61 & 44 \\
\hline Disadvantaged non-Dalit & 88 & 66 & 56 & 40 & 67 & 44 \\
\hline Advantaged/upper castes & 90 & 52 & 68 & 60 & 67 & 47 \\
\hline Total & 87 & 62 & 59 & 46 & 64 & 45 \\
\hline
\end{tabular}

gender differences. There are some wealth-related differentials with wealthier adolescents being more likely to perceive and express values that support gender equity than poorer adolescents. There are no notable variations by caste.

\section{MASCULINITY}

Boys and girls respond similarly to the statement that "to be a man, you need to be tough" with $45 \%$ agreeing. Likewise, 64\% among boys and girls believe that men have to fight to defend their reputation (Figure 26). In general the regional differences are not large. However, older adolescents are more likely to concur (72\% vs. $60 \%)$.
FIGURE 26 Percentage who agree with statements about masculinity among adolescents aged $10-19$, by sex

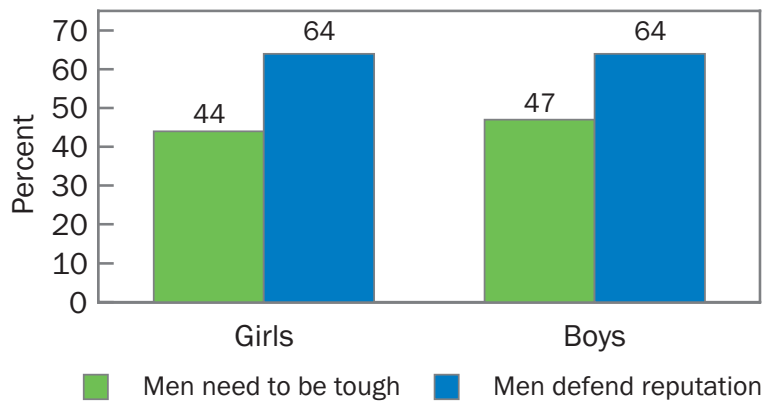




\section{TOLERATING VIOLENCE}

Nearly half of adolescents ( $46 \%$ of boys and $42 \%$ of girls) believe that women should tolerate violence in order to keep harmony in the family and similar proportions believe there are times when women should be beaten.

Adolescents were asked whether or not they agreed with a series of statements to assess attitudes toward gender norms and equity. Boys and girls similarly agreed with statements suggesting hyper-masculine gender roles for men-that men need to be tough or defend their reputations. Adolescents were also asked about rights to refuse arranged marriage. Both boys and girls are more likely to agree that boys can refuse an arranged marriage compared to girls. Nearly $60 \%$ believe boys are allowed to say no to an arranged marriage but only $46 \%$ believe a girl can (Table 26). More than 3 out of 4 older adolescent girls say girls have a right to divorce while among boys only $56 \%$ agree. About one in five women and one in four men believe avoiding pregnancy is solely a woman's responsibility.

\section{WHEN ASKED WHETHER WOMEN SHOULD TOLERATE VIOLENCE IN ORDER TO KEEP HARMONY IN THE FAMILY:}

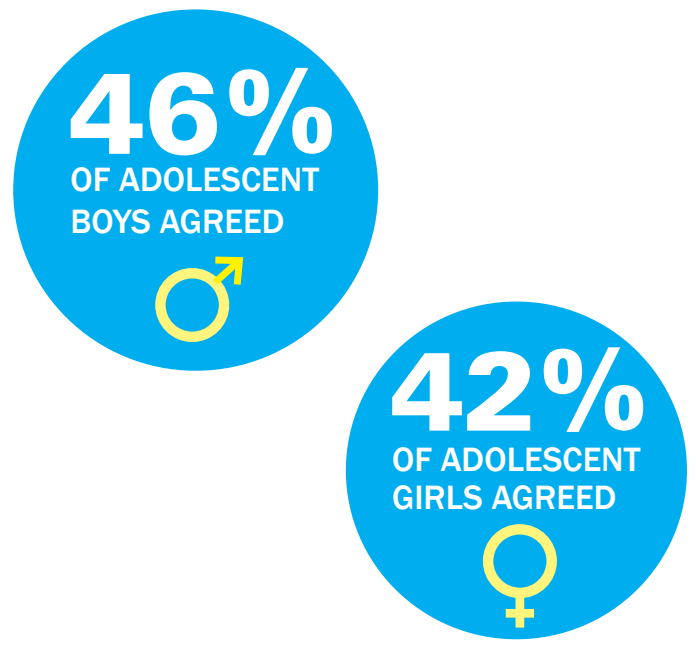

\section{GENDER DISCRIMINATION}

Gender discrimination can occur in various environments. Girls are more likely to say they feel discriminated against when they are at home (by their own family) than when they are in school (Figure 27). Girls are more likely to perceive being discriminated against than boys and are more likely to say that they have sometimes gone hungry because a sibling of the opposite gender was given food-12\% of girls said they have experienced such circumstances compared to $5 \%$ of boys (Table 27 ).

Qualitative data obtained from respondents on the topic of discrimination revealed a link between gender discrimination and parental education and status:

“Whenever there are drunken boys, they always tease us. It is difficult to walk on broad daylight. If we say about such teasing at home, parents contrarily scold the girls saying you must not have been a good person." -GIRLS' GROUP, AGES15-19, ACHHAM

“When parents are uneducated, there's more discrimination against girls.

They don't allow us to go outside. They make girls do the household chores but send boys to school." -GIRLS' GROUP, AGES 15-19, PARSA

FIGURE 27 Perception of discrimination in school and within family among adolescents aged 10-19, by sex

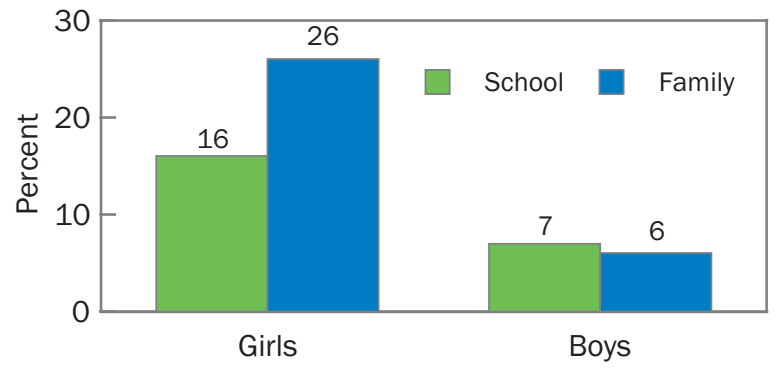


TABLE 27 Gender discrimination values and perceptions among adolescents aged 10-19

\begin{tabular}{|c|c|c|c|c|c|c|}
\hline & $\begin{array}{r}\text { Feel } \\
\text { discriminated } \\
\text { against in my } \\
\text { family because } \\
\text { of gender }\end{array}$ & $\begin{array}{r}\text { Feel discrimi- } \\
\text { nated against } \\
\text { in school } \\
\text { because } \\
\text { of gender }\end{array}$ & $\begin{array}{r}\text { Q: Should son's } \\
\text { or daughter's } \\
\text { health treatment } \\
\text { be prioritized? } \\
(A: \text { son's) }\end{array}$ & $\begin{array}{r}\text { Q: Mother is } \\
\text { busy. Who } \\
\text { should feed } \\
\text { the baby? } \\
\text { (A: mother) }\end{array}$ & $\begin{array}{r}\text { Q: Who } \\
\text { needs } \\
\text { more edu- } \\
\text { cation? } \\
\text { (A: son) }\end{array}$ & $\begin{array}{r}\text { Have sometimes } \\
\text { gone hungry } \\
\text { because brother } \\
\text { sister was } \\
\text { given food }\end{array}$ \\
\hline \multicolumn{7}{|l|}{ Age } \\
\hline $10-14$ & 15 & 12 & 23 & 33 & 26 & 8 \\
\hline $15-19$ & 19 & 12 & 16 & 23 & 12 & 10 \\
\hline \multicolumn{7}{|l|}{ Sex } \\
\hline Boys & 6 & 7 & 18 & 30 & 27 & 5 \\
\hline Girls & 26 & 16 & 23 & 28 & 15 & 12 \\
\hline \multicolumn{7}{|l|}{ Region } \\
\hline Terai & 17 & 11 & 21 & 26 & 19 & 10 \\
\hline Mid and Far Western & 15 & 13 & 18 & 36 & 24 & 6 \\
\hline Total & 17 & 12 & 20 & 29 & 20 & 9 \\
\hline
\end{tabular}

Table 28 shows a breakdown of perceived gender discrimination by wealth and ethnic/caste group. Adolescents from poorer households are more likely than those from richer households to perceive being discriminated against because of gender both in the family and at school. The advantaged indigenous and upper castes are less likely to feel

TABLE 28 Perception of discrimination among adolescents aged $10-19$, by wealth quintile and caste/ethnicity (\%)

\begin{tabular}{lrc}
\hline & $\begin{array}{r}\text { Feel } \\
\text { discriminated } \\
\text { against in my } \\
\text { family because } \\
\text { of gender }\end{array}$ & $\begin{array}{r}\text { Feel discrimi- } \\
\text { nated against } \\
\text { in school } \\
\text { because } \\
\text { of gender }\end{array}$ \\
\hline $\begin{array}{l}\text { Wealth quintile } \\
\text { Poorest }\end{array}$ & 19 & 15 \\
Poorer & 19 & 13 \\
Middle & 17 & 10 \\
Richer & 14 & 12 \\
Richest & 13 & 9 \\
Caste/ethnicity & 18 & 11 \\
Dalit \\
$\begin{array}{l}\text { Indigenous/religious } \\
\text { minority }\end{array}$
\end{tabular}

discriminated against but all other caste groups are similar with regard to discrimination at home. Religious minorities are slightly more likely to feel discrimination in school but all other caste groups are similar in reporting low levels of perceived discrimination in school.

Figure 28 shows responses to two questions intended to measure attitudes of acceptance of gender-based violence by gender. It shows that a similarly high proportion of respondents agreed that women should tolerate violence for the sake of harmony in the household and that it is accept-

FIGURE 28 Attitudes toward intimate partner violence among adolescents aged $15-19$, by sex

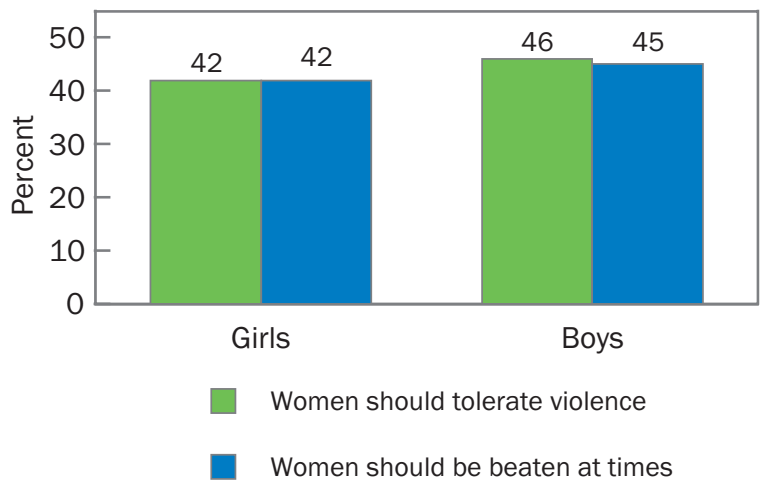


able for men to beat women under certain circumstances. Responses from boys and girls are remarkably similar with girls being as likely as boys to support statements that convey a clear gender-biased sentiment regarding violence against women.

Table 29 shows responses to questions measuring acceptance of violence against women by wealth quintile and ethnicity and caste. Sentiments of acceptance of violence are highest among the poorest adolescents and similar for the two responses in showing declining acceptance with greater wealth. Ethnic differences were not as consistent in their responses. Dalits ranked lowest in their response to a question of whether women should tolerate violence but highest among all ethnic groups in terms of the question of whether women deserve to be beaten under certain circumstances. All of the ethnic groups responded inconsistently to the two questions.

Table 30 shows adolescents' attitudes toward five questions regarding gender roles by region and gender. The results suggest that gender discriminatory attitudes are common among both boys and girls but slightly more common among boys. With the exception of attitudes of acceptance of violence where both regions report similar levels of acceptance, adolescents in the Terai had a somewhat greater tendency to report gender inequitable values.
TABLE 29 Attitudes toward intimate partner violence among adolescents aged $15-19$, by wealth quintile and caste/ethnicity (\%)

\begin{tabular}{|c|c|c|}
\hline $\begin{array}{r}\text { A woma } \\
\text { tolerate } \\
\text { ir } \\
\text { keep h }\end{array}$ & $\begin{array}{l}\text { n should } \\
\text { violence } \\
\text { order to } \\
\text { er family }\end{array}$ & $\begin{array}{r}\text { There are } \\
\text { times when a } \\
\text { woman should } \\
\text { be beaten }\end{array}$ \\
\hline \multicolumn{3}{|l|}{ Wealth quintile } \\
\hline Poorest & 48 & 47 \\
\hline Poorer & 44 & 49 \\
\hline Middle & 50 & 46 \\
\hline Richer & 39 & 40 \\
\hline Richest & 39 & 37 \\
\hline \multicolumn{3}{|l|}{ Caste/ethnicity } \\
\hline Dalit & 39 & 46 \\
\hline Indigenous/religious minority & 45 & 42 \\
\hline Disadvantaged non-Dalit & 47 & 41 \\
\hline Advantaged/upper caste & 41 & 44 \\
\hline
\end{tabular}

\section{DISCUSSION}

Although many young people believe that men and women deserve to be treated equally, girls in Nepal are more likely than boys to perceive and experience discrimination. It is more common to perceive discrimination in the home rather than in school. Both boys and girls perceive that men more than women are allowed to say no in an arranged marriage. Both boys and girls are equally likely to feel that a woman's most important role is to take care of the home; about two out of three

TABLE 30 Attitudes toward gender roles and violence among adolescents aged 15-19 (\%)

\begin{tabular}{|c|c|c|c|c|c|}
\hline & $\begin{array}{r}\text { Women } \\
\text { should have } \\
\text { the right } \\
\text { to divorce }\end{array}$ & $\begin{array}{r}\text { There are } \\
\text { times when a } \\
\text { woman should } \\
\text { be beaten }\end{array}$ & $\begin{array}{r}\text { It is only a } \\
\text { woman's respon- } \\
\text { sibility to avoid } \\
\text { pregnancy }\end{array}$ & $\begin{array}{r}\text { A woman should } \\
\text { tolerate violence } \\
\text { in order to keep } \\
\text { her family }\end{array}$ & $\begin{array}{l}\text { A man should } \\
\text { be outraged if his } \\
\text { wife asks him to } \\
\text { use a condom }\end{array}$ \\
\hline \multicolumn{6}{|l|}{ Age } \\
\hline $15-19$ & 68 & 43 & 24 & 43 & 17 \\
\hline \multicolumn{6}{|l|}{ Sex } \\
\hline Boys & 56 & 45 & 26 & 46 & 24 \\
\hline Girls & 77 & 42 & 23 & 42 & 11 \\
\hline \multicolumn{6}{|l|}{ Region } \\
\hline Terai & 65 & 43 & 22 & 43 & 18 \\
\hline Mid and Far Western & 74 & 45 & 30 & 44 & 13 \\
\hline
\end{tabular}


respondents feel this way. There is little difference between boys and girls in beliefs that may promote men's violence against women as well as beliefs that women need to tolerate violence and be subject to violence as sanctions or disciplinary behavior.

Gender-inequitable attitudes are surprisingly high among girls. Although girls are more likely than boys to hold gender equitable values and are more likely to report that they perceive discrimination in the home and at school than boys, a high proportion of girls and boys hold values about masculinity that may encourage violence by men. A high proportion of girls and boys say they believe girls and women need to tolerate violence and that under certain circumstances deserve to be beaten.

Programs that raise awareness about laws and harmful practices, emphasize rights to live violencefree lives, and promote the importance of men and women sharing household and childcare responsibilities should have positive impact on promoting more gender-equitable values. 


\section{Health and Healthy Behavior}

Adolescents are faced with a complex set of challenges related to puberty, sexuality, and their health between the ages of 10 and 19. They go through important physiological changes during this time and make the transition into puberty and sexual maturity, exposing them to significant risks including child marriage, unintended pregnancy, sexually transmitted infections, and HIV.

Related to these changes, adolescents are also confronted with social and normative factors that bring about additional risks including harmful and restrictive social norms, gender-based violence, poor mental health, etc. Adolescence is also a time when they are prone to being exposed to risky behaviors including substance and drug abuse.

Adolescents are thus required to navigate this complex set of risks, build coping mechanisms to tackle them, and develop resilience against them.

\section{MAJOR ISSUES RAISED BY ADOLESCENTS DURING PARTICIPATORY GROUP DISCUSSIONS}

\section{GIRLS}

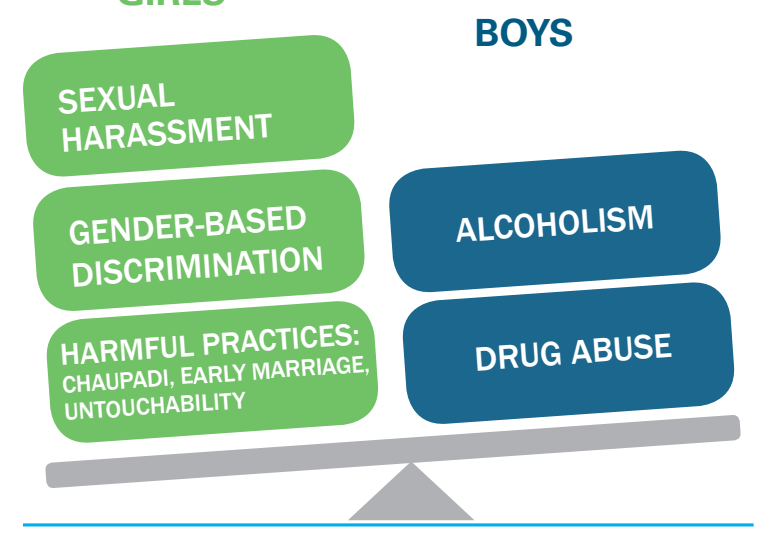

\author{
Adolescence is a period of \\ rapid physical and emotional \\ growth, posing increased \\ risks to young people. It is \\ critical that young people \\ be given the opportunity to \\ learn about healthy behavior \\ during this time.
}

The way in which adolescents navigate these risks and how they address behaviors, attitudes, and norms related to health and healthy behaviors has a direct impact on their well-being.

In order to help adolescents successfully navigate these risks and to ensure a healthy transition into adulthood, appropriate support systems from their peers, parents, and families and also from social and institutional structures are essential. Effective programs and policies that are informed by evidence-based decision-making are thus critical to facilitate healthier transitions to adulthood and to enable adolescents to lead healthy lives.

\section{PUBERTY AND NORMS}

Physiological and biological changes related to puberty are among the first and most critical changes that adolescents face during this period of their lives. The challenges are particularly significant for girls who face a range of socially and institutionally sanctioned barriers during 
FIGURE 29 Rituals/activities observed during menstruation among adolescent girls aged 13-19

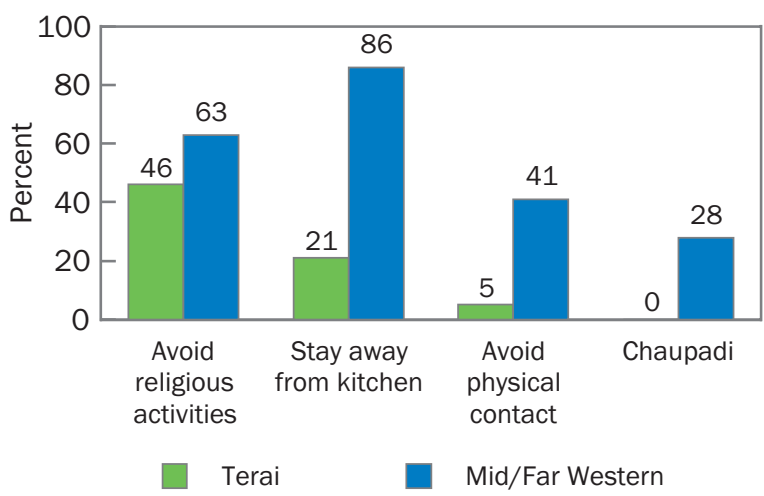

this transition. Results from this study show that restrictions related to notions of pollution associated with menstruation for girls have wideranging implications in Nepal, particularly in the Mid and Far Western districts.

Adolescent girls aged 13-19 were asked about norms and expectations from families and their actual observance of restrictive rituals and behaviors related to regular menstruation (see Tables 31-33). Adolescent girls in the Mid and Far Western regions were more likely to be asked to restrict activities such as avoiding religious activities, staying away from the kitchen, and observing the more restrictive tradition of staying in a shed outside, also known as Chaupadi. Girls in these regions were also more likely to actually observe these restrictive norms. For instance, $44 \%$ of girls in the Far and Mid Western regions reported that they were asked to observe Chaupadi. About $28 \%$ of girls reported that they were obligated to observe Chaupadi (Table 31). When asked whether they actually observe the ritual, one in every five girls in this region reported having done so (22\%; Table 32). When asked if girls would still observe Chaupadi even if they were not obligated to, $11 \%$ of girls from this region reported that they would (Table 33).

The results also suggest that older girls faced more restrictions. Significant differences in the expectation and observance of these rituals varied by caste and ethnicity of girls. Interestingly, girls from advantaged indigenous and upper caste castes, followed by Dalit castes, appear to face the most significant expectations to be obligated to observe and actually observe harmful and restrictive rituals such as Chaupadi, compared to other caste/ ethnic groups.

TABLE 31 Was obligated to observe ritual/activity during menstruation among adolescents aged 13-19 who have menstruated, by age, region, and caste/ethnicity (\%)

\begin{tabular}{|c|c|c|c|c|c|c|c|c|c|}
\hline & $\begin{array}{r}\text { Avoid } \\
\text { offering/ } \\
\text { prayer }\end{array}$ & $\begin{array}{r}\text { Stay away } \\
\text { from } \\
\text { kitchen }\end{array}$ & $\begin{array}{r}\text { Avoid } \\
\text { physical } \\
\text { contact }\end{array}$ & $\begin{array}{r}\text { Stay in } \\
\text { shed } \\
\text { (Chaupadi) }\end{array}$ & $\begin{array}{r}\text { Stay in } \\
\text { separate } \\
\text { room }\end{array}$ & $\begin{array}{r}\text { Avoid } \\
\text { plants/ } \\
\text { seeds }\end{array}$ & $\begin{array}{r}\text { Avoid } \\
\text { school }\end{array}$ & $\begin{array}{l}\text { Other } \\
\text { obli- } \\
\text { gations }\end{array}$ & $\begin{array}{r}\text { No } \\
\text { obli- } \\
\text { gations }\end{array}$ \\
\hline \multicolumn{10}{|l|}{ Age } \\
\hline $13-14$ & 49 & 33 & 13 & 7 & 11 & 7 & 0 & 12 & 40 \\
\hline $15-19$ & 52 & 40 & 15 & 7 & 13 & 7 & 0.2 & 13 & 35 \\
\hline \multicolumn{10}{|l|}{ Region } \\
\hline Terai & 46 & 21 & 5 & 0 & 6 & 5 & 0 & 9 & 48 \\
\hline Mid and Far Western & 63 & 86 & 41 & 28 & 32 & 15 & 0.4 & 22 & 4 \\
\hline \multicolumn{10}{|l|}{ Caste/ethnicity } \\
\hline Dalit & 42 & 36 & 12 & 10 & 11 & 6 & 0 & 14 & 44 \\
\hline $\begin{array}{l}\text { Disadvantaged } \\
\text { indigenous/religious }\end{array}$ & & & & & & & & & \\
\hline minority & 20 & 13 & 2 & 2 & 5 & 2 & 0 & 8 & 68 \\
\hline Disadvantaged non-Dalit & 60 & 23 & 5 & 0 & 6 & 4 & 0 & 9 & 37 \\
\hline Advantaged/upper caste & 70 & 77 & 37 & 17 & 29 & 16 & 0 & 20 & 5 \\
\hline Total & 51 & 38 & 14 & 7 & 13 & 7 & 0.1 & 13 & 37 \\
\hline
\end{tabular}


TABLE 32 Actually observed ritual/activity during menstruation among adolescents aged 13-19 who have menstruated, by age, region, and caste/ethnicity (\%)

\begin{tabular}{|c|c|c|c|c|c|c|c|}
\hline & $\begin{array}{r}\text { Avoid } \\
\text { offering/ } \\
\text { prayer }\end{array}$ & $\begin{array}{r}\text { Stay away } \\
\text { from } \\
\text { kitchen }\end{array}$ & $\begin{array}{r}\text { Avoid } \\
\text { physical } \\
\text { contact }\end{array}$ & $\begin{array}{r}\text { Stay in } \\
\text { shed } \\
\text { (Chaupadi) }\end{array}$ & $\begin{array}{r}\text { Avoid } \\
\text { plants/ } \\
\text { seeds }\end{array}$ & $\begin{array}{r}\text { Stay in } \\
\text { separate } \\
\text { room }\end{array}$ & Other \\
\hline \multicolumn{8}{|l|}{ Age } \\
\hline 13-14 & 49 & 31 & 10 & 5 & 5 & 7 & 7 \\
\hline $15-19$ & 52 & 34 & 9 & 6 & 4 & 8 & 5 \\
\hline \multicolumn{8}{|l|}{ Region } \\
\hline Terai & 47 & 18 & 2 & 0 & 3 & 3 & 5 \\
\hline Mid and Far Western & 62 & 18 & 30 & 22 & 10 & 20 & 7 \\
\hline \multicolumn{8}{|l|}{ Caste/ethnicity } \\
\hline Dalit & 44 & 32 & 9 & 6 & 5 & 6 & 7 \\
\hline $\begin{array}{l}\text { Disadvantaged indigenous/ } \\
\text { religious minority }\end{array}$ & 21 & 11 & 2 & 3 & 2 & 3 & 5 \\
\hline Disadvantaged non-Dalit & 59 & 21 & 3 & 0 & 2 & 3 & 4 \\
\hline Advantaged/upper caste & 70 & 67 & 25 & 15 & 10 & 18 & 7 \\
\hline Total & 51 & 33 & 10 & 6 & 5 & 8 & 6 \\
\hline
\end{tabular}

TABLE 33 Would observe activity during menstruation even if not obligated among adolescents aged 13-19 who have menstruated, by age and region (\%)

\begin{tabular}{lrrrrrrr}
\hline & $\begin{array}{r}\text { Avoid } \\
\text { offering/ } \\
\text { prayer }\end{array}$ & $\begin{array}{r}\text { Stay away } \\
\text { from } \\
\text { kitchen }\end{array}$ & $\begin{array}{r}\text { Avoid } \\
\text { physical } \\
\text { contact }\end{array}$ & $\begin{array}{r}\text { Stay in } \\
\text { shed } \\
\text { (Chaupadi) }\end{array}$ & $\begin{array}{r}\text { Avoid } \\
\text { plants/ } \\
\text { seeds }\end{array}$ & $\begin{array}{r}\text { Stay in } \\
\text { separate } \\
\text { room }\end{array}$ & Other \\
\hline Age & 38 & 19 & 8 & 2 & 3 & 4 & 3 \\
$13-14$ & 42 & 19 & 7 & 3 & 3 & 6 & 2 \\
$15-19$ & & & & & & & \\
Region & 42 & 9 & 2 & 0 & 2 & 2 & 3 \\
$\quad$ Terai & 39 & 49 & 25 & 11 & 5 & 15 & 2 \\
Mid and Far Western & 41 & 19 & 8 & 3 & 3 & 5 & 2 \\
Total & & & & & & & \\
\hline
\end{tabular}

The prevalence of the practice of Chaupadi in the Mid and Far Western region was also noted widely during participatory group activities with girls aged 15-19. Girls reported that this ritual is compounded by additional and more serious risks such as sexual assault and physical and psychological abuse. Girls noted a strong element of coercion in having to observe this tradition. Group participants also suggested that although there has recently been a drive to uproot Chaupadi through government and program-supported declarations of "Chaupadi-Free VDCs," the practice continues to exist in this region.
“When girls are menstruating, they are not allowed to touch food or go into the kitchen."

-GIRL 15-19, PARSA

"There is no proper sanitation during menstruation. The snakes and wild animals come during menstruation because they can smell the blood. But people here think that it is because God is angry with us."

$$
\text { -GIRL 15-19, ACHHAM }
$$

"I had to stay at the chhau goth for seven days.

I was very scared during that time. I was scolded when I touched the water in the tap." 
Overall, $90 \%$ of girls interviewed responded that they had knowledge about the menstrual cycle. A significantly smaller proportion of girls however reported that they have access to commercial sanitary products to manage their menstruation. Over $85 \%$ of girls reported using cotton cloths to manage their bleeding.

\section{SEXUAL INITIATION}

In the study districts in Nepal, nearly universally sexual debut is reported as occurring within marriage for girls but not for boys (Table 34). Approximately $14 \%$ of boys and $26 \%$ of girls aged $15-19$ reported having had sexual intercourse. Among boys and girls who had sex, nearly all respondents were married. The mean age at first sex for adolescents aged 15-19 did not vary significantly by gender and was around 15.7 years for both boys and girls in study districts.

\section{FAMILY PLANNING}

Even though girls and boys in Nepal enter into sexual relations early, most of them lack access to adequate family planning and contraceptive methods, particularly when it comes to modern contraceptives. Approximately $86 \%$ of all adolescents (15-19-year-olds and both boys and girls) have heard of at least one form of a modern method of contraception. The utilization of contraceptives among those who have ever had sex however is much lower. Only $56 \%$ of all adolescents reported that they had ever used a method with only $25 \%$ reporting having used a modern method. Much of the contraceptive use among these adolescents was dominated by traditional methods such as withdrawal.

Currently married adolescents aged 15-19 were also asked about their current use of contraceptives (Table 35$)$. Only $19 \%$ of $15-19$-year-olds who ever had sex had ever used a modern method of contraception. Boys reported more than three times the rate of use of modern contraceptives compared to girls $(45 \%$ vs $14 \%)$ (Figure 30$)$. The Terai region

FIGURE 30 Current use of modern contraceptive methods among married adolescents aged 15-19 who have ever had sex, by sex and region

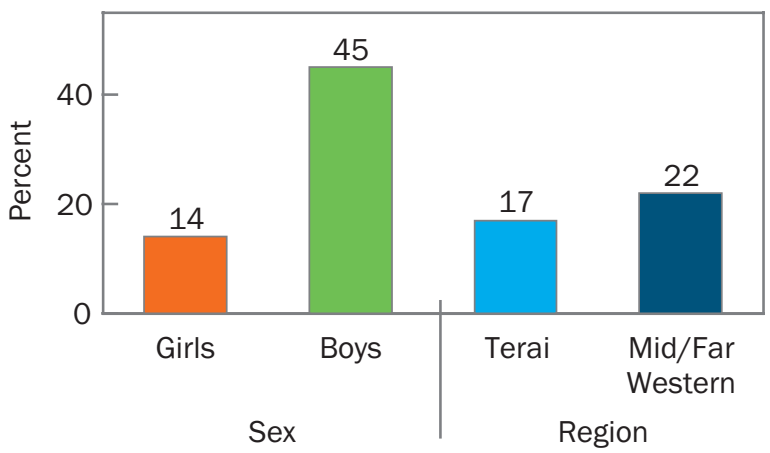

TABLE 34 Sexual activity among adolescents aged 15-19 by age, gender, and region (\%)

\begin{tabular}{|c|c|c|c|c|c|c|c|}
\hline & \multirow{3}{*}{$\begin{array}{r}\text { Ever engaged } \\
\text { in sexual } \\
\text { activity }\end{array}$} & \multirow{2}{*}{\multicolumn{3}{|c|}{ Ever had sexual intercourse }} & \multicolumn{3}{|c|}{ Among those who have ever had sex } \\
\hline & & & & & \multirow{2}{*}{$\begin{array}{r}\text { Had sex } \\
\text { before } \\
\text { age } 15\end{array}$} & \multirow{2}{*}{$\begin{array}{r}\text { Mean age at } \\
\text { first sex } \\
\text { [range] }\end{array}$} & \multirow{2}{*}{$\begin{array}{r}\text { Ever had a } \\
\text { sexually } \\
\text { transmitted } \\
\text { disease }\end{array}$} \\
\hline & & All & $\begin{array}{r}\text { Never } \\
\text { married }\end{array}$ & $\begin{array}{r}\text { Ever } \\
\text { married }\end{array}$ & & & \\
\hline \multicolumn{8}{|l|}{ Age } \\
\hline 15-19 & 24 & 21 & 4 & 100 & 5 & $15.7[10-19]$ & 3 \\
\hline \multicolumn{8}{|l|}{ Sex } \\
\hline Boys & 21 & 14 & 9 & 100 & 4 & $15.6[10-19]$ & 4 \\
\hline Girls & 26 & 26 & 0 & 99 & 6 & $15.7[11-19]$ & 3 \\
\hline \multicolumn{8}{|l|}{ Region } \\
\hline Terai & 24 & 19 & 5 & 99 & 5 & $15.6[10-19]$ & 3 \\
\hline Mid and Far Western & 26 & 25 & 3 & 100 & 3 & $16[12-19]$ & 5 \\
\hline Total & 24 & 21 & 4 & 100 & 5 & 16 & 3 \\
\hline
\end{tabular}


recorded a smaller proportion of modern method use compared to the Mid and Far Western region. Contraceptive use did not show striking variations by socioeconomic status, but Dalits and disadvantaged non-Dalits had the highest rates of modern method use (22\% and 29\%, respectively) compared to the upper caste and advantaged indige-

\section{TABLE 35 Current contraceptive use} among currently married adolescents aged $15-19$, by age, sex, region, wealth quintile, and caste/ethnicity (\%)

\begin{tabular}{lrr}
\hline & $\begin{array}{r}\text { Any } \\
\text { method }\end{array}$ & $\begin{array}{r}\text { Any } \\
\text { modern } \\
\text { method }\end{array}$ \\
\hline Age & 26 & 19 \\
15-19 & & \\
Sex & 52 & 45 \\
Boys & 21 & 14 \\
Girls & & \\
Region & 24 & 17 \\
Terai & 29 & 22 \\
Mid and Far Western & & \\
Wealth quintiles & 13 & 9 \\
Poorest & 26 & 15 \\
Poorer & 18 & 15 \\
Middle & 22 & 17 \\
Richer & 23 & 14 \\
Richest & & \\
Caste/ethnicity & 15 & 22 \\
$\quad$ Dalit & & \\
Disadvantaged indigenous/ & 12 & 18 \\
$\quad$ religious minority & 20 & 29 \\
Disadvantaged non-Dalit & 7 & 12 \\
Advantaged indigenous/upper castes & & \\
\hline
\end{tabular}

nous groups that had the lowest levels of modern method use (12\%) (Table 35).

\section{EARLY PREGNANCY AND ABORTION}

Given the observed lack of access to modern contraceptives, married adolescents aged 15-19 are at a particularly high risk of early and unintended pregnancy, exposing them (and their babies) to a series of health risks.

In the study sample, approximately $16 \%$ of girls aged 15-19 had ever been pregnant (less than 1\% among never-married girls) (Table 36). Among evermarried adolescent girls, $8 \%$ had had a pregnancy by the age of 15 . The median age at first pregnancy was 16.2 years for all adolescent girls aged 15-19. Similarly, adolescents who had been pregnant were asked whether their last pregnancy had been unintended. Approximately $36 \%$ of the everpregnant sample reported that their last pregnancy was unintended.

The study also explored adolescents' knowledge about abortion in general and, specifically, about the legality of abortion in Nepal. Only a very small proportion of adolescents reported that they had had an abortion (less than 1\%). In terms of knowledge, overall $71 \%$ had heard of abortion but a significantly smaller proportion were aware that it was legal in Nepal (approximately $40 \%$ of boys and $30 \%$ of girls) (Figure 31). Knowledge levels did not vary significantly by geographic region.

TABLE 36 Adolescent females aged 15-19 who were ever pregnant or pregnant before age 15, by region (\%)

\begin{tabular}{|c|c|c|c|c|c|c|c|}
\hline & \multicolumn{3}{|c|}{ Ever pregnant } & \multicolumn{3}{|c|}{ Pregnant by age 15} & \multirow{2}{*}{$\begin{array}{r}\text { Mean age at } \\
\text { first pregnancy } \\
\text { [range }]\end{array}$} \\
\hline & All & $\begin{array}{r}\text { Never } \\
\text { married }\end{array}$ & $\begin{array}{r}\text { Ever } \\
\text { married }\end{array}$ & All & $\begin{array}{r}\text { Never } \\
\text { married }\end{array}$ & $\begin{array}{r}\text { Ever } \\
\text { married }\end{array}$ & \\
\hline \multicolumn{8}{|l|}{ Age } \\
\hline $15-19$ & 16 & 0 & 61 & 2 & 0 & 8 & 16.2 \\
\hline \multicolumn{8}{|l|}{ Region } \\
\hline Terai & 16 & 0 & 64 & 2 & 0 & 8 & $16.1[13-19]$ \\
\hline Mid and Far Western & 17 & $<1$ & 52 & 2 & 0 & 8 & $16.3[14-18]$ \\
\hline
\end{tabular}


FIGURE 31 Knowledge about induced abortion among adolescents aged 15-19

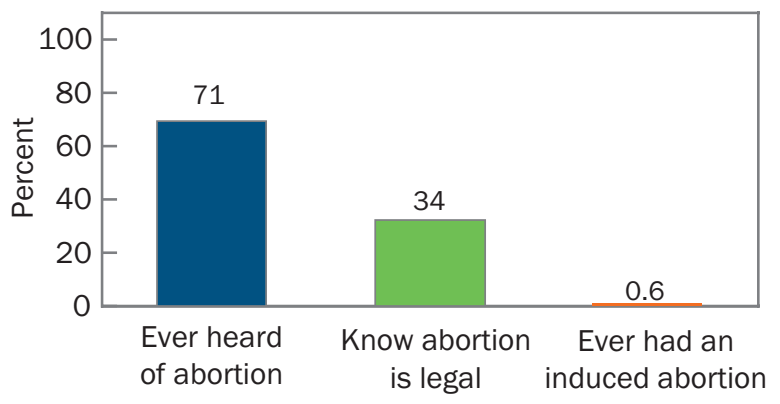

\section{SON PREFERENCE}

Approximately $38 \%$ of adolescents aged 15-19 who had ever been pregnant (or who had had a partner who was pregnant) reported having had a preference for a son during that pregnancy.

\section{MATERNAL HEALTH}

The study also explored the utilization of maternal and child health $(\mathrm{MCH})$ services among girls aged 15-19 who have ever been pregnant, particularly focusing on safe motherhood services utilized during their last pregnancy or childbirth. Among 15-19-year-olds who had ever been pregnant, overall, only $55 \%$ reported that they had the recommended four antenatal care (ANC) visits during their last pregnancy. A significant proportion of girls in the study districts reported that during their last pregnancy they delivered at home (41\%) while approximately $30 \%$ reported using a government facility. Girls in the Mid and Far Western region were, surprisingly, far more likely to have had four ANC visits than girls in the Terai (71\% compared to 49\%) (Figure 32). A higher rate of public facility delivery in this region was also observed compared to the Terai region, but with virtually no use of private facilities.

\section{HIV KNOWLEDGE}

The survey also asked questions of 15-19-yearolds about their knowledge of HIV/AIDS. Although $72 \%$ overall (both girls and boys aged 15-19) had heard of HIV, only $23 \%$ had correct knowledge
FIGURE 32 Antenatal care and delivery at home among adolescent girls aged 15-19 who have ever been pregnant

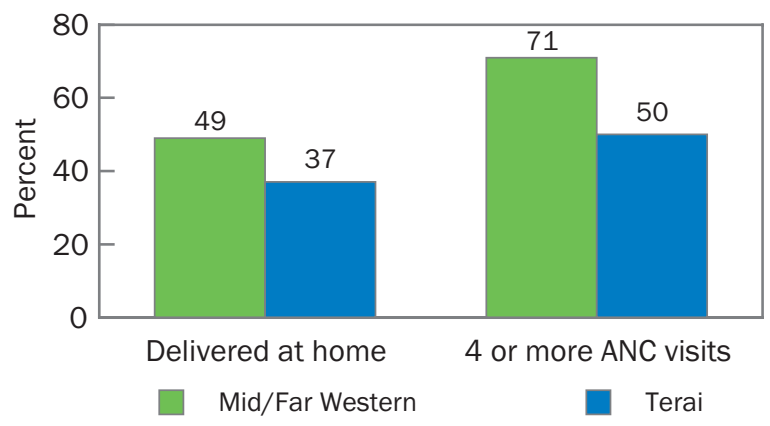

of its transmission. There was significant variation of both these indicators by gender and geographic regions (Figure 33). A significantly higher proportion of boys than girls had heard of HIV and a higher proportion of boys also had correct knowledge of the modes of transmission. Similarly, a significantly higher proportion of adolescents in the Mid and Far Western regions had heard of HIV, while adolescents in the Terai region had only a very slightly higher correct knowledge of HIV compared to the Mid and Far Western Region. By region, boys in both the regions had higher levels of correct knowledge of modes of transmission of HIV compared to girls, with the gender disparity being much wider in the Mid and Far Western regions.

FIGURE 33 HIV knowledge among adolescents aged 15-19, by sex and region

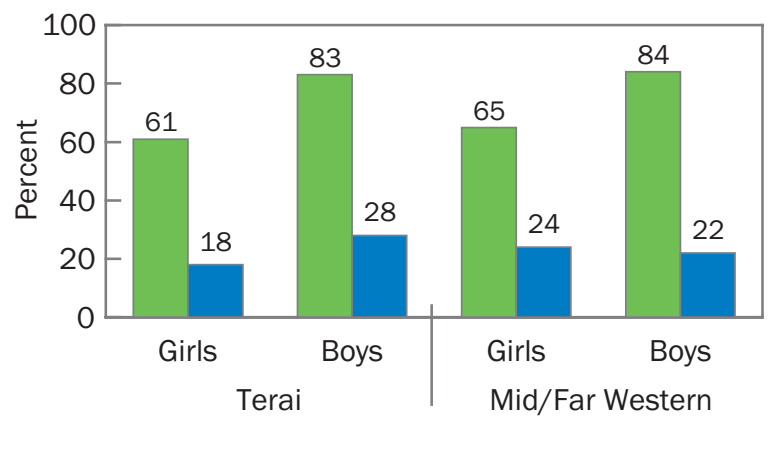

Heard of HIV 


\section{NUTRITION AND FOOD SECURITY}

Beyond challenges related to sexual and reproductive health and related outcomes, adolescents are also faced with a host of other challenges that they are particularly vulnerable to during this period in their lives. Food insecurity is one such factor that affects adolescents in Nepal. This study asked questions regarding nutrition and food security to all adolescents. Among adolescents approximately one in four, both younger (10-14) and older (15-19-year-olds), responded that they had experienced a food deficit at times whereas approximately $5 \%$ reported a deficit all the time (Table 37). Geographic differences were stark. Around $37 \%$ of adolescents reported that they had a deficit of food sometimes or all the time in the Mid and Far Western regions compared to $25 \%$ in the Terai. This corroborates much of the anecdotal evidence about food insecurity in the remote Mid and Far Western regions.

On nutrition, over half of adolescents in this study reported having been exposed to interventions or campaigns related to nutritional supplements
TABLE 37 Food availability in households among adolescents aged 10-19 by age, sex, and region (\%)

\begin{tabular}{lccr}
\hline & $\begin{array}{r}\text { Always } \\
\text { a food } \\
\text { deficit }\end{array}$ & $\begin{array}{r}\text { Food } \\
\text { deficit } \\
\text { at times }\end{array}$ & $\begin{array}{r}\text { No } \\
\text { deficit }\end{array}$ \\
\hline Age & 5 & 23 & 63 \\
$10-14$ & 6 & 22 & 70 \\
$15-19$ & & & \\
Sex & 7 & 21 & 64 \\
$\quad$ Boys & 4 & 25 & 67 \\
Girls & & & \\
Region & 5 & 20 & 69 \\
$\quad$ Terai & 6 & 31 & 58 \\
Mid and Far Western & 6 & 23 & 66 \\
Total & & & \\
\hline
\end{tabular}

(Table 38). Approximately $40 \%$ had been exposed to a campaign for iodized salt and over half to campaigns on deworming. Less than $10 \%$ of adolescents in the study however had been exposed to campaigns for folic acid. When asked whether adolescents had ever taken nutritional

TABLE 38 Nutritional campaigns and ever-use of supplements among adolescents aged 10-19, by age, sex, region, and wealth quintile (\%)

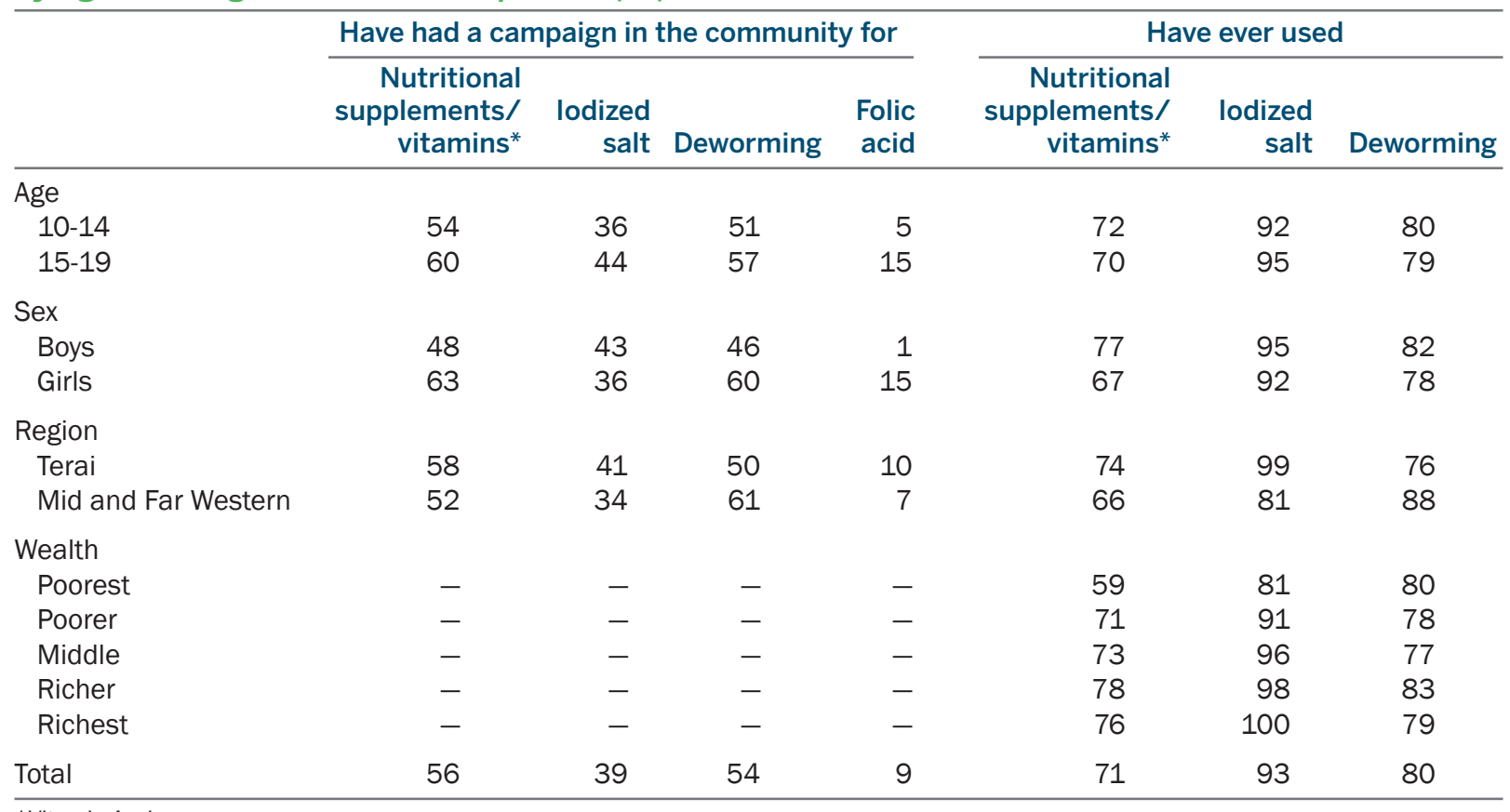

*Vitamin A, zinc. 
supplements, $71 \%$ reported having taken a nutritional supplement such as Vitamin A or zinc, $80 \%$ had taken deworming tablets, and over 93\% had taken iodized salt.

\section{MENTAL HEALTH AND SUBSTANCE ABUSE}

Adolescents in this study were also asked about their general mental health status as well as their abuse of substances (Table 39). An unusually high percentage of adolescents-approximately one in every four boys or girls-reported that they had lost confidence in themselves at some point. A higher proportion of older adolescents responded about loss in confidence compared to young adolescents. Approximately $9 \%$ of adolescents aged 15-19 reported having had thoughts about hurting themselves, of whom approximately $33 \%$ had sought treatment. These numbers are unexpectedly high and reflect the growing need for mental health prevention and treatment in Nepal. When disaggregated by socioeconomic status, the differences were not significant.
Substance abuse is another significant risk that afflicts young people in Nepal as it does in other countries around the world. Adolescents were asked about their own and their peers' use of various substances (Table 40). Adolescents reported higher rates of use for their peers than for themselves. Adolescents aged 13-19 noted that while approximately $22 \%$ of their peers had used alcohol, only $4 \%$ of them had used it themselves. Approximately $22 \%$ had friends who smoke cigarettes but only $3 \%$ reported they had smoked themselves. Reporting on actual use of drugs including injectable drugs or marijuana was mostly negligible; however; approximately $8 \%$ of adolescents aged 13-19 reported that their friends had done so. As expected, gender disparities between use rates were stark, with boys reporting both a higher proportion of exposure to alcohol or cigarettes through peer networks and actual use. Contrary to expectations, there were no differences in reported self or peer use by socioeconomic background.

TABLE 39 Mental health indicators reported among adolescents aged 13-19, by age, sex, region, and wealth quintile (\%)

\begin{tabular}{|c|c|c|c|c|c|}
\hline & $\begin{array}{r}\text { Felt like you } \\
\text { have lost } \\
\text { confidence } \\
\text { in yourself }\end{array}$ & $\begin{array}{r}\text { Have ongoing } \\
\text { occurrences } \\
\text { of feeling } \\
\text { you can't cope }\end{array}$ & $\begin{array}{l}\text { Ever felt } \\
\text { hopeless }\end{array}$ & $\begin{array}{c}\text { Felt like } \\
\text { hurting } \\
\text { yourself }\end{array}$ & $\begin{array}{r}\text { Among those who } \\
\text { thought about } \\
\text { hurting themselves, } \\
\% \text { who sought treatment }\end{array}$ \\
\hline \multicolumn{6}{|l|}{ Age } \\
\hline $13-14$ & 19 & 9 & 41 & 4 & 28 \\
\hline $15-19$ & 31 & 14 & 53 & 9 & 33 \\
\hline \multicolumn{6}{|l|}{ Sex } \\
\hline Boys & 26 & 15 & 46 & 6 & 35 \\
\hline Girls & 27 & 10 & 51 & 8 & 30 \\
\hline \multicolumn{6}{|l|}{ Region } \\
\hline Terai & 28 & 12 & 54 & 8 & 30 \\
\hline Mid and Far Western & 23 & 13 & 37 & 6 & 39 \\
\hline \multicolumn{6}{|l|}{ Wealth quintiles } \\
\hline Poorest & 27 & 15 & 47 & 6 & 25 \\
\hline Poorer & 27 & 13 & 45 & 6 & 22 \\
\hline Middle & 31 & 13 & 56 & 9 & 32 \\
\hline Richer & 21 & 9 & 47 & 6 & 36 \\
\hline Richest & 28 & 11 & 48 & 8 & 40 \\
\hline Total & 27 & 12 & 49 & 7 & 32 \\
\hline
\end{tabular}


TABLE 40 Self-reports of substance use and reports of friends' substance use, among adolescents aged 13-19, by age, gender, and region (\%)

\begin{tabular}{|c|c|c|c|c|c|}
\hline & \multicolumn{5}{|c|}{ Have you ever used the following? } \\
\hline & Liquor & $\begin{array}{l}\text { Cigarettes } \\
\text { or tobacco }\end{array}$ & Marijuana & $\begin{array}{r}\text { Opium, cocaine, } \\
\text { or injectable drugs }\end{array}$ & $\begin{array}{l}\text { Any medicine } \\
\text { without a prescription }\end{array}$ \\
\hline \multicolumn{6}{|l|}{ Age } \\
\hline $13-14$ & 1 & 1 & 0 & 0 & 0 \\
\hline $15-19$ & 6 & 7 & 1 & 0 & 0 \\
\hline \multicolumn{6}{|l|}{ Sex } \\
\hline Boys & 7 & 9 & 1 & 0 & 1 \\
\hline Girls & 2 & 1 & 0 & 0 & 0 \\
\hline \multicolumn{6}{|l|}{ Region } \\
\hline Terai & 4 & 5 & 0 & 0 & 0 \\
\hline Mid and Far Western & 4 & 5 & 2 & 0 & 0 \\
\hline \multirow[t]{3}{*}{ Total } & 4 & 3 & 1 & 0 & 0 \\
\hline & \multicolumn{5}{|c|}{ Do your friends use the following? } \\
\hline & Liquor & $\begin{array}{l}\text { Cigarettes } \\
\text { or tobacco }\end{array}$ & Marijuana & $\begin{array}{r}\text { Opium, cocaine, } \\
\text { or injectable drugs }\end{array}$ & $\begin{array}{l}\text { Any medicine } \\
\text { without a prescription }\end{array}$ \\
\hline \multicolumn{6}{|l|}{ Age } \\
\hline $13-14$ & 14 & 17 & 4 & 1 & 1 \\
\hline $15-19$ & 27 & 32 & 11 & 1 & 1 \\
\hline \multicolumn{6}{|l|}{ Sex } \\
\hline Boys & 36 & 41 & 14 & 2 & 2 \\
\hline Girls & 11 & 15 & 4 & 1 & 1 \\
\hline \multicolumn{6}{|l|}{ Region } \\
\hline Terai & 21 & 25 & 6 & 1 & 1 \\
\hline Mid and Far Western & 25 & 29 & 14 & 2 & 1 \\
\hline Total & 22 & 22 & 8 & 1 & 1 \\
\hline
\end{tabular}

Qualitative data collected in the Achham district of the Mid and Far Western region suggest however that substance use among adolescent boys is a particularly acute problem. In focus groups, boys described using drugs and struggling to manage their addiction.

“There is nothing to hide. Today's youth are facing the problem of drug abuse. Here are many friends who encourage us to use cigarettes and drugs. There is no one to discourage using such kind of substance." -BOYS' GROUP: 15-19, ACHHAM
Both girls and boys who participated in group discussions in the Mid and Far Western region also consistently reported that alcoholism is a problem among parents, both mothers and fathers, and that it had a detrimental effect on their lives including influencing behavior among children and adolescents to take up these behaviors. 


\section{DISCUSSION}

Significant challenges in Nepal are evident as girls in particular face significant risks that arise from harmful social norms around puberty and child marriage, leading to early sex, pregnancy and childbearing, and elevated risks of STIs and HIV. These challenges are particularly significant in the Mid and Far Western districts where harmful practices such as Chaupadi continue to dominate the experiences of girls as they go through this important physiological transition. This challenge has a strong caste/ethnic dimension in addition to the geographic dimension as it remains a practice among the disadvantaged castes, giving important clues to how it may be addressed most effectively.

Although sexual debut occurs within marriage for most girls, child marriage results in early sexual debut. The mean age of first sex is as low as 15.7 years and first pregnancy 16.2 years, exposing girls to multiple risks. Less than half of sexually active adolescents in study districts had ever used a contraceptive method. Only one in five reported currently using a modern method. Adolescents are aware of HIV but only one in four adolescents had correct knowledge of HIV transmission. The strong geographic and caste/ethnic dimension of disadvantage suggests that interventions to address this should be targeted to specific geographic areas and groups.
Adolescents also remain vulnerable to a multitude of other health challenges including that of food insecurity, poor mental health, and substance abuse. Each of these vulnerabilities presents challenges that vary by gender (in substance abuse for boys) or by geographic region (in food insecurity in the Mid and Far Western region) and will need targeted and well-designed interventions to address these vulnerabilities.

In the study districts, which are among the nation's poorest performing areas, these issues are particularly pronounced. A concerted response, both programmatic and policy-based, that addresses specific paternalistic norms is needed to address issues around health and healthy behavior. Changes are likely to take time to manifest, but interventions must prioritize the issues highlighted above. 


\section{Participation and Civic Engagement}

As important members of society, young people are entitled to the rights accorded to adults. When young people participate in matters that shape their lives, they can actively contribute to the quality of decisions that are made to ensure their smooth transition into adulthood. Such participation enables young people to exercise citizenship, develop life skills, and play an active role in shaping their futures. There is increasing recognition of the importance of civic engagement and participation of young people by governments, international development agencies, NGOs, and young people themselves.

In Nepal, participation by young people in institutions and organizations is quite limited despite numerous avenues through which young people can be a part of decision-making processes. In particular, children's clubs have become increasingly popular in Nepal, and have emerged as important institutions to enhance the participation of children and youth in advocating for their rights and in democratic processes. Other institutions and organizations include community groups, women's and savings and credit groups, voluntary organizations, and political organizations. However, access to these clubs remains limited in study districts.

Participation in institutions and organizations overall is very low among adolescents, with almost $90 \%$ of 10-19-year-olds not affiliated with any institutions, groups, or clubs, with no significant variation by age group or gender. Adolescents in the Mid and Far Western regions however, contrary to conventional indications, have significantly higher rates of participation in institutions compared to adolescents in the Terai ( $21 \%$ vs. $5 \%$ respectively).

\section{Adolescents' participation in the matters that shape their lives is instrumental in enhancing the quality of decisions that are made to ensure their smooth transition into adulthood.}

\section{PARTICIPATION IN A CHILDREN'S OR YOUTH CLUB}

Children's clubs constitute much of the overall participation among adolescents in Nepal (Figure 34). Approximately $7 \%$ of all adolescents interviewed responded that they were members of children's clubs. Older adolescents and girls are slightly more likely to be members of children's clubs. Children in the Mid and Far Western districts

FIGURE 34 Most common forms of participation among adolescents aged 10-19

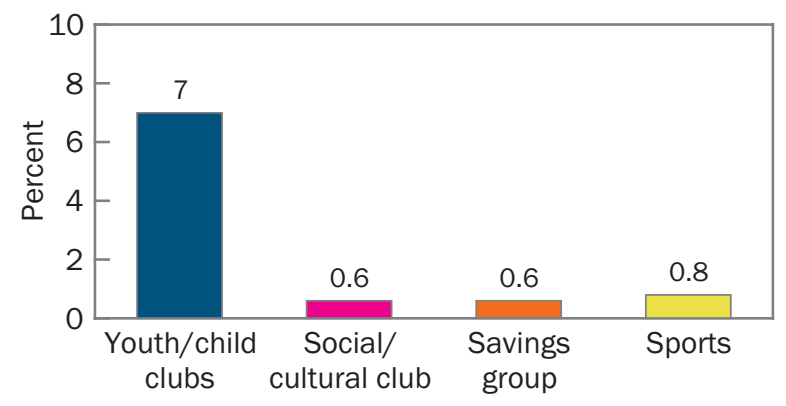


are also more likely to be members of youth clubs compared to the Terai ( $40 \%$ vs $18 \%$ ) (Figure 35). Participation in other institutions and groups including savings groups, sporting activities, and sociocultural groups was negligible with no discernible variation by gender, age, or region.

\section{ACCESS TO YOUTH/CHILDREN'S CLUBS}

When analyzed for differences in access by caste/ ethnic differences (Table 41), as expected, participa-

FIGURE 35 Access to youth clubs in the community among adolescents aged 10-19

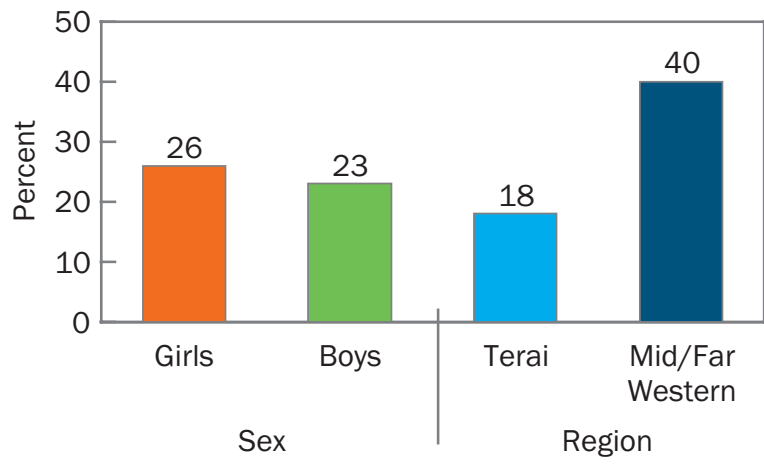

TABLE 41 Access to youth clubs in the community among adolescents aged 10-19, by sex, region, wealth quintile, and caste/ ethnicity (\%)

\begin{tabular}{lc}
\hline \multicolumn{1}{c}{ Have access to a club } \\
\hline Sex & \\
Girls & 26 \\
Boys & 23 \\
Region & \\
Terai & 18 \\
Mid and Far Western & 40 \\
Wealth & \\
Poorest & 29 \\
Poor & 28 \\
Middle & 25 \\
Richer & 19 \\
Richest & 21 \\
Caste/ethnicity & \\
Dalit & 25 \\
Disadvantaged indigenous/religious minority & 15 \\
Disadvantaged non-Dalit & 19 \\
Advantaged indigenous/upper caste & 37 \\
\hline
\end{tabular}

tion was much higher for advantaged castes including upper caste and advantaged indigenous groups $(37 \%)$ compared to disadvantaged indigenous and religious minority groups (15\%) or disadvantaged non-Dalits (19\%).

\section{PARTICIPATION IN ACTIVITIES IN THE LAST WEEK}

Despite this observed lack of participation in organized institutions, young people participated in informal activities in much larger numbers. $42 \%$ of respondents had participated in outdoor sporting activities while $21 \%$ of respondents had been participants at cultural activities in school. More boys and younger adolescents participated in outdoor sports than did girls and older adolescents. A significantly higher proportion of younger adolescents participated in cultural events than did older adolescents. In the Terai, gender inequity in participation, particularly in cultural events, was observed favoring boys. Unexpectedly, the trend was reversed in the Mid and Far Western regions with girls participating in cultural events more than boys.

Among all adolescents in the study districts

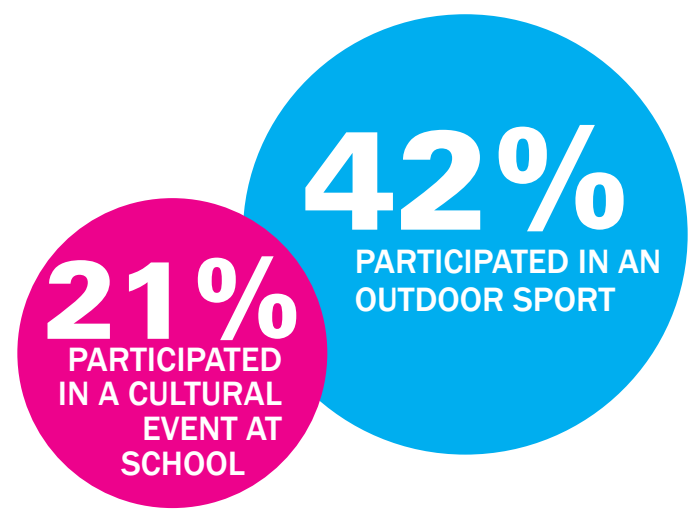




\section{ACCESS TO FACILITIES THAT ENABLE PARTICIPATION OF ADOLESCENTS IN COMMUNITIES}

Despite low participation levels in institutions such as clubs, adolescents in the study districts have relatively good access to institutions such as playgrounds, sports clubs, and youth clubs. Although variation by gender is relatively equitable, access in the Terai is seen to be substantially lower than in the Mid and Far Western region.

Over $95 \%$ had access to a school. One-fourth of those interviewed responded that they had access to a children's or youth club, one-fifth to a sports club, and one-tenth to a library. Half of all adolescents had access to a playground. Access to children's or youth clubs, sports clubs, and libraries were notably higher in the Mid and Far Western Region compared to districts in the Terai, a result that again defies conventional geographic expectations about access. In contrast, access to markets, cinemas, and banks was considerably lower.

\section{PARTICIPATION IN SELECTED INSTITUTIONS WHEN AVAILABLE}

When adolescents had access to institutions, young people had high levels of participation in most institutions such as youth or children's clubs, sports clubs, or libraries (Figure 36). Despite low levels of overall participation, a function of poor access, participation when institutions were available was disproportionately higher when compared to overall participation rates. Almost half of adolescents who responded that they had access to a children's or youth club, a sports club, or a library reported that they participated. Nearly one-sixth of adolescents who had access to a playground played in them. Beyond a slight gender disparity in sports club participation favoring boys, and the observed disparity in participation in youth/adolescent clubs and use of libraries that is higher in the Mid and Far Western Regions (Figure 37), most differences by gender, age, or region were not significant.

There were marked differences for youth/children's club participation rates and use of libraries by
FIGURE 36 Participation in selected institutions when available among adolescents aged 10-19

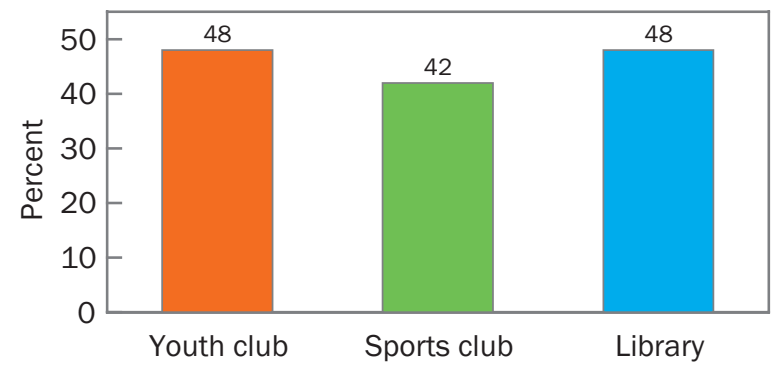

FIGURE 37 Participation in selected institutions when available among adolescents aged 10-19, by region

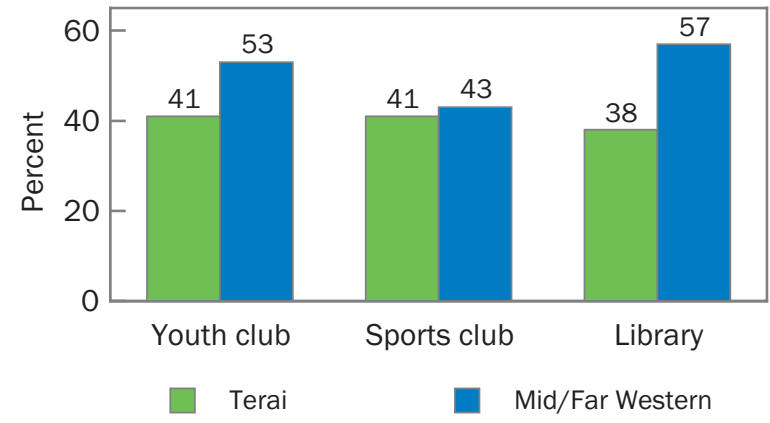

TABLE 42 Participation in selected institutions when available among adolescents aged 10-19, by caste/ethnicity

\begin{tabular}{lrrr}
\hline & $\begin{array}{r}\text { Youth } \\
\text { club }\end{array}$ & $\begin{array}{r}\text { Sports } \\
\text { club }\end{array}$ & Library \\
\hline Dalit & 47 & 46 & 47 \\
$\begin{array}{l}\text { Disadvantaged indigenous/ } \\
\text { religious minority }\end{array}$ & 38 & 41 & 33 \\
Disadvantaged non-Dalit & 39 & 37 & 46 \\
$\begin{array}{l}\text { Advantaged indigenous/ } \\
\quad \text { upper castes }\end{array}$ & 54 & 45 & 52 \\
\hline
\end{tabular}

caste/ethnic differences (Table 42). Advantaged indigenous and upper caste individuals showed the highest level of participation (54\% and 52\% respectively) compared to the lowest levels of participation for disadvantaged indigenous and religious minorities (38\% and 33\% respectively). 


\section{PARTICIPATION IN DECISIONMAKING BODIES}

Participation in higher decision-making bodies can be critical in ensuring that adolescents' voices are heard at a level where policies and programs can be influenced. In Nepal, opportunities exist for youth representation in decisionmaking processes in the Village Development Committees (VDCs) and in local health management committees. The Government of Nepal has made significant efforts to enable youth involvement in decision-making at such levels. This survey found, however, that participation in these bodies was virtually nil in the study districts. This result is surprising, particularly since provisions and policies for such participation do exist in Nepal.

\section{DISCUSSION}

Young people and adolescents benefit from participation in institutions and groups in leading successful transitions to adulthood. In the study districts, the participation rates are disproportionately low despite there being multiple institutions that facilitate participation of adolescents.

Study results show that adolescents are interested in participating in formal or informal activities but generally lack access. Access to institutions such as youth and sports clubs, microfinance institutions, and vocational or livelihood institutions are nevertheless limited in the study districts and particularly so in the Terai districts. However, when they have access to them, adolescents participate strongly and enthusiastically.
There is significant participation in informal activities, with adolescents of both genders playing outdoor games and participating in cultural events at school. The most common form of formal participation in Nepal is in children's or youth clubs, but the overall rate is as low as $7 \%$. Participation disparities exist by region (Terai has lower rates of participation compared to Mid and Far Western regions) and by caste (Advantaged indigenous and upper caste have the highest levels of participation) when activities are available. Participation in higher decision-making bodies such as school management committees, Village Development Committees, and health management committees for adolescents is nonexistent in the study districts.

Programmatic and policy responses should facilitate civic engagement and participation by young people not only by helping form institutions, clubs, and groups, but by making participation much more accessible by facilitating membership and removing barriers for all, but with a specific focus in the Terai and for socially disadvantaged groups. 


\section{Future Directions for the Adolescent Development and Participation program}

The Adolescent Development and Participation program is a holistic initiative undertaken to improve the situation of adolescents living in 15 of the most impoverished districts in Nepal. The ADAP baseline study is based on quantitative and qualitative investigations carried out in 20132014 in the study districts. The objective of this report is to present evidence and analysis in a manner that can inform future directions of programs and policy for adolescents. The study is based on the adolescent population of the study districts and as such provides detailed data on the situation and characteristics of ADAP's target population at a level of detail not previously available for the region.

A successful program needs to fully understand the characteristics of the population, their strengths, and their constraints. While both the Terai and the Mid and Far Western regions rank among the most disadvantaged on a number of indicators, the survey reveals that differences between the Terai and the Mid and Far Western regions are important for programs to take into account. Adolescents in the Terai region are generally worse off than those in the Mid and Far Western region. Caste/ethnicity and socioeconomic status are key factors of social exclusion that are associated with the poorer indicators documented in the Terai. An interesting and unique finding from this study that challenges the conventional understanding of the situation in the country is the finding that the Mid and Far Western regions had better outcomes than the Terai on a number

\section{Any program that seeks to improve the lives of adolescents needs to have a clearly articulated strategy for identifying the most vulnerable groups so that program strategies can be appropriately tailored to meet their needs.}

\author{
of key indicators. This finding is contrary to the \\ conventional wisdom that the remote Mid and Far \\ Western region has the poorest outcomes in the \\ country. Certainly some disadvantages (such as \\ Chaupadi and harmful social norms around puberty) \\ persist in this region, but educational, participation, \\ and other outcomes were comparatively better \\ than in the Terai. While improving access to \\ services and resources may be the preferred \\ strategy in the Mid and Far Western region, \\ adolescent interventions in the Terai may have to \\ focus more on the disadvantaged ethnic groups \\ and religious minorities to improve the overall \\ quality of life of adolescents.
}


Our data on migration of other household members as reported by adolescents in both regions suggest that migration to other parts of Nepal, India, and even further to Malaysia and the Middle East is an important part of household livelihood strategies. Consistent with that conclusion, we find that young people expect to migrate at some time in their lives. The importance of migration means that young people's expectation about the future and evaluation of their immediate surrounding may be influenced by events in typical destinations for migrants. Although boys/men migrate in greater numbers, both girls and boys say they expect to migrate. While young people believe that migration may provide the promise of a better life, it may also expose young people to new forms of abuse and exploitation and set them up for unfulfilled expectations.

Education is clearly key to positive transitions to adulthood. Education is associated with a number of positive outcomes including more genderequitable values, better social networks, greater knowledge and better health outcomes, and more opportunities for civic engagement. Girls drop out at a faster rate and earlier than boys in a manner that compromises their ability to reap these positive benefits associated with education. Child marriage and practices of dowry that are differently affected by ethnic group and household wealth need to be addressed. Success in school depends on the home environment-even though girls and boys are relatively equal and their reports of perceived discrimination at home and in school suggest that there is more discrimination at home, girls are more likely to perceive discrimination than boys. It is reassuring to note that once in school girls and boys are equally likely to play and interact with each other and use resources such as playgrounds and libraries. Their workload and responsibility at home are limiting for girls. The ADAP program should seek to strategically use schools, not just in terms of physical space to locate activities, but also as an institution that is perceived by adolescents to be more gender-equitable than their own homes. Part of efforts at promoting gender equity should target unequal treatment at home in ways that can ensure better access to school for girls and more time spent in school or similar institutions.
Earlier marriage for girls than for boys is a key norm that adversely affects girls and leads to their disadvantaged position later in life. Few adolescents know about laws to prevent child marriage and discourage the practice of dowry. Dowry practice is highly prevalent and surprisingly high among religious minorities.

Only $7 \%$ of adolescents are working, but those who do work substantial hours. Boys work longer hours but also earn disproportionately more than girls. Saving and borrowing are other livelihood strategies that adolescents are engaged in from young ages. Girls save more and have slightly better knowledge of household budget and banking issues. However, young people's access to financial institutions is lacking and few of the respondents know about services. Similarly, young people had very poor knowledge of budgeting and money management. Given that young people become financial actors from a young age, efforts to empower girls and boys should include skills that are relevant for income earning as well as financial management and that can help improve financial knowledge and access.

An important dimension of change that has begun to emerge even in remote rural regions of Nepal is access to mobile technology. While mobile phones that are commonly used are basic and may not yet have the cutting-edge capabilities of smartphones available elsewhere, access to even the most basic cell phone technologies nevertheless has considerable potential. In addition to reaching young people with informational text messages, mobile phones have been used successfully for educational purposes, and also as a way of providing small incentives such as rewards in airtime for attending meetings. In the study areas, access to mobile phones is high at 91 percent in the Terai and 73 percent in the Mid and Far Western region and potentially something that can be a platform for reaching adolescents even in communities that are otherwise remote and out of reach because of difficult terrain and poor transportation access. 
The report results regarding gender norms and gender equity show that girls and boys are strongly influenced by societal norms of gender inequality in how they perceive the roles of men and women. These perceptions are evident in their attitudes about important roles and functions by gender, and in their views regarding gendered conventions in marriage and gender relationships. While the respondents in the survey were genderequitable when asked about broad principles and believed that boys and girls have the right to be treated equally, they revealed values that suggest how gender inequity is perpetuated through the norms and beliefs held in society. Most alarming is the high level of acceptance of violence against women, which can be a focus of targeted attitudinal change. Sexual violence is unusually high in this survey as reported by married girls and perpetrated by husbands. There needs to be recognition that gender-based violence is common and potentially a factor preventing full participation of young girls.

Challenges for girls include harmful social norms around puberty such as Chaupadi which continue to dominate the lives of adolescent girls, particularly in the Mid and Far Western region despite policy and programmatic interventions to address these issues. Social normative changes will be necessary to address them. Specifically on menstruation, more alarming than isolation at home (Chaupadi) is the potentially negative influence on school attendance-a function of notions of untouchability during menses. This is less a question of adequate toilets and more a matter of reeducation regarding purity and pollution. Food insecurity continues to be a challenge for adolescents, particularly in the Mid and Far Western region. Substance abuse, although less prominently observed in the adolescent survey, was repeatedly seen as a concern in participatory group discussions with adolescents.
Sexual debut, child marriage, and early pregnancy continue to be lingering risks for adolescents, particularly as an child marriage culture continues to prevail. In the face of these risks, adolescents often find themselves without adequate support to navigate them. Access to contraception and actual use of modern methods were limited among married adolescents. Programmatic focus should shift to targeting young married adolescents who might be most disadvantaged in terms of access. Despite national campaigns, while awareness of HIV is high, accurate knowledge of transmission remains dismal. Concerted efforts must be made to deliver services and support to adolescents in order for them to lead healthy lives and make healthier transitions to adulthood.

Participation and civic engagement was seen to be extremely low in study districts. The most common form of participation was children's clubs. To the extent that ADAP program will expand clubs and offer opportunities, it can potentially greatly expand young people's opportunities for civic participation. Any program that seeks to improve the lives of adolescents needs to have a clearly articulated strategy of identifying the most vulnerable groups and the sources of their vulnerability so that program strategies and modalities can be appropriately tailored to meet the distinct and specific needs of the communities. 


\section{REFERENCES}

Bajracharya, A., and S. Amin 2012. "Poverty, marriage timing, and transitions to adulthood in Nepal: A longitudinal analysis using the Nepal Living Standards Survey," Studies in Family Planning 43(2): 79-92.

_. n.d. "Mapping key adolescent outcomes in schooling, employment and early marriage for adolescent girls by district level data in Nepal, utilizing DHS 2006 data." New York: Population Council. Unpublished.

Bronfenbrenner, U. (1977). "Toward an experimental ecology of human development," American Psychologist 32(7): 513-531.

1981. The Ecology of Human Development: Experiments by Nature and Design. Cambridge, MA: Harvard University Press.

Central Bureau of Statistics. 2012. National Population and Housing Census 2011 (National Report). <http://cbs.gov.np/wp-content/ uploads/2012/11/National\%20Report.pdf>.

Girls Discovered: Global Maps of Adolescent Girls. 2005-2008. "India/Children never in school." <http://girlsdiscovered.org/map/education/>. Accessed 2 October 2014

Lloyd, C.B. (ed.). 2005. Growing Up Global: The Changing Transitions to Adulthood in Developing Countries. Washington, DC: National Academies Press.
Ministry of Health and Population (MOHP) [Nepal], New ERA, and ICF International Inc. 2012. Nepal Demographic and Health Survey 2011. Kathmandu and Calverton, MD: Ministry of Health and Population, New ERA, and ICF International.

Pradhan, R., and Shrestha, A. 2005. "Ethnic and caste diversity: Implications for development." Nepal Resident Mission Working Paper No. 4. Kathmandu: Asian Development Bank.

Teerawichitchainan, B., H. Vinh, and T.P.L. Nguyen. 2007. "Changing transitions to adulthood in Vietnam's remote northern uplands: A focus on ethnic minority youth and their families." Hanoi: Population Council. < http://www.popcouncil.org/ uploads/pdfs/Niet_YFStudy_FinalReport.pdf>

Temin, M., M.M. Montgomery, S. Engebretsen, and K.M. Barker. 2013. Girls on the Move: Adolescent Girls \& Migration in the Developing World: A Girls Count Report on Adolescent Girls. New York: Population Council. <http://www.popcouncil.org/uploadspdfs/ 2013PGY_GirlsOnTheMove.pdf>.

United Nations Development Programme. 2004. Nepal Human Development Report 2004: Empowerment and Poverty Reduction. Kathmandu: Government of Nepal National Planning Commission and United Nations Development Programme.

UNICEF. 2014. Ending Child Marriage: Progress and Prospects. New York: UNICEF. <http://www.unicef.org/media/files/Child_ Marriage_Report_7_17_LR.pdf >. 
Appendixes 



\section{APPENDIX 1: METHODOLOGY}

\section{STUDY DESIGN, TRAINING, AND DATA COLLECTION}

\section{$\rightarrow$ Adolescent Household Survey}

\section{SITES}

Adolescents were surveyed in the 15 study districts: Achham, Baitadi, Bajhang, Bajura, Dhanusha, Dolpa, Doti, Humla, Jumla, Kalikot, Mahotari, Mugu, Parsa, Rautahat, and Saptari.

\section{SAMPLE}

In total, 3000 adolescents aged 10-19 completed individual surveys. By sex, $54 \%$ of adolescents interviewed were female and $46 \%$ were male. The majority of those sampled $(61 \%)$ were younger adolescents aged $10-14 ; 39 \%$ were aged 15-19. $70 \%$ of the sample lived in the Terai Plains which is more highly populated than the Mid and Far Western region.

\section{SAMPLE SIZE CALCULATIONS}

The sample size calculations for the adolescent baseline survey assumed a magnitude of change in the indicators between baseline and endline to be $10 \%$. If change in the impact indicator is $10 \%$ or higher the survey would be able to measure statistically significant change. Other assumptions include a power of $80 \%$, and a type I error of $5 \%$, to detect that level of change. The required sample size for each year of the program is therefore calculated using the formula:

$\mathrm{N}=\frac{\operatorname{deff} \mathrm{x}\left[\mathrm{Z}_{1-\alpha} \sqrt{2 * \mathrm{p}(1-\mathrm{p})}+\mathrm{Z}_{1-\beta} \sqrt{\mathrm{p}_{1}\left(1-\mathrm{p}_{1}\right)+\mathrm{p}_{2}\left(1-\mathrm{p}_{2}\right)}\right]^{2}}{\left(\mathrm{p}_{2}-\mathrm{p}_{1}\right)^{2}}$ where:

$\mathrm{p}_{1}$ is the hypothesized value of the indicator at year $\mathrm{X}$ $\mathrm{p}_{2}$ is the expected value of the indicator at year $\mathrm{X}+1$ $\mathrm{p}=\left(\mathrm{p}_{1}+\mathrm{p}_{2}\right) / 2$ $\mathrm{Z}_{1-\alpha}=\mathrm{z}$ value providing the standard normal deviate value for an $\alpha$ type I error (the statement about the probability of making a type I error is a restatement of the level of significance for the test)

$\mathrm{Z}_{1-\beta}=\mathrm{z}$ value providing the standard normal deviate for a $\beta$ type II error (the statement about the probability of making a type II error is the additional statement that must be provided in order to determine the sample size)

deff is the design effect in case of multi-stage cluster sample design

In the above formula, we assume a design effect (deff) of $1.5^{1} ; \mathrm{p}\left(\mathrm{p}_{1}+\mathrm{p}_{2} / 2\right)$ is $55 . \mathrm{p}_{1}$-the proportion reporting use in the time one is $0.5, \mathrm{p}_{2}$-the pro-

\footnotetext{
1 Sampling statisticians typically design surveys that have a design effect in the range of 1.5-3.0, and certainly no greater than 4.0 (Frankfort-Nachmais and Nachmais 1996). The design effect estimated in the NDHS 2011 for maternal and newborn care-related variables ranged from 1.1-4.0. Therefore, 1.5 is considered an appropriate design effect that will give the appropriate size of 20 households in each cluster for the proposed study.
} 
portion expected to report use in the next round is $0.6, Z_{1-\alpha}$ (where $\alpha=$ type I error) is 1.645 , and $Z_{1-\beta}$ (where $\beta=$ statistical power to detect an increaseor a one-sided change-is 0.84). This gives a sample size of 461 . After adjusting for a nonresponse rate $(5 \%)$ and refusal rate $(5 \%)$, the sample size would be 507 per domain. Since we planned to analyze the data by six main domains (by two broad regions, sex of respondents, and age group), we needed approximately 3000 respondents (approx. $500 \times 6$ major domains $=3000$ ) for the survey.

\section{SAMPLE SELECTION}

The selection of the adolescents interviewed was based on a multi-stage cluster sampling approach.

In the first stage: All Village Development Committees (VDCs) and Municipalities were listed separately for each of the 15 districts, in alphabetical order together with their household/population in each ward using data from the Population Census 2011. A ward of a VDC or ward or subward of a Municipality having at least 100 households would be considered a cluster and would serve as the Primary Sampling Unit (PSU). From the list of clusters, 150 clusters were chosen following a probability proportional to size (PPS) method, weighting the clusters by their respective population/household (Popn). From the list, the total population figure was noted, and the sampling fraction (Popn) calculated by dividing Popn/150. A random number was selected from a table of random numbers to identify the first cluster, with subsequent clusters selected by adding the value of the sampling fraction to select the other 149 clusters. Thus, a total of 150 clusters were selected. This level of selection was made in Kathmandu.

In the second stage: The field team prepared a sketch map of each sampled cluster (ward) delineating mainly the public places, villages/settlements, forest, rivers, temples, farmlands, trails, etc., prior to proceeding for the data-collection activity. This map was prepared with the help of community leaders and key informants of the selected sampled cluster. An updated household list was be prepared with the help of community leaders and adolescent key informants of the selected cluster. The list served as a sampling frame for selecting households. A systematic random sampling technique was applied to the list to select a predetermined number of sample households from each cluster, i.e., 20 households per cluster (20 households $\times 150$ PSUs $=3000$ households). After selecting a house, a short screening questionnaire was administered to the most knowledgeable person of the household. This identified the eligible respondent for the individual interview-i.e., 10-19-year-old boys or girls. Then, individual interviews were conducted with the eligible respondent in the household. Otherwise, interviews were terminated after completing a short screening questionnaire.

In the third stage: Individual respondents were selected from the selected households. The sample consisted of approximately an equal number of girls and boys aged between 10-19 years. One participant fitting these criteria was randomly selected from each household and interviewed. For adolescent interviews, in households with more than one eligible respondent, a single respondent was selected using a Kish grid table to avoid household clustering in responses and also for ethical reasons. An individual interview was then conducted with the eligible adolescent respondent in the household. When the respondent selected was not available, the interviewer made an appointment to return to conduct the interview. At least two additional visits were made before the respondent was considered not available for interview. Respondents were requested not to disclose any questions or responses from their interviews. No replacement of households was made during sampling procedure.

Table A1 lists the number of clusters, households, and adolescents selected for the baseline survey.

\section{QUESTIONNAIRE DEVELOPMENT}

Questionnaires were developed by the Population Council in consultation with CREHPA, UNICEF, and Yuwalaya. The survey instruments were developed to ensure that all six domains considered important 
TABLE A1 District-wise distribution of clusters, households, and adolescents

\begin{tabular}{lccccc}
\hline Name of district & $\begin{array}{r}\text { Number of } \\
\text { sampled } \\
\text { clusters }\end{array}$ & $\begin{array}{r}\text { Number of } \\
\text { households } \\
\text { covered }\end{array}$ & $\begin{array}{r}\text { Number of } \\
\text { males } \\
\text { interviewed }\end{array}$ & $\begin{array}{r}\text { Number of } \\
\text { females } \\
\text { interviewed }\end{array}$ & $\begin{array}{r}\text { Total number } \\
\text { of adolescents } \\
\text { interviewed }\end{array}$ \\
\hline Dhanusha & 24 & 634 & 227 & 253 & 480 \\
Mahotari & 20 & 465 & 183 & 217 & 400 \\
Parsa & 19 & 466 & 155 & 225 & 380 \\
Rautahat & 22 & 462 & 205 & 235 & 440 \\
Saptari & 20 & 429 & 189 & 211 & 400 \\
Baitadi & 8 & 187 & 73 & 84 & 160 \\
Achham & 8 & 178 & 76 & 66 & 160 \\
Doti & 6 & 137 & 54 & 65 & 120 \\
Bajhang & 6 & 133 & 55 & 60 & 120 \\
Bajura & 5 & 115 & 40 & 33 & 100 \\
Jumla & 3 & 64 & 27 & 44 & 60 \\
Kalikot & 4 & 93 & 36 & 23 & 80 \\
Mugu & 2 & 42 & 17 & 21 & 40 \\
Humla & 2 & 41 & 8 & 12 & 40 \\
Dolpa & 1 & 22 & $1,364(45.5 \%)$ & $1,636(54.5 \%)$ & 3,000 \\
Total & 150 & 3,470 & & & 20 \\
\hline
\end{tabular}

to UNICEF's holistic adolescent development were covered by the survey:

1) Education and Skills

2) Livelihood, Employment and Financial Literacy

3) Enabling and Protective Environment

4) Gender Equity and Social Inclusion

5) Health and Healthy Behavior

6) Participation and Civic Engagement

The instruments were informed by surveys conducted in similarly disadvantaged groups and included a mix of knowledge, attitude, and practice-related questions.

\section{KEY INFORMANT SEMI-STRUCTURED INTERVIEWS}

Semi-structured interviews were conducted with community-level key stakeholders, gatekeepers, and community members and other individuals who could provide insights into adolescents and their experience in Nepal as well as the policy and program contexts for adolescents in the country. These informants were selected purposively from diverse working areas: government officials, education and health professionals, social workers, members of local committees, female community health volun- teers, and others including a religious leader, journalist, and former ward chairperson. The Population Council contracted the implementation of interviews and data management of the semi-structured interviews to the Center for Research on Environment Health and Population Activities.

Community-level stakeholders were interviewed in the 15 study districts: Achham, Baitadi, Bajhang, Bajura, Dhanusha, Dolpa, Doti, Humla, Jumla, Kalikot, Mahotari, Mugu, Parsa, Rautahat, and Saptari. Interviews were conducted in the same geographic regions that were selected for the household survey.

In total, 96 community leaders participated in the semi-structured interviews; ranging from 2-10 per district. $43 \%$ of the interviews (41) were among informants in the Terai; $59 \%$ (55) were in the Mid and Far Western region. Respondents were from diverse disciplines. For example, 31 were social workers, 20 were educational professionals, 14 were health workers, 11 were government officials, 8 each represented local community-based organizations and female community health volunteers, 4 were local political leaders. A majority of respondents $(63 \%)$ had been working in the districts for more than five years. 
TRAINING, PRE-TESTING, AND DATA COLLECTION OF THE ADOLESCENT HOUSEHOLD SURVEY AND KEY INFORMANT INTERVIEWS

Training: The lead researcher at CREHPA oversaw all activities during the implementation of the baseline adolescent survey and key stakeholder interviews. Under the senior staff, a team of survey interviewers/enumerators was recruited and trained, and they collected data from 3000 households in the 15 UNICEF program districts using the household questionnaires. Training of interviewers was conducted over a period of six days. Led by CREHPA, Population Council, and UNICEF staff, the training included an introduction to the UNICEF ADAP program, study background, objectives, and importance. Interviewers were also advised on how to work with and ask adolescents questionsparticularly those under age 15 . Special attention was also given to discussing how to ask sensitive questions. Field staff were trained in ethical considerations and practices for the study.

Pre-Testing: After receiving training from the core team members, six experienced field supervisors conducted a pre-test of the questionnaires. Pre-test of the survey questionnaire occurred between 9-10 December 2013 in two rural settlements-Sankhu and Indarayani Village Development Committee of Kathmandu district. Altogether 60 eligible respondents (28 males and 32 females aged 10-19) were found in 29 households (about two people per household). A total of 29 individual interviews (15 females and 14 males) were conducted during the pre-test. Survey questionnaires were modified based on the pre-test results and shared with UNICEF for final approval.

Data Collection: The CREHPA field staff consisted of seven teams of five individuals-a supervisor and four field enumerators. The teams covered 150 clusters in the 15 districts in two phases. The teams covered 127 clusters from eight districts (Terai and Hill) in the first phase. The remaining 23 clusters in seven districts (Far Western) were covered in the second phase. Data collection for the adolescent surveys and key informant interviews took place between December 2013 and March 2014.

\section{$\rightarrow$ Adolescent Participatory Discussions}

\section{STUDY DESIGN}

Participatory group discussion sessions were conducted to obtain input and ensure an appropriate level of youth participation in identifying issues that are important to their lives. The group sessions covered a wide range of issues corresponding to broad areas of concern such as education, work, marriage, migration, health and reproduction, and social and gender equity. The Population Council contracted the group discussion implementation to Yuwalaya, a youth-led nonprofit organization with expertise in qualitative research with adolescents.

Twelve participatory group discussion (PGD) sessions were conducted with approximately 8-12 adolescents taking part in each group. Groups were segregated by gender and also by the two age groups (10-14; 15-19). Four PGD groups (Female 10-14; Female 15-19; Male 10-14; and Male 15-19) were conducted in each district.

Participants were recruited through key informants and existing networks of formal and informal youth groups within the various districts. The community key informant persons contacted the local children's clubs, government schools, informal education centers, as well as their networks to organize participants for the PGDs in the selected districts.

TABLE A2 Adolescent household survey sample $(\mathrm{N}=3000)$

\begin{tabular}{lrr}
\hline $\begin{array}{l}\text { Demographic } \\
\text { characteristics }\end{array}$ & Percent & (N) \\
\hline Age & 64 & 1,854 \\
$10-14$ & 38 & 1,146 \\
$15-19$ & & \\
Sex & 46 & 1,366 \\
$\quad$ Boys & 54 & 1,634 \\
$\quad$ Girls & & \\
Region & 70 & 2,100 \\
$\quad$ Terai & 30 & 900 \\
$\quad$ Mid and Far Western & 100 & 3,000 \\
TOTAL & & \\
\hline
\end{tabular}


The discussions attempted to capture and characterize groups, adolescent priorities, and needs through four structured exercises:

River of Life: In the groups having 10-14-year-olds, the facilitators started the group discussion with a river of life activity. The facilitators asked the participants to think back to the earliest time of their childhood they can remember and to think of a river as representing their life. Then the facilitators asked the participants to put stones for any sad incidents or events that caused them pain or sorrow in their lives. Similarly, they instructed the participants to draw fish for any happy incidents. This exercise was done to help the participant reflect back on their lives. Some of the participants were asked to explain their picture.

Social Mobility Mapping: This activity was used to identify the physical spaces used by adolescents and assess levels of safety with both age groups (10-14 and 15-19). Participants were asked to draw maps of important places in their home, community, and locality that they visit regularly. After listing all the places, the participants were asked to put red marks on those places where they felt most unsafe or discriminated, green on those places where they can easily go or which are easily accessible, black on those places where they feel most safe, and blue on those places where there is a possibility of being abused but they are coerced to go.

Helping Hands Exercise: This activity identified important people in the lives of adolescents in both age groups. The facilitators asked the participants to draw their hands on a paper and list in each finger the person whom they trust and from whom they first seek help in times of need. The most trusted person the participants went to with their problems was written on the thumb. Then, the next trusted person was written on the forefinger and in that way the top five list of trusted and most helpful people was written on the five fingers.

Problem Tree Analysis: The goal of the exercise was to identify common problems affecting the lives of adolescents and their root causes. Facilita- tors conducted problem tree analyses with the older adolescent age groups only. The facilitators asked the participants about the personal, social, or societal problems they face or see in their homes, communities, and daily environments. Problems were written on the leaves of a tree drawn on paper. Participants were probed about the causes of these issues and these were recorded on the roots of the tree.

\section{SITES}

Three districts (Saptari, Parsa, and Achham) of the 15 study districts were selected to conduct participatory group discussions (PGDs). The sites selected for conducting the PGDs were based on the population diversity, sociocultural context, social norms and practices, and access to basic facilities such as education, hospitals, roads, etc. among the adolescent girls and boys. These selected districts were known as poor performers on a range of development factors.

\section{SAMPLE}

In total, 161 adolescents aged 10-19 took part in the participatory group discussions. Boys constituted $55 \%$ of the total participants; girls were $45 \%$. By district, 51 were in Achham, 62 in Parsa, and 48 in Saptari. The average age of participants was 13.8.

TABLE A3 Sample characteristics of participants in participatory group discussions

\begin{tabular}{lrr}
\hline $\begin{array}{l}\text { Demographic } \\
\text { characteristics }\end{array}$ & Percent & (N) \\
\hline Age & & \\
10-14 & 55 & $(88)$ \\
15-19 & 42 & $(68)$ \\
Unidentified/Other & 3 & $(5)$ \\
Sex & & \\
$\quad$ Boys & 55 & $(89)$ \\
$\quad$ Girls & 45 & $(72)$ \\
Region & & \\
Achham & 32 & $(51)$ \\
Parsa & 39 & $(62)$ \\
Saptari & 30 & $(48)$ \\
TOTAL & 100 & $(161)$ \\
\hline
\end{tabular}




\section{TRAINING AND TOOL REFINEMENT}

The Population Council trained senior members of the Yuwalaya team on the research instruments and informed consent process and ethical considerations for the study. Yuwalaya then conducted preparatory workshops for two days with field staff to finalize the research plan and study sites, identify the local contact people, and refine tools to be used in the PGDs.

\section{FIELD WORK}

Yuwalaya sent teams of two facilitators, one male and one female, and a rapporteur to each district. Attempts were made to have male/female facilitators lead same-gendered groups so that participants would be encouraged to actively participate and discuss in a gender-friendly environment. Fieldwork took place in March and April 2014.

\section{DATA MANAGEMENT AND ANALYSIS}

\section{Adolescent Household Survey and Key Stakeholder Interviews}

The data management unit at CREHPA stored all data from the adolescent household survey and key stakeholder interviews in password-protected computers. Paper questionnaires were used to capture quantitative data. Hard copies of questionnaires, anonymized records of the questionnaires, and data were stored securely in a locked room, in accordance with Population Council policy and current data protection policies in Nepal. Data from paper questionnaires were entered into CS Pro software by a specially trained data entry team at CREHPA using the double data entry method to ensure data accuracy and quality. Data were exported to Stata for analysis. Only the Principal Investigators and the research team had access to this data.

\section{Participatory Group Discussions}

The rapporteurs recorded sessions and took notes during group discussions with adolescents. The rapporteurs prepared transcripts using the recorded audio and personal notes. Drawings and materials created by adolescents and the group during the exercises were collected. Rapporteurs analyzed the outcomes of each activity and quantified the infor- mation from these materials in a report submitted to the Population Council.

\section{ETHICAL CONSIDERATIONS}

This study received ethical approval from the Population Council Institutional Review Board; Government of Nepal, Nepal Health Research Council; and the Social Welfare Council Nepal.

Given that a majority of the participants in this study were under the legal age of consent in Nepal, 18, careful considerations were made on obtaining permission from parents and guardians of adolescents aged under 18 in addition to assent from the respondents themselves. Data were collected only after informed consent was received from each respondent. Participatory group discussion sessions were recorded on an audio-recording device only after interviewers received informed consent from all respondents in the group. Several groups did not consent to being recorded.

Careful steps were taken in the questionnaire design to minimize potential discomfort to our respondents. Respondents sampled from the chosen districts were asked a set of standardized questions based on their sex and by their age (younger 10-14 year-old adolescents and older 15-19 year-old adolescents) and marital status. During the household survey interviews, older adolescents were asked a number of potentially sensitive questions, including about their reproductive behaviors, contraceptive use, gender norms, marriage, dowry, migration, substance abuse, violence, harassment, discrimination, social cohesion, etc. If the respondent appeared distressed at any time, they were reminded they could skip any question that made them uncomfortable or could end the survey at any time without penalty. Younger adolescents were not asked any questions deemed age or culturally inappropriate such as sexual activity or experiences of violence. All participants were also offered service referrals if requested.

\section{REFERENCE}

Frankfort-Nachmais, Chava and David Nachmais. 1996. Research Methods in the Social Sciences (Fifth edition). New York. St. Martin's Press 


\section{APPENDIX 2: CASTE/ETHNIC GROUPS}

\section{CASTE/ETHNIC CATEGORY}

\section{Dalit (untouchable caste/ethnicity)}

Badi

Bantar/Sardar

Chamar/Harijan/Ram

Chunara

Damai/Dholi

Disadvantaged indigenous groups (Janajati)

Danuwar

Dhanuk

Gharti/Bhujel

Kumal

Disadvantaged non-Dalit (untouchable) Terai caste groups

Badhaee
Baniyaa/ Kayabaniya
Baraee
Bin
Gaderi/Bhedihar
Hajam/Thakur
Halwai
Kahar

Advantaged indigenous groups (Janajati)

Gurung

Newar

\section{Religious minorities}

Muslims

\section{Upper caste group}

Brahman-Hill

Brahman-Tarai

Kayastha

Marwadi

Chhetri

Kalwar
Kanu
Kathabaniyan
Kewat
Koiri/Kushwaha
Kumhar
Kurmi
Lohar

Mali Mallaha

Nuniya

Sonar

Sudhi

Teli

Yadav
Musahar

Parki

Sarki

Tatma/Tatwa

Sherpa

Tamang

Tharu 


\section{APPENDIX 3: STUDY TEAM MEMBERS OF CREHPA AND YUWALAYA}

\section{CREHPA}

\section{The Core Team}

Dr. Mahesh Puri, Study Coordinator

Deepak Joshi, Research Officer

Shophika Regmi, Research officer

\section{Field Supervisors}

Lochan Bhatarai

Zinita Dhakal

Dhurba Raj Dhital

Badri Dulal

\section{Field Researchers}

Kashindra Pd Adhikari

Nabin Bhatta

Samjhana Bhujel

Dikshya Bhattarai

Dhirendra Bohora

Rajiv Chaudhary

Sitaram Darlami

Kashi Ram Devkota

Ajantha Dhungana

Dil Kumari Dhungana
Umesh Giri

Kamala Karki

Sushma Sharma

Achala Shrestha

Bhawana Giri

Meena Giri

Binod Kumar Gupta

Shyamendra Jha

Chetendra Raj Joshi

Radhika Karki

Anjita K.C

Hemu Khadka

Sangeeta Koirala

Ram Kumar Mandal
Thag Prasad Paudel

Usha Kiran Pokharel

Preety Thapa

Santoshi Thapa

Sita Kumari Timalsina

Navin Kumar Yadav

Pramod Kumar Yadav

Ram Kumar Yadav

\section{Project Support Team}

Sabina Tamang, Finance and Administration

Luna Shakya, Finance and Administration

Dev Chandra Maharjan, Data Management Officer

Radhika Singh, Word Processor

\section{YUWALAYA}

\section{Project Coordinators}

Subash Neupane, President

Chetana Tulachan

$\begin{array}{ll}\text { Group Facilitators } & \text { Santosh Maharjan } \\ \text { Nirijana Bhatta } & \text { Rubina Shreshtha }\end{array}$

Kamal Chapagain

Sushila K.C.

\section{Rapporteurs}

Diwakar Pyakurel

Chetana Tulachan 



\section{unicef (9)}

United Nations Children's Fund

Nepal Country Office

Adolescent Development and Participation Section

Pulchowk, Lalitpur

NEPAL

kathmandu@unicef.org

\section{POPULATION \\ COUNCIL \\ Ideas. Evidence. Impact.}

One Dag Hammarskjold Plaza

New York, NY 10017 USA

popcouncil.org 